University of Louisville

ThinkIR: The University of Louisville's Institutional Repository

Electronic Theses and Dissertations

$12-2014$

\title{
The role of Porphyromonas gingivalis in the regulation of epithelial-mesenchymal transition markers in migration.
}

Akintunde Ojo 1981-

University of Louisville

Follow this and additional works at: https://ir.library.louisville.edu/etd

Part of the Dentistry Commons

\section{Recommended Citation}

Ojo, Akintunde 1981-, "The role of Porphyromonas gingivalis in the regulation of epithelial-mesenchymal transition markers in migration." (2014). Electronic Theses and Dissertations. Paper 1761.

https://doi.org/10.18297/etd/1761

This Doctoral Dissertation is brought to you for free and open access by ThinkIR: The University of Louisville's Institutional Repository. It has been accepted for inclusion in Electronic Theses and Dissertations by an authorized administrator of ThinkIR: The University of Louisville's Institutional Repository. This title appears here courtesy of the author, who has retained all other copyrights. For more information, please contact thinkir@louisville.edu. 


\title{
THE ROLE OF PORPHYROMONAS GINGIVALIS IN THE REGULATION OF EPITHELIAL-MESENCHYMAL TRANSITION MARKERS \\ IN MIGRATION
}

\section{By}

\author{
Akintunde Ojo \\ B.Sc., University of Ado-Ekiti, 2003 \\ BDS, University of Benin, 2010
}

\begin{abstract}
A Thesis
Submitted to the Faculty of the

School of Dentistry of the University of Louisville

in Partial Fulfillment of the Requirements

for the Degree of
\end{abstract}

Master of Science

Oral Biology

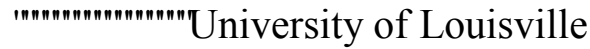

Louisville, Kentucky

December 2014 



\title{
THE ROLE OF PORPHYROMONAS GINGIVALIS IN THE REGULATION OF EPITHELIAL-MESENCHYMAL TRANSITION MARKERS IN MIGRATION
}

\section{By}

\author{
Akintunde Ojo \\ B.Sc., University of Ado-Ekiti, 2003 \\ BDS, University of Benin, 2010
}

A Thesis Approved on

December 3, 2014

by the following Thesis Committee:

Dr. Richard J. Lamont (Mentor)

Dr. Douglas S. Darling (Committee member)

Dr. Brian S. Shumway (Committee member) 


\section{DEDICATION}

This thesis is dedicated to Almighty God

who knows my expected end before I was born

and for being there for me all the time. 


\section{ACKNOWLEDGEMENTS}

I would like to use this opportunity to extend my sincere thanks and gratitude to all those who have helped me to accomplish the completion of this project. The entirety of this project would not have been possible without the support and encouragement of Dr. Richard J. Lamont, I am grateful for his continuous mentorship, which inspired my enthusiasm and passion for research. Additionally, I would like to thank my thesis committee for their insight, guidance, and direction on this project. I am deeply obliged to Dr. Douglas S. Darling, for his words of wisdom throughout my graduate studies, which allowed me to keep my long-term goals in sight. My heartfelt gratitude goes to Brian S. Shumway for his advice and encouragement all through this period. I must offer my sincere appreciation to Chris, Maryta, Tiana, Yun, Ella, Jae, Rakesh, Emeri, Yan, Cortney and all my other friends for their guidance, encouragement and for making life fun in and out of the lab. I am also very thankful to Dr. Ransdell, Dr. Babbage and Dr. McCants for their words of encouragement and support. In addition, special thanks goes to Pastor \& Pastor Mrs. Akenroye and all other members of RCCG Agape House Louisville for their prayers and support all through this period.

My deepest and heartfelt gratitude goes to my parents, Prof. Akin Ojo and Mary Ojo, for their endless supply of support throughout my academic career. Also, I must appreciate my wife Judith for her special care and affection, all through my pursuit for academic advancement. All gratitude goes to my siblings, Toyin, Sola, and Ayo. The faith and support of my family has been the foundation of my excellence. I also appreciate my cousin, Dr. Kolawole Atandeyi for his support both financially and in kind. My in-laws are well appreciated for their prayers, all-round support and best wishes. 


\begin{abstract}
THE ROLE OF PORPHYROMONAS GINGIVALIS IN THE REGULATION OF EPITHELIAL-MESENCHYMAL TRANSITION MARKERS IN MIGRATION.
\end{abstract}

Akintunde Ojo

December 3, 2014.

A relationship between periodontal disease and oral squamous cell carcinoma (OSCC) has been demonstrated in recent studies. Porphyromonas gingivalis' antigen have been found in oral cancer cells. The embryonic program "epithelial-mesenchymal transition" (EMT) is thought to trigger cancer invasion by allowing tumor cell propagation. The objective of this study was to examine the role of $P$. gingivalis in the expression of ZEB1, vimentin, and repression of miRNA-200 family as EMT prognostic markers in cancer cell metastasis. Human telomerase immortalized gingival keratinocytes (TIGK) cells were challenged with $P$. gingivalis strain ATCC 33277 in vitro for $24 \mathrm{~h}$ at MOI 50 and 100. Expression of ZEB1, and vimentin mRNA levels was determined using qRT-PCR. The expression of ZEB1 and vimentin was up regulated 2.5-fold, and 3-fold respectively, while that of miRNA-200 family was repressed in $P$. gingivalis infected TIGK cells compared to controls. $P$. gingivalis infected cells invaded Matrigel-coated Transwell membrane compared to non-infected cells. Knockdown of ZEB1 reduced the invasiveness of $P$. gingivalis infected TIGK cells. Thus, the presence of $P$. gingivalis in the periodontium of cancer patients may contribute significantly to the overexpression of ZEB1, and vimentin as crucial promoters of oral squamous cell cancer invasion. 


\section{TABLE OF CONTENTS}

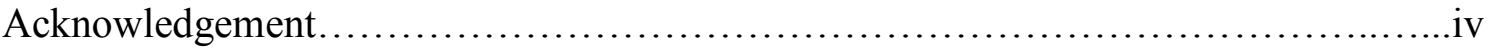

Abstract.........................................................................

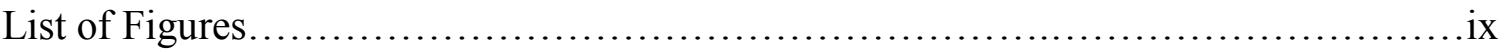

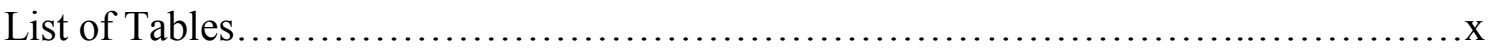

\section{Chapter I: INTRODUCTION}

1.1 Oral Squamous Cell Carcinoma ...............................................

1.1.1 Oral Squamous cell Carcinoma Epidemiology $\ldots \ldots \ldots \ldots \ldots \ldots \ldots \ldots \ldots \ldots \ldots \ldots \ldots$

1.1.2 Oral Squamous Cell Carcinoma Risk Factors ..................................2

1.2 Epithelial-Mesenchymal Transition........................................

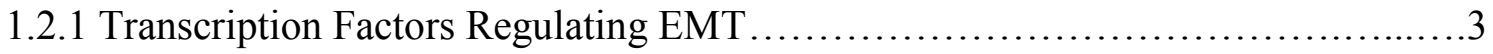

1.2.2 EMT in Normal Development.........................................4

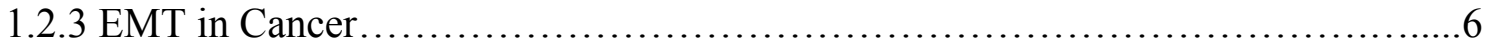

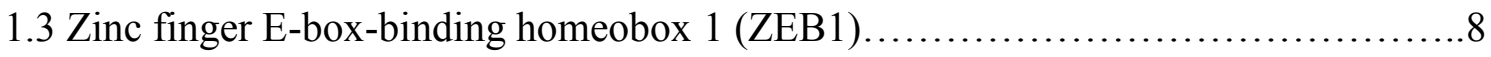

1.4 Vimentin............................................................. 9

1.5 Micro-Ribonucleic Acid (miRNA) ...................................... 11

1.5.1 MiRNA as Gene Regulators.............................................12

1.5.2 MiRNA 200 family.................................................. 14

1.5.3 ZEB1/miR-200 feedback loop....................................... 14

1.6 Porphyromonas gingivalis ............................................... 16 
1.6.1 Growth Requirements........................................................ 18

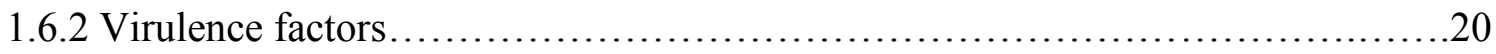

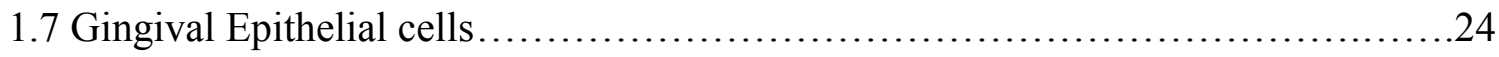

1.7.1 Telomerase Immortalized Gingival Keratinocytes (TIGKs) ....................26

1.7.2 Immortalization of gingival epithelial cells with human telomerase reverse

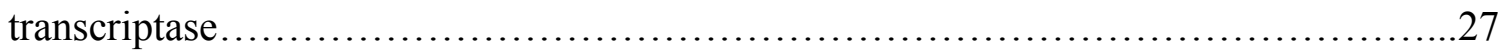

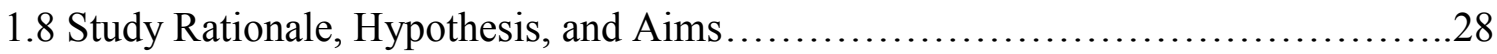

Chapter II: MATERIALS AND METHODS

2.1 Bacterial Stains and Growth Condition............................................

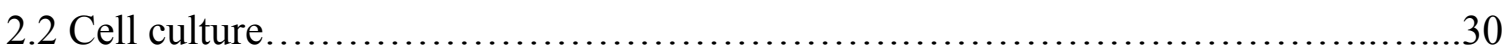

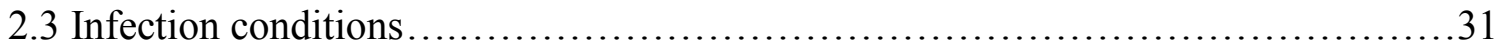

2.4 Quantitative RT-PCR (qRT-PCR) analysis of mRNA expression...................32

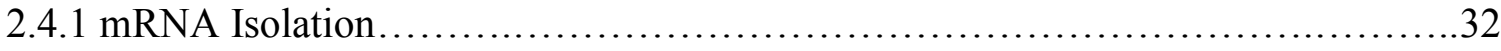

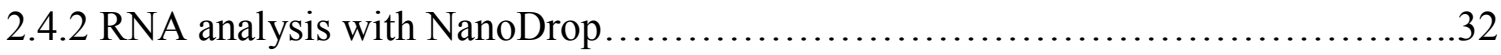

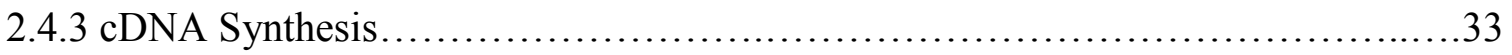

2.4.4 SYBR Green real-time qRT-PCR assays.......................................34

2.5 Quantitative RT-PCR (qRT-PCR) analysis of miRNA expression...................36

2.5.1 microRNA Isolation by the $70 \%$ Ethanol method...............................36

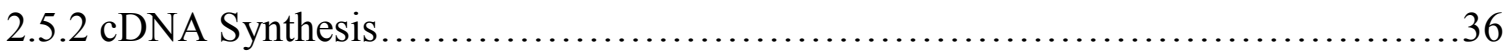

2.5.3 TaqMan real-time qRT-PCR MicroRNA Assays.................................37

2.6 Dual-Glo Luciferase Reporter Assay.............................................

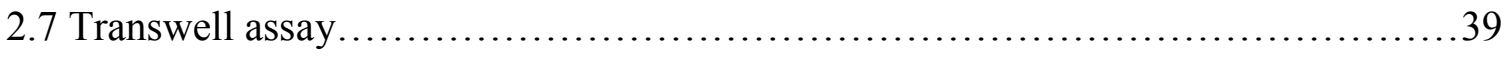


2.9 Transfection of TIGKs with short interfering RNA

\section{Chapter III: RESULTS}

3.1 Vimentin and its transcriptional inducer, ZEB1 were up-regulated following $P$.

gingivalis infection of TIGK cells.

3.2. $P$. gingivalis infection of TIGK cells enhances activity at the ZEB1 promoter region.

3.3. Up-regulation of ZEB1 mRNA represses miR-200 family in P. gingivalis infected TIGK cells

3.4. P. gingivalis-Epithelial cells interaction is required for the up-regulation of ZEB1..51 3.5. P. gingivalis molecules have varying effect on the up-regulation of ZEB1 ..........52

3.6. P. ginivalis infection promotes invasive potential of TIGK cells .................57

3.7. Knockdown of ZEB1 by ZEB1-specific siRNA reduces the invasiveness of P. gingivalis infected TIGK cells..............................................60

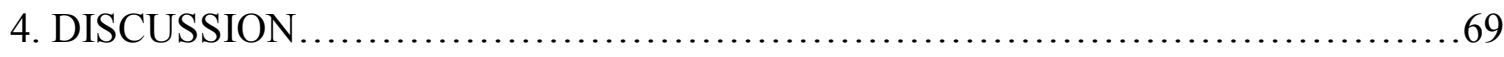

5. DIRECTIONS FOR FUTURE RESEARCH................................ 73

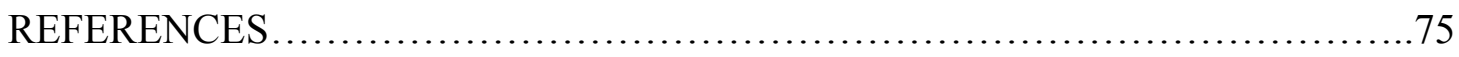

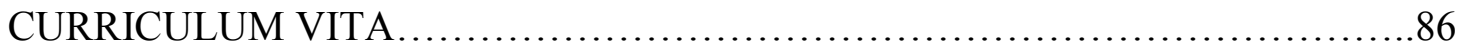




\section{LIST OF FIGURES}

Figure 1 EMTs give rise to progenitors of many organs and tissues ..............................5

Figure 2 Contribution of EMT to cancer progression...........................................

Figure 3 Processing and mechanism of action of miRNA .........................................13

Figure 4 Epithelial-to-mesenchymal transition regulation by non-coding RNAs............15

Figure 5 Black-pigmented Porphyromonas gingivalis colonies...................................19

Figure 6 Electron micrograph showing budding vesicles of $P$. gingivalis ......................19

Figure 7 Anatomy of the three areas of the gingival epithelium interface with the

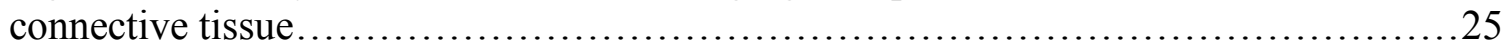

Figure 8 Schematic of a Transwell Permeable Support..............................................40

Figure $9 P$. gingivalis infection up-regulated ZEB1 mRNA expression.........................44

Figure $10 P$. gingivalis infection up-regulated vimentin mRNA expression....................44

Figure $11 P$. gingivalis infection induces ZEB1 promoter activity in TIGK cells...........46

Figure 12 Effect of P. gingivalis infection on the expression of Zeb1 and miR-200 family

Figure 13 P. gingivalis infection down-regulated miR-200 family...............................50

Figure 14 Epithelial internalization of $\mathrm{P}$. gingivalis is important for ZEB1 up-

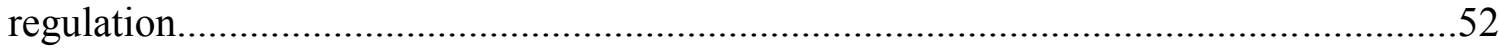

Figure $15 P$. gingivalis molecules have varying effect on the up-regulation of ZEB1...53

Figure 16 ZEB1 expression with $\mathrm{P}$. gingivalis mutant strains infection in terms of their

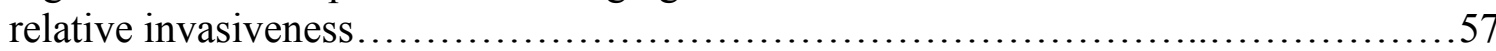

Figure $17 P$. gingivalis infection promotes the invasiveness of TIGK cells.............58 ix 
Figure 18 Effect of knockdown of ZEB1 on the relative expression of ZEB1 mRNA

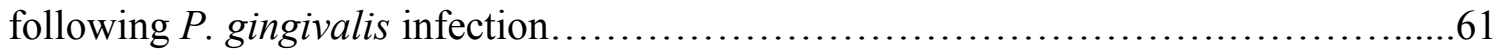

Figure 19 Effect of knockdown of ZEB1 on the relative expression of vimentin

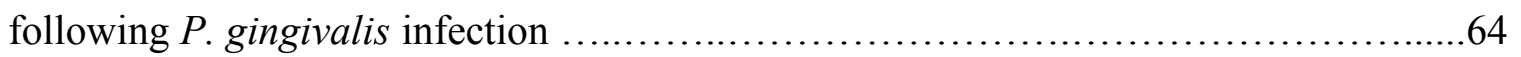

Figure 20 Effect of ZEB1 knockdown on the invasiveness of $P$. gingivalis infected TIGK cells .65 


\section{LIST OF TABLES}

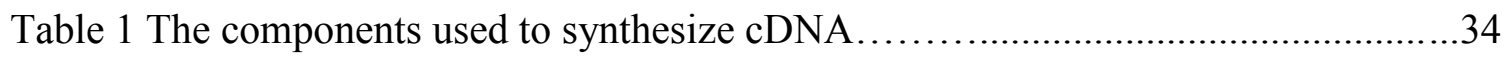

Table 2 The reagents used in SYBR Green real-time qRT-PCR ...................................35

Table 3 List of primers used for SYBR Green real-time qRT-PCR ............................35

Table 4 The components used to synthesize cDNA using specific microRNA Primers...37

Table 5 The reagents used in TaqMan MicroRNA Assays...........................................38 


\section{CHAPTER I}

\section{INTRODUCTION}

\subsection{Oral Squamous Cell Carcinoma}

Oral cancer has been described as the sixth most common cancer worldwide [1]. Squamous cell carcinoma of the oral cavity constitutes about ninety percent of all oral malignancies [2]. They can affect any site of the oral mucosa, the tongue and the floor of the mouth are the most commonly affected areas [3]. Prognosis of oral squamous cell carcinoma (OSCC) remains poor even with advances in diagnostic techniques and improvement in treatment modalities, this is mainly due owing to the high-rate of local and regional recurrence and to the development of new malignant changes within the original field of precancerisation [4].

\subsubsection{Oral Squamous cell Carcinoma Epidemiology}

Oral SCC affects men more frequently than women $(\mathrm{M}: \mathrm{F}=1.5: 1)$, this is due to the fact that men indulge in more high-risk habits than women [5]. The probability of developing OSCC increases with the period of exposure to risk factors, and increasing age adds the further dimension of age-related mutagenic and epigenetic changes. In the USA the median age of diagnosis of OSCC is 62 years. However, the incidence of OSCC in persons under the age of 45 is increasing [6].

In Western countries OSCC affects the tongue in $20 \%-40 \%$ of cases and the floor of the mouth in $15 \%$ - $20 \%$ of the cases, and together these sites account for about $50 \%$ of all cases of OSCC $[3,7]$. The gingivae, palate, retro-molar area, buccal and labial mucosa are oral sites less frequently affected [6]. The ventral surface of the tongue and the floor 
of the mouth are sites most commonly affected by SCC because they are lined by thin non-keratinized epithelium [8]. The mean 5-year survival rate of persons with OSCC is about $50 \%$ with no gender difference; but black persons have a lower five year survival rate than persons of other races $[6,8]$.

\subsubsection{Oral Squamous Cell Carcinoma Risk Factors}

OSCC is considered to be a multi-causal disease influenced by the interrelationships among various etiologic factors, including smoking, alcohol consumption, dietary micronutrient deficiency, occupational activity, external agent exposure, genetic susceptibility, and infection. The most important risk factors for OSCC are use of tobacco or betel quid and the regular drinking of alcoholic beverages [1].The chief risk factors for oral squamous cell carcinoma are smoking (especially $>2$ packs/day) and alcohol use. The combination of both factors seems to enhance the carcinogenic effect, but nearly 15 to $20 \%$ of the cases occur in patients without these traditional risk factors [9]. The highest incidence and prevalence of oral SCC is found in the Indian subcontinent where the risk of developing oral SCC is increased by the very prevalent habits of chewing tobacco, betel quid and areca-nut [10].

Cancers of the head and neck are usually caused by tobacco and alcohol, but recent studies show that about $25 \%$ of mouth and $35 \%$ of throat cancers in the United States of America are associated with Human Papilloma Virus (HPV). Increased incidence of oropharyngeal cancers in the USA have been attributed to HPV infection in recent studies $[11,12]$. The discussion about human papilloma virus (HPV) in OSCC points at a general role of infection for the development of oral carcinomas.

Studies have also demonstrated a significant relationship between periodontitis and OSCC. A very recent epidemiological survey in 2012, showed that periodontitis was markedly associated with orodigestive cancer mortality, while $P$. gingivalis, a major 
periodontal pathogen, was identified as a specific and potentially independent microbial factor to increase the risk of orodigestive cancer death [13]. P. gingivalis has been shown to occur frequently in the mouth of oral cancer patients, its antigens have also been detected in gingival squamous carcinoma tumors [14]. All these findings indicate the possibility that the interactions of $P$. gingivalis with OSCC cells are involved in cancer progression and metastasis.

\subsection{Epithelial-Mesenchymal Transition}

Epithelial-mesenchymal transition (EMT) is a multi-step morphogenetic process during which epithelial cells down-regulate their epithelial properties and up-regulate mesenchymal characteristics. Namely, static epithelial cells lose cell to cell junctions and as a consequence they lose apico-basal polarity to become migratory mesenchymal-like cells. This process of down-regulation of the epithelial phenotype mimics the normal developmental process of gastrulation, in which cells from the epithelial sheet of the ectoderm start to form the third germinal layer, the mesoderm, whose migratory cells are called mesenchymal cells. Hence, this process is competently referred to as epithelialmesenchymal transition [15].

EMT is an essential and tightly controlled developmental process that plays a fundamental role during embryogenesis, wound healing, and tissue repair [2]. EMT is regulated by many signaling pathways, transcriptional factors, and post-transcriptional factors.

\subsubsection{Transcription Factors Regulating EMT}

There are a number of known transcription factors that play vital roles in the regulation of EMT. The most characterized are ZEB 1, ZEB 2, snail, slug and twist [16]. These transcription factors mastermind the down-regulation of the epithelial junction proteins E-cadherin, occludins, claudins, and connexins, and the up-regulation of the mesenchymal proteins $\mathrm{N}$-cadherin, vimentin, $\alpha$ - smooth muscle actin, fibronectin, 
specific myosin isoforms, and matric metallo proteinases (MMPs) [17].

Expression of ZEB1 and ZEB2 are induced by factors such as TGF- $\beta$, hypoxic conditions and inflammatory cytokines and many growth factors are all known to initiate EMT [18]. Like the two ZEB transcription factors, snail and slug can be induced by TGF- $\beta$, hypoxic conditions and other EMT-related signaling pathways [19]. There is a significant overlap in the regulatory signals of these transcription factors. Expression of ZEB factors is regulated by Snail, Snail in turn also increases the stability of Twist which then activates the transcription of Slug. This interaction network may be involved in the spatial and temporal regulation of EMT [20].

\subsubsection{EMT in Normal Development}

During embryogenesis, multiple structures and organs including the palate, skeletal muscle, derivatives of the neural crest and cardiac heart valves rely on EMT [21]. EMT consists of a series of defined events. These include the degradation of the underlying basement membrane, detachment from neighboring epithelial cells, alteration of cell shape and cytoskeletal remodeling, invasion through the underlying basement membrane and movement into the surrounding tissue [22].

Importantly, dysregulation of pathways involved in developmental EMT have been correlated with embryonic defects in mice including cleft palate, as well as heart valve and cranial facial and peripheral nervous system defects, thereby demonstrating that EMT is a critical process in normal development [23]. 


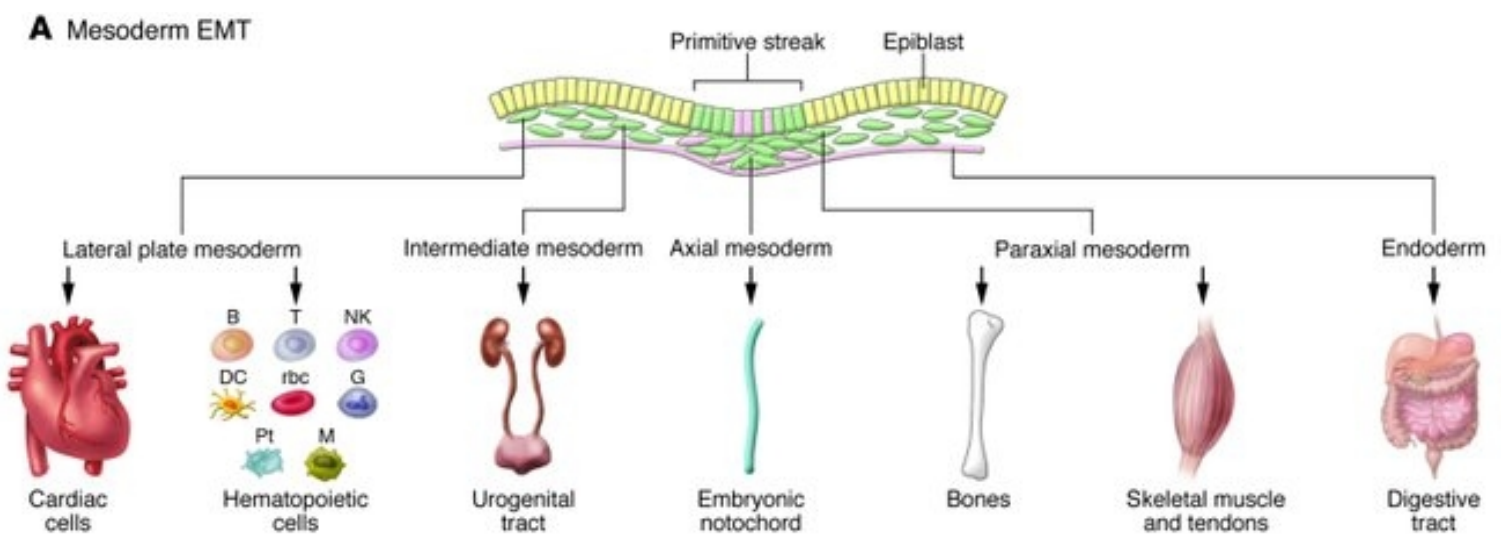

B Neural crest EMT
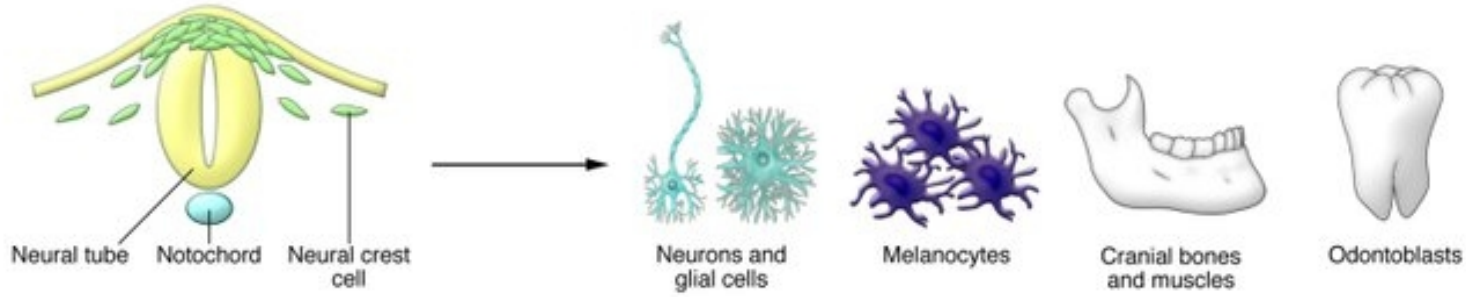

Figure 1: EMTs give rise to progenitors of many organs and tissues.

(A) Epiblast cells that internalize at gastrulation give rise to different mesodermal and endodermal populations from which a variety of cell types form. Embryonic cells undergoing EMT are shown in green. Pt, platelets; B, T, and NK, lymphocytes; G, granulocytes; M, macrophages. (B) In turn, the neural crest delaminates from the dorsal neural tube and will generate neurons of the peripheral nervous system, glial and satellite cells, pigment cells, odontoblasts, and the craniofacial cartilage, as well as other cell types. Adapted from J Clin Invest. 2009. 


\subsubsection{EMT in Cancer}

Studies have shown the involvement of EMT in contexts outside development such as wound healing, fibrosis and cancer. Excessive epithelial cell proliferation and angiogenesis are hallmarks of the initiation and early growth of primary epithelial cancers [24]. During cancer progression cancerous epithelial cells are thought to undergo EMT and acquire stem cell-like properties, allowing individual cells to bud off the tumor mass, invade the surrounding tissue, intravasate into lymph and blood vessels and finally metastasize by forming distant, secondary tumors [25].

Cancer cells enhance their migratory and invasive capacity through the down-regulation of epithelial markers involved in the maintenance of cell polarity and intercellular adhesion, chiefly the inhibition of E-cadherin. The transcriptional repressor zinc-finger Ebox binding homeobox 1 (ZEB1) is a crucial inducer of EMT in various human tumors [26]. 


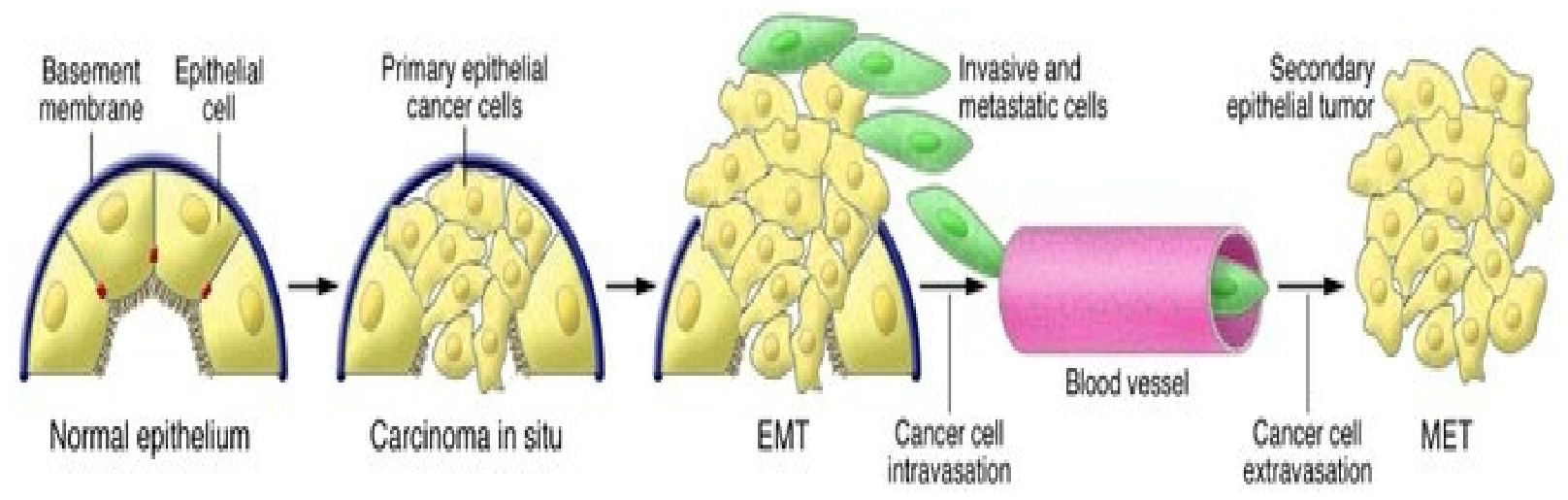

Figure 2. Contribution of EMT to cancer progression.

Progression from normal epithelium to invasive carcinoma goes through several stages. The invasive carcinoma stage involves epithelial cells losing their polarity and detaching from the basement membrane. The composition of the basement membrane also changes, altering cellECM interactions and signaling networks. The next step involves EMT and an angiogenic switch, facilitating the malignant phase of tumor growth. Progression from this stage to metastatic cancer also involves EMTs, enabling cancer cells to enter the circulation and exit the blood stream at a remote site, where they may form micro- and macro-metastases, which may involve METs and thus a reversion to an epithelial phenotype. Adapted from J Clin Invest. 2009. 


\subsection{Zinc finger E-box-binding homeobox 1 (ZEB1).}

ZEB proteins are sequence-specific DNA-binding transcription factors. In upper vertebrates, the ZEB1 belongs to the ZFH family comprising ZEB1 (delta EF1) and ZEB2 (Smad-interacting protein 1, SIP1) [27]. ZEB1 (also known as TCF8 and delta EF1) and ZEB2 (also known as ZFXH1B and SMAD-interacting protein 1 [SIP1]) are large transcription factors (124 and $136 \mathrm{kDa}$, respectively) containing two zinc-finger domains, separated by a homeodomain. The zinc-finger structures are highly conserved and allow DNA binding at E-boxes present within the promoter regions of target genes, such as E-cadherin [28]. One of Zeb1 roles is to regulate the expression of E-Cadherin, a crucial molecule in maintaining the characteristics of epithelial cells.

Enforced expression of ZEB factors in epithelial cells results in a rapid EMT associated with a breakdown of cell polarity, loss of cell-cell adhesion and induction of cell motility. Vise-versa, a knockdown of ZEB factors in undifferentiated cancer cells induces a mesenchymal-to-epithelial transition (MET) [29]. Expression of ZEB1 promotes metastasis of tumor cells in a mouse xenograft model, indicating a role for ZEB1 in invasion and metastasis of human tumors [30]. As a repressor of E-cadherin, ZEB1 is not expressed in normal epithelium or the tumor center of well-differentiated carcinomas [31].

ZEB1 is induced by multiple signaling pathways including TGF- $\beta$, Notch, and canonical Wnt (b-catenin/TCF4) [32]. The nuclear factor $\kappa \mathrm{B}(\mathrm{NF}-\kappa \mathrm{B})$ pathway have also been shown to play a role in mediating the process of EMT through the up-regulation of 
transcription repressor function of ZEB1, which in turn represses the expression of the miR-200 family by binding to E-box sequence of miR-200 promoter. Cell innate immunity has been shown to be triggered by bacterial peptidoglycan leading to activation of NF- $\mathrm{BB}$, known as a master transcription factor in inflammatory responses following microbial infection. This process thus leads to the NF- $\mathrm{kB}-\mathrm{dependent}$ transcription of multiple target genes including pro-inflammatory interleukin (IL)-1 $\beta$, IL-6, IL-8 and tumor necrosis factor $\alpha[33]$.

\subsection{Vimentin}

Vimentin, a 57-kDa protein, is one of the most widely expressed and highly conserved proteins of the type III IF protein family. It is found in many mesenchymal and epithelia tissues, tissue culture cells, and developing neuronal and astrocytic precursor cells of the central nervous system. Vimentin is crucial for supporting and anchoring the position of the organelles in the cytosol. It provides cells with a resilience absent from the microtubule or actin filament networks, when under mechanical stress in vivo. It is also responsible for maintaining cell integrity and for stabilizing cytoskeletal interactions [26].

Vimentin is expressed at sites of cellular elongation and is associated with a migratory phenotype. Increased vimentin is frequently used as an EMT marker in cancer [26]. Cytoskeletal intermediate filaments (IFs) undergo a significant compositional change as epithelial cells, which normally express only keratin IFs (KIFs), initiate the expression of vimentin IFs (VIFs). Because of this dramatic change in IF composition, VIF expression has become a canonical marker of the EMT [34]. Recent observations have broadened the 
relevance of the EMT and further emphasized that VIF assembly is a hallmark of these changes. For example, VIF expression can be predictive of the recurrence and invasive potential of prostate cancer cells and can be used to determine the origin of metastatic breast carcinoma cells $[35,36]$.VIF expression has been reported to be also up-regulated in model cell culture systems used to study wound healing [37].

Vimentin expression has been shown to be transcriptionally regulated by various factors. Initiation of the transcription of EMT-related transcription factor families, including ZEB (ZEB1 and ZEB2), the zinc finger Snail (SNAI1 and SNAI2) are critical in the upregulation of vimentin. It was reported that miR-506 inhibit TGF $\beta$-induced EMT by directly targeting vimentin in human breast cancer cell line. miR-30 miR-17-3p, miR-17, miR-124 and miR-203 has also been reported to suppress the migratory ability and invasiveness of breast cancer cell lines by directly targeting its 3'UTR [38, 39].

Vimentin expression may also play an important role in modulating an epithelial cell's response to mechanical stress during the EMT. Epithelial cells expressing VIFs are flatter than normal epithelial cells expressing only KIFs. The height of cells above their growth substrates has been shown to be a determining factor in the response of epithelial and endothelial cells to shear stress; flatter cells are much less sensitive to shear stress relative to taller, neighboring cell $[40,41]$. The epithelial cell flattening induced by vimentin expression may play a role in facilitating the ability of these cells to withstand a variety of external mechanical forces. This may be a critical factor for the survival of metastatic cells, which are exposed to abnormal physical stresses as they navigate from primary to secondary tumor sites [42]. 
Migrating epithelial cells in wound margins and deep epithelial ridges that had gained mesenchymal features such as vimentin have an enhanced capability for speedy wound closure. Significant delays in wound healing, attributable to a reduced migratory capability of epithelial cells, are exhibited by vimentin-knockout mice [43].

\subsection{Micro-Ribonucleic Acid (miRNA)}

Less than a decade ago, miRNAs were considered relatively unimportant. Today, miRNAs have been identified as important gene regulators that are involved in how and when genes are turned on and off. The first miRNA, lin-4, was discovered in 1993 by Lee and his colleagues in C. elegans [44]. Seven years later, a second small RNA was identified in C. elegans, named let-7 When the genes were cloned they were identified to code for two 21-22 nt long RNAs with an important role in developmental timing. Let-7 was thereafter identified in several vertebrates, including humans [45].

miRNAs are a recently discovered class of small nucleic acids (approximately 18-24 nt) that negatively regulate gene expression by binding to the 3'-untranslated regions (3'UTR) of specific mRNAs. They have been identified in plants and animals and are highly conserved [46]. Up to date, more than 700 miRNAs are identified in human. The name of miRNAs found in the miR database includes 3 or 4 letters that designates the species (e.g., "hsa" for Homo sapiens), while the core of the miRNA name is the designation "miR" (denoting a mature sequence) followed by a unique identifying number [47].

Profiles of miRNA are highly informative because they reflect the developmental lineage and differentiation state of tumors. A study performed has identified miRNAs that are 
significantly differentially expressed between tumor tissue and normal tissue. Till now, several miRNAs have been implicated in tumorigenesis and many are thought to behave as tumour suppressors or oncogenes and are either up- or down- regulated [48].

\subsection{1 miRNA as Gene Regulators}

Each of the $\sim 400$ miRNAs known to exist in mammalian cells has multiple targets, making them powerful regulators of complex processes such as differentiation and cancer progression. In mammals, the mature miRNA negatively regulates target mRNA by either binding to imperfect complementary sites within the 3'- UTR of mRNA-targets, or by targeting specific cleavage of homologous mRNAs. However, studies have indicated that miRNAs can also down-regulate the expression of genes by base-pairing to the coding region or 5'-UTR of some mRNAs [49, 50]. A perfect or almost perfect complementarity to the target site can induce gene silencing via the RNA interference pathway. By binding to imperfect complementary sites on the mRNA-target strand, miRNAs inhibit translation and reduce protein levels of target genes without affecting mRNA levels of these genes [51]. 


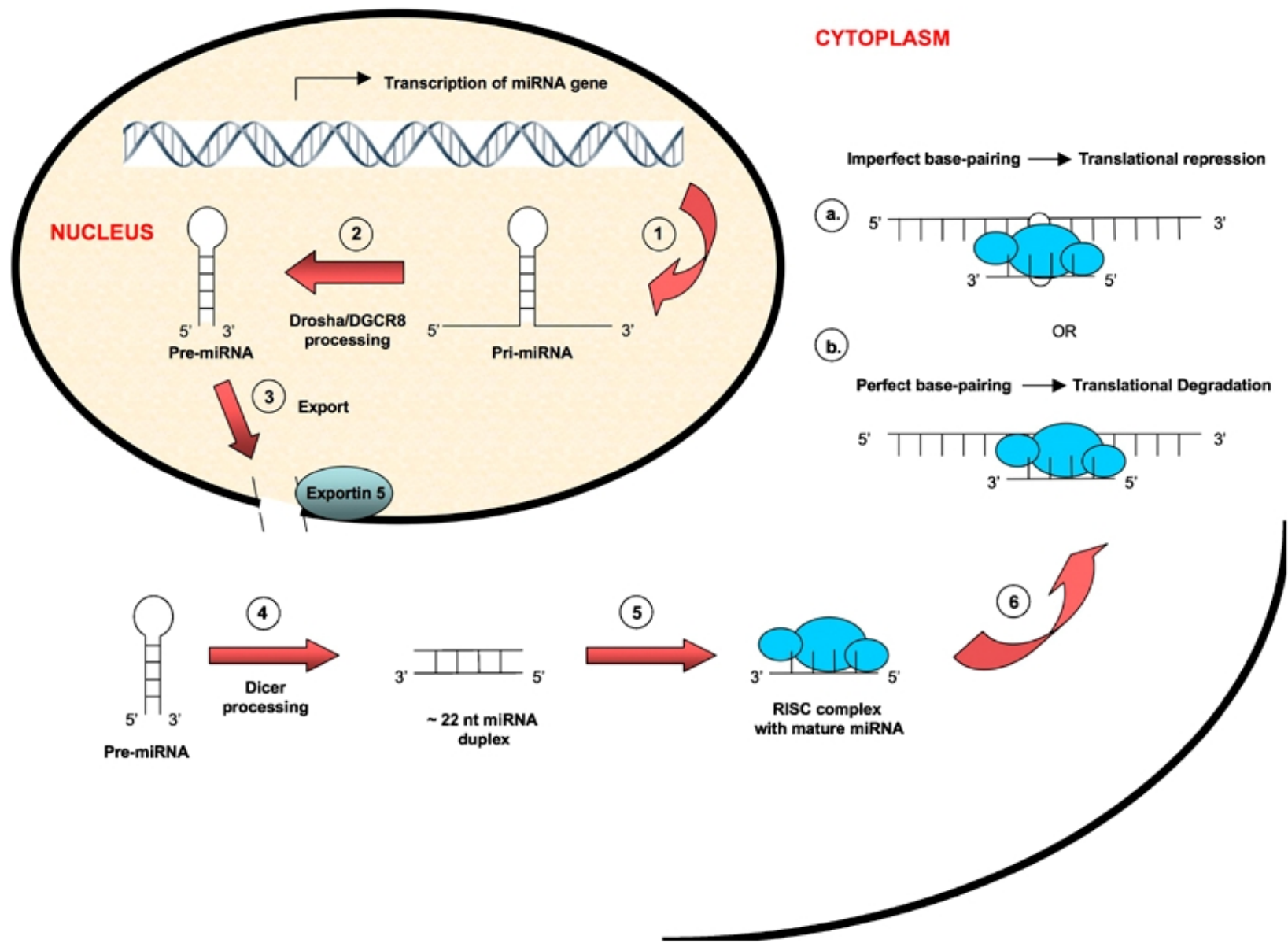

Figure 3. Processing and mechanism of action of miRNA.

(1) Transcription of miRNA in the nucleus by RNA polymerase II to generate primary transcripts (primiRNAs). (2) Processing of transcripts by the Drosha/DGCR8 complex to generate pre-miRNAs. (3) Transportation of the pre-miRNAs into the cytoplasm. (4) Processing of pre-miRNAs into duplexes that contain the mature miRNA product. (5) Incorporation of one strand of miRNA duplex with the RNAinduced silencing complex (RISC), which directs miRNA targeting of mRNAs. (6) Partial sequence complementarity between the miRNA and the target results in (a) translational repression, while complete sequence complementarity leads to (b) translational degradation. Adapted from: Unraveling the complex regulation of stem cells: implications for aging and cancer E J Oakley and G Van Zant. 


\subsection{2 miRNA 200 family}

The miR-200 family contains miR-200a, miR-200b, miR-200c, miR-141, and miR-429. The five members of the miR-200 family are grouped in two independent transcriptional units: a) miR-200b, miR-200a and miR-429 are clustered in an intergenic region of chromosome 1; and b) miR-200c and miR-141 are located on chromosome 12, within the intron of a noncoding RNA. Recent studies have shown that both clusters are subject to epigenetic regulation in cancer and normal tissue. The miR-200 family opposes EMT by directly targeting genes involved in motility and invasion [52, 53].

\subsubsection{ZEB1/miR-200 feedback loop}

Members of the miR-200 family have been shown to be major regulators of EMT through the targeted silencing of the EMT-transcriptional inducers ZEB1, which in turn transcriptionally repress miR-200 family in a double-negative feedback loop [54]. Recent studies showed that miR-200 could repress ZEB1 expression through binding to a sequence of the 3'-UTR of ZEB1 mRNA (ZEB1 3' UTR contains eight miR-200 binding sites) and that ZEB1 could directly bind to the promoter of the miR-200 gene cluster, resulting in the repression of miR-200 expression and establishing a double-negative feedback loop controlling the expression of ZEB1 and the miR-200 family during EMT $[54,55]$. 


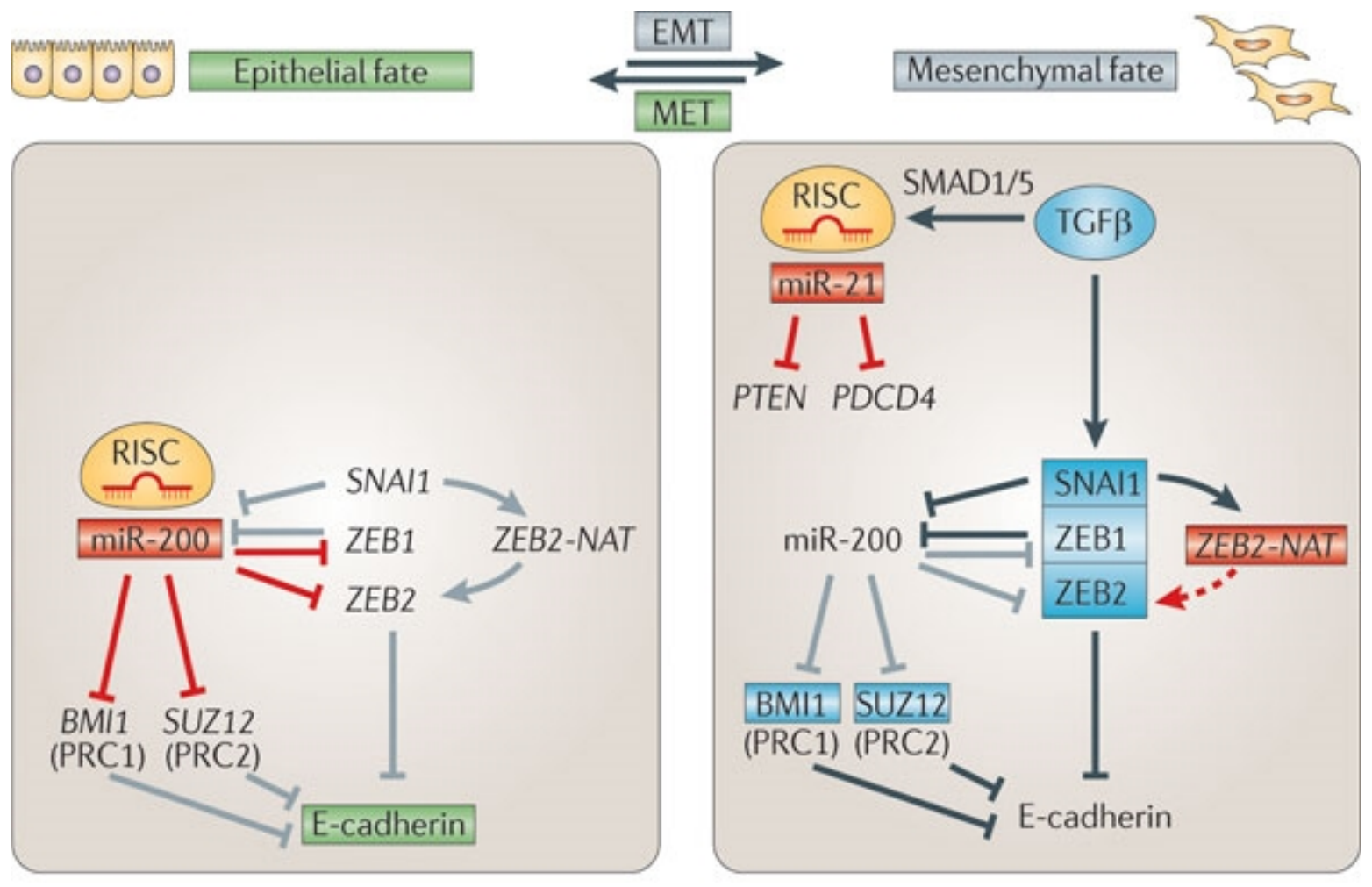

Figure 4. Epithelial-to-mesenchymal transition regulation by non-coding miRNAs.

The central role of miR-200 is to stabilize the epithelial state (green) by repressing negative regulators of E-cadherin expression. In the epithelia state, miR-200 targets subunits of Polycomb repressive complex 1 (PRC1) (BMI) and PRC2 (SUZ12) as well as the transcription factors ZEB1 and ZEB2. Transforming growth factor- $\beta$ (TGF $\beta)$-induced ZEB1, ZEB2 and homologue of Snail (SNAI1) repress miR-200 and E-cadherin in negative fashion, thus promoting mesenchymal fate (grey). Active miRNAs are indicated by Red boxes; active proteins by light blue boxes; inactive genes/miRNAs by unboxed text; inactive processes are represented by grey lines. PDCD4, programmed cell death 4; PTEN, phosphatase and tensin homologue; MET, mesenchymal-to-epithelial transition; RISC, RNA-induced silencing complex. Adapted from: Non-coding RNAs as regulators of embryogenesis. Andrea Pauli, John L. Rinn \& Alexander F. Schier Nature Reviews Genetics 12, 136-149 (February 2011). 


\subsection{Porphyromonas gingivalis}

Porphyromonas gingivalis is a Gram-negative anaerobe that has strongly been associated with severe and chronic cases of periodontal disease [56]. It is a non-spore forming bacterium, belonging to the phylum Bacteroidetes. This opportunistic pathogen is an inhabitant of the sub-gingival crevice and is known to cause disease by disturbing the host immune homeostasis (dysbiosis) [57]. P. gingivalis is an opportunistic pathogen that can also exist in commensal harmony with the host. This bacterium, a member of the red complex group of bacteria maintain a polymicrobial synergy with other bacteria in initiating periodontitis [56].

$P$. gingivalis, is a prominent component of the oral microbiome and a successful colonizer of the oral epithelium [58]. P. gingivalis can invade and survive within gingival epithelial cells, and an intracellular location physically sequesters the organism from recognition by the immune system [59]. The perturbation of epithelial cells by bacteria is the first stage in the initiation of inflammatory and immune processes which eventually cause destruction of the tissues surrounding and supporting the teeth which ultimately result in tooth loss [60]. P. gingivalis can locally invade periodontal tissues and evade the host defense mechanisms. In doing so, it utilizes a panel of virulence factors that cause deregulation of the innate immune and inflammatory responses [61].

$P$. gingivalis can also penetrate deep into gingival tissue and degrade basement membrane proteins. It adheres to, invades, remain viable, could replicate, and survive for a long period within human epithelial cells. Adhesion of $P$. gingivalis to host cells involves the interaction of bacterial cell-surface adhesins with receptors expressed on the 
surfaces of epithelial cells, this it achieves by exploiting host cell signaling pathways [62, 63]. The interaction between $P$. gingivalis fimbriae and its cognate receptor $\beta-1$ on gingival epithelial cells surfaces can initiate signal transduction that leads to its uptake into epithelial cells [63]. Destruction of gingival tissues by bacterial or host proteases usually follows as a result. One other important characteristic of periodontal infection induced by $P$. gingivalis is inflammation. This is as a result of neutrophil infiltration into infected sites, continuous production of pro-inflammatory cytokines, such as IL-8, appears to be important for the progression of periodontal infections and tissue destruction [64] .

P. gingivalis is said to rapidly adhere to the host cell surface followed by internalization via lipid rafts and incorporation of the bacterium into early phagosomes. $P$. gingivalis activates cellular autophagy to provide a replicative niche while suppressing apoptosis. The replicating vacuole contains host proteins delivered by autophagy that are used by this asaccharolytic pathogen to survive and replicate within the host cell. When autophagy is suppressed by 3-methyladenine or wortmannin, internalized $P$. gingivalis transits to the phagolysosome where it is destroyed and degraded. For that reason, the survival of $P$. gingivalis depends upon the activation of autophagy and survival of the endothelial host cell, but the mechanism by which $P$. gingivalis accomplishes this remains unclear [65].

To survive within the oral cavity, $P$. gingivalis must first adhere to oral structures, i.e. epithelium, tooth surfaces, or most commonly primary bacterial colonizers. It does this via adhesins present on its cell surface, which include fimbriae and haemagglutinins. 
After the initial adherence, $P$. gingivalis must colonize and survive within the subgingival environment.

It achieves this via expression of molecules important for resisting oxidative stress, nutrient acquisition, immune evasion, and it is thought, cellular internalization [63, 66].

\subsubsection{Growth Requirements}

P. gingivalis grows in vitro by forming smooth, raised colonies on blood agar plates. The colonies appear creamy to white in color initially and turn to black in three to four days with a specific unpleasant odor. The odor has been suggested due to the conversion of Lmethionine to methyl mercaptan along with other volatile sulfur compounds that play a role in the virulence of the bacterium [67]. P. gingivalis is an asaccharolytic organism, with a requirement for hemin (as a source of iron) and peptides for growth. At least three hemagglutinins and five proteinases are produced to satisfy these requirements [57]. Bacterial colonies turn black due to the uptake of hemin from blood in the plates. 


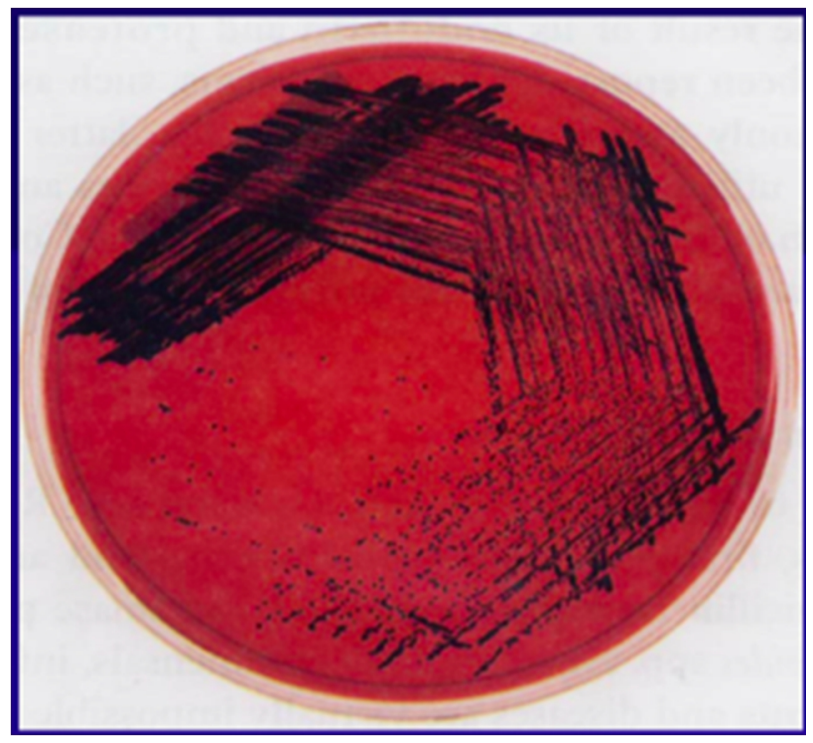

Figure 5. Black-pigmented Porphyromonas gingivalis colonies.

On blood agar, $P$. gingivalis forms black-pigmented colonies.

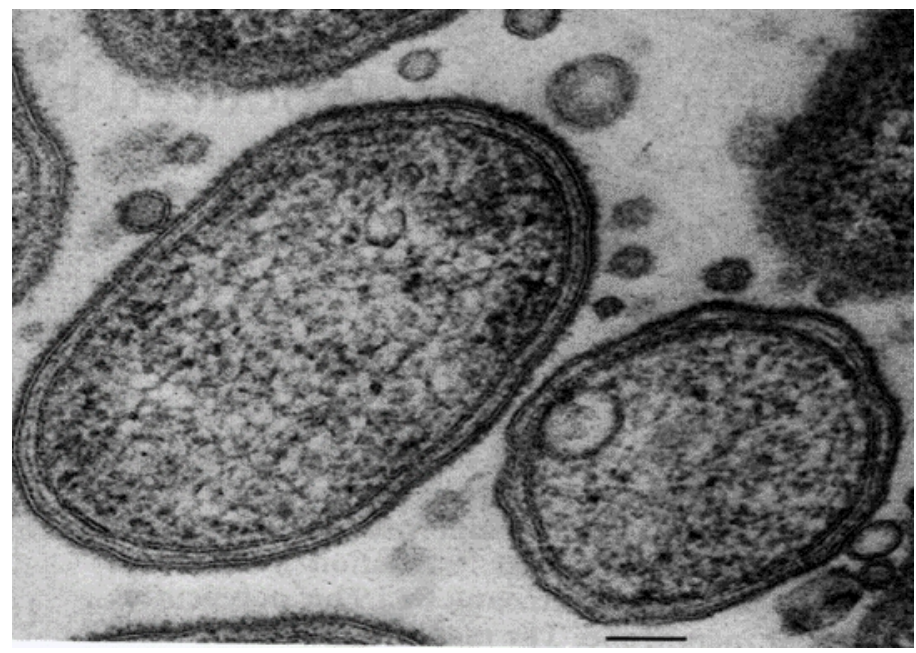

Figure 6. Electron micrograph showing budding vesicles of $P$. gingivalis.

Adapted from P. gingivalis proteases and the unique protein transport system expressed by this organism, J. Potempa. 


\subsubsection{Virulence factors}

$P$. gingivalis has some sneaky characteristics that makes it capable of evading or suppressing many aspects of innate and acquired immunity [68]. The pathogen has a wide spectrum of virulence factors including capsule, outer membrane vesicles, lectin like adhesins, lipopolysaccharide, fimbriae and cysteine proteinases which make it a very potent periodontal pathogen. $P$. gingivalis produces large amounts of arginine- and lysine-specific cysteine proteinases in cell-associated and secretory forms [69]. These enzymes, referred to as gingipains, cleave protein and peptide substrates after arginine (gingipain R) and lysine residues (gingipain K), and it has been found that neither is easily inhibited by host proteinase inhibitors [70].

P. gingivalis fimbriae are a critical factor for mediation of interaction of this bacterial organism with host tissues, as $P$. gingivalis promotes both bacterial adhesion to and invasion of targeted sites. $P$. gingivalis fimbriae are likely to interrupt the cellular signaling via extracellular matrix proteins/integrins in periodontal regions. Fimbriae are also thought to be critically important in invasive events of this bacterial organism to host cells [71]. $P$. gingivalis adhesion and invasion requires the presence of two fimbriae, termed the major and minor fimbriae. The major fimbria is composed of a $41-\mathrm{kDa}$ protein termed fimbrillin, encoded by the fimA gene [72]. The minor fimbria is comprised of a $67-\mathrm{kDa}$ protein that is encoded by the $m f a l$ gene [73]. The major and minor fimbriae are antigenically distinct, and they also differ based on amino acid composition and size [74]. A deficiency in the fimA gene leads to a diminished capacity to adhere to human gingival fibroblasts and epithelial cells, and attenuation of periodontal bone loss in gnotobiotic-rat 
model. Short fimbriae reportedly mediate co-adhesion between $P$. gingivalis and $S$. gordonii via adhesin-receptor interactions with streptococcal SspA and SspB surface proteins (antigen I/II family) [75].

The lipopolysaccharide (LPS) of $P$. gingivalis is a key factor in the development of periodontitis. Gingival fibroblasts, which are the major constituents of gingival connective tissue, may directly interact with $P$. gingivalis and its bacterial products, including lipopolysaccharide (LPS), in periodontitis lesions [76]. P. gingivalis LPS induces pro-inflammatory cytokines, such as IL-1 $\beta$, IL-6, and IL-8, which induce periodontal tissue destruction.

Majority of $P$. gingivalis strains are encapsulated. The non-encapsulated strains would probably be less efficient in progression of periodontitis due to their reduced ability of both biofilm participation and tissue invasiveness. The capsule increases resistance to phagocytosis [77].The capsule polysaccharides (CPS) down regulate the expression of several pro-inflammatory cytokines including IL-6, IL-1 $\beta$ and IL-8 expression levels, thereby compromising the host immune system and enhancing bacterial tissue invasion [78].

The cysteine proteases of $P$. gingivalis are extracellular products of an important etiological agent in periodontal diseases. Many of the in vitro actions of these enzymes are consistent with the observed deregulated inflammatory and immune features of the disease [79]. These enzymes are involved in both the destruction of periodontal tissues and interrupting host-defense mechanisms through the degradation of immunoglobulins and complement factors leading eventually to disease progression [80]. 
Recent studies have implicated $P$. gingivalis in the etiology of rheumatoid arthritis, based on its unique property among pathogens to express a citrullinating peptidylarginine deiminase enzyme [81]. $P$. gingivalis peptidyl-arginine deiminase has the ability to convert arginine residues in proteins to citrulline. Protein citrullination alters protein structure and function; hence, peptidyl-arginine deiminase may be involved in deregulation of the host's signaling network and immune evasion. Furthermore, accumulating evidence suggests a role for autoimmunity against citrullinated proteins in the development of rheumatoid arthritis [82].

\section{$\operatorname{fim} A$ Mutant $(\Delta \operatorname{fim} A)$}

fimA fimbriae (long fimbriae) are a critical factor for colonization of $P$. gingivalis in subgingival regions, as they promote both bacterial adhesion to, and invasion of, targeted sites. The fim $A$ gene exists as a single copy in the fim gene cluster (fim cluster). This cluster contains 7 genes: fim $X$, pgmA, and fim $A B C D E$. P. gingivalis is able to adhere to and enter a variety of host cells, including macrophages, fibroblasts, and epithelial and endothelial cells, which is considered to be mediated by the interactions between long fimbriae and host components such as $\alpha 5 \beta 1$-integrin, $\beta 2$-integrin $(\mathrm{CD} 11 / \mathrm{CD} 18)$ and lipid rafts [83]. The fimA mutant strain of $P$. gingivalis shows impaired invasion capability of epithelial cells compared with wild-type strain, this suggests the involvement of fimA in the bacterial interaction with surface receptor(s) on gingival cells [84]. fimA-deficient mutants were found to be relatively avirulent compared with wildtype strains of $P$. gingivalis at inducing periodontal bone loss [85]. 


\section{Mfa Mutant ( $\Delta \mathrm{mfa})$}

Short fimbriae are shorter than long fimbriae and can only be visualized when the latter are absent. The short fimbriae of $P$. gingivalis are 0.1 to $0.5 \mu \mathrm{m}$ in length and are composed predominantly of $m f a$ protein subunit [72]. Studies have shown that short fimbriae play roles in adherence to host cells and co-aggregation. Mutants of $P$. gingivalis that lack $m f a(\Delta m f a)$, show impaired formation of both monospecies biofilms as well as heterotypic biofilms with $S$. gordonii [86]. Abundance of $m f a$ protein on the cell surface may disrupt physical parameters of fimA fimbrial surface presentation and impede the ability of fimA fimbriae to activate their cognate integrin receptors.

\section{ndk Mutant ( $\Delta n d k)$}

Physically stressed, infected or dying cells release small molecules called "danger signals" that specifically interact with "danger signal receptors" on neighboring cells to alter the immune response and control colonization by pathogens [86]. Among these host-derived molecules, ATP, contributes to bacterial clearance by stimulating the secretion of cytokines, recruitment of immune cells, and sensing of pathogens. Recent studies suggest that extracellular ATP (eATP) released from immune cells can directly function as a sensor against intracellular pathogens upon ligation of the purinergic receptor, $\mathrm{P} 2 \mathrm{X}_{7}[87]$.The $\mathrm{P} 2 \mathrm{X}_{7}$ receptor has recently emerged as an important multi-level mediator in controlling intracellular infections by regulating the innate immune response, apoptosis, intracellular trafficking, and generation of reactive oxygen species (ROS) [88, 89].

$P$. gingivalis, is capable of intracellular survival, replication, and intercellular spreading within the gingival epithelium, can withstand the challenge of host-mediated immune 
responses working to destroy pathogens and interrupt their colonization [90]. $P$. gingivalis can diminish eATP/P2X7 receptor-mediated apoptosis of primary GECs. Secretion of a nucleoside-diphosphate-kinase $(n d k)$ homolog by the $P$. gingivalis has been proposed to consume eATP, thereby inhibiting P2X7 ligation [91]. A ndkdeficient $P$. gingivalis mutant ( $\Delta n d k)$ lacked the ability to inhibit ROS production and persist intracellularly following eATP stimulation. Treatment with recombinant $n d k$ significantly diminished eATP-evoked ROS production [92]. We therefore proposed that a $n d k$ mutant strain would show reduced expression of Zeb1 compared to wild-type strain of $P$. gingivalis.

\subsection{Gingival Epithelial cells}

The gingival epithelial comprise the epithelial tissue that covers the external surface of the gingiva as well as the epithelium lining the gingival sulcus and the junctional epithelium The gingival epithelium is subdivided into 3 sections, the oral epithelium, the secular, and the junctional epithelium. The oral epithelium extends from the mucogingival junction to the gingival margin. It is continuous with the sulcular epithelium that lines the lateral aspect of the gingival sulcus. The junctional epithelium forms the dentoepithelial junction apical to the sulcus. Its coronal end forms the bottom of the gingival sulcus and is overlapped by the sulcular epithelium. These epithelia differ from one another in their function and, therefore, in some of their histological characteristics. 


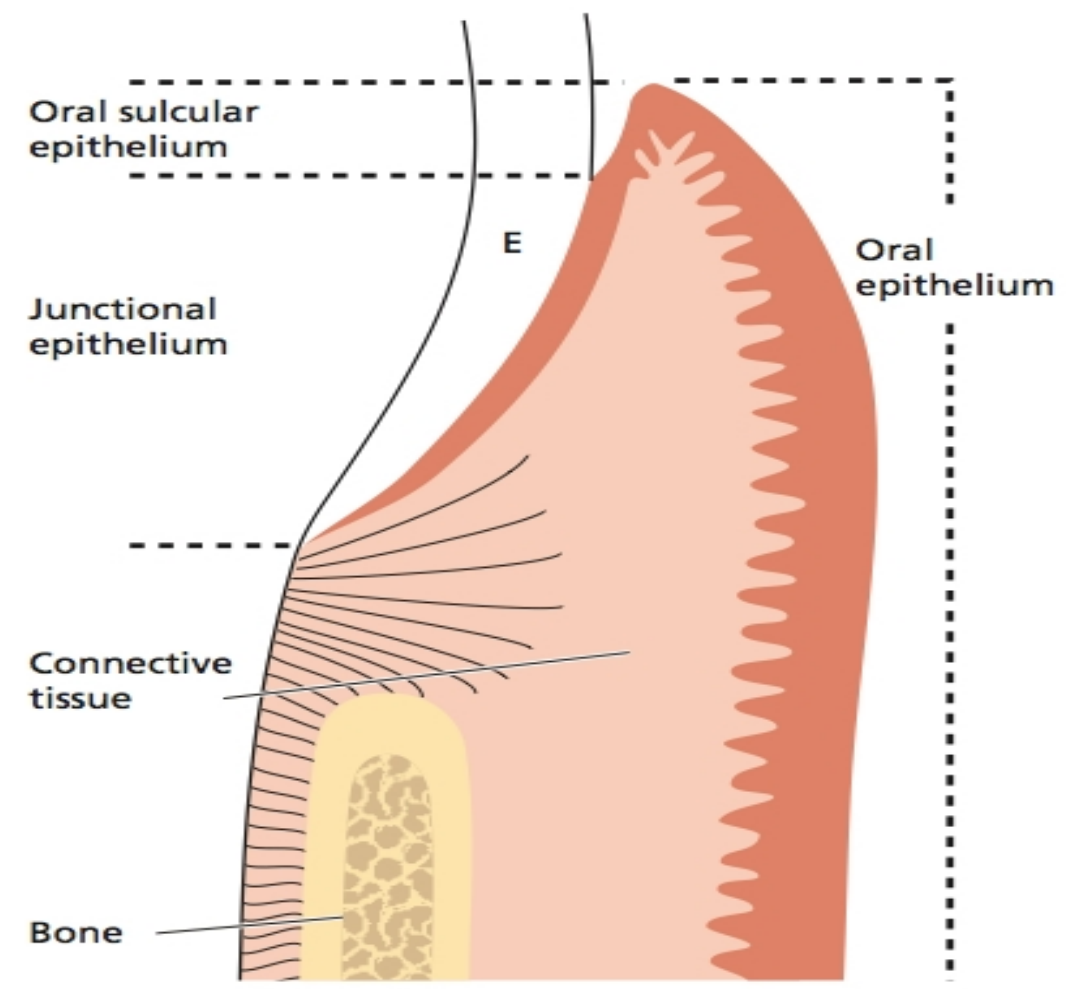

Figure 7. Anatomy of the three areas of the gingival epithelium interface with the connective tissue.

Adapted from Clinical Periodontology and Implant Dentistry 5th by Jan Lindhe.

The major cells within the epithelium are epithelial cells, and together these form a dense structure joined by cell-cell junctions and cell adhesion receptors, including integrins. The oral epithelium is a stratified, squamous epithelium, which may or may not be keratinized. There are three distinct layers within the epithelium. These are known as the basal layer, spinous layers (prickle cell layers) and superficial layers. The cytoskeleton of epithelial cells, and indeed all eukaryotic cells, functions as a cellular scaffold. The dynamic nature of the cytoskeleton aids in intracellular trafficking, mitosis and cellular 
migration [93]. Three types of protein filaments form the cytoskeleton, and these are known as intermediate filaments, microtubules and actin filaments.

The gingival epithelial cells (GECs) constitute a very important tool in simulating the interaction between periodontal pathogens and host cells in vitro. They are the first to encounter the colonizing bacteria in the oral cavity and are thereby, well-known to play an important role in the host-bacterial environment. Several studies have shown the significant role of gingival epithelial cells in the immunological interplay, alongside being the first line of defense i.e. barriers against pathogens. The immunological modulation of epithelial cells is essential for the initiation and progression of periodontitis [94].

\subsubsection{Telomerase Immortalized Gingival Keratinocytes (TIGKs)}

Keratinocytes form a predominant cellular component of the epithelial surface of oral mucosa. The culture of keratinocytes is necessary for wide applications like the treatment of burns, surgical correction of a mucosal defect, in developing model systems for in vitro research experiments, gene therapy etc. [94]. Primary gingival epithelial cells have a finite lifespan in culture of about nine passages, after which they cease replicating and enter senescence state [95]. The limited lifespan of somatic cells in culture can be triggered by progressive telomere shortening through a p53-/p21cip1-dependent senescence mechanism $[96,97]$.

The enzyme telomerase contains a catalytic subunit, hTERT, expressed solely in germ cells and immortal cancer cells [98]. Introduction of hTERT into fibroblasts (which are 
mesenchymal cells responsible for much of the synthesis of extracellular matrix in connective tissues) and some epithelial cells confers telomere maintenance and unlimited replicative potential. The replication potential of these cell types during serial passaging is generally limited by a telomere independent mechanism mediated by the attenuated repression of CDKN2A (cyclin-dependent kinase inhibitor 2A), which encodes p16INK4A and p14ARF. The function of p16INK4 is to attenuate Cdk4/6 phosphorylation of retinoblastoma protein and thus promote cell cycle arrest, whereas p14ARF functions in the p53 pathway to inhibit MDM2-mediated degradation of p53 and promote p53-mediated transcriptional activation (e.g. p53-/p21cip1-dependent senescence) [99]. Transduction of cells with bmil (BMI1 polycomb ring finger oncogene), a natural repressor of CDKN2A, facilitates immortalization upon subsequent expression of hTERT [100]. Keratinocytes immortalized by bmi1 + hTERT display unaffected cell morphology, growth control and differentiation potential [101].

\subsubsection{Immortalization of gingival epithelial cells with human telomerase reverse transcriptase}

GECs were immortalized with bmil transduction followed by human telomerase reverse transcriptase (hTERT) by the Rheinwald Laboratory at the Harvard Skin Disease Research Center [101]. GECs were cultured in keratinocyte serum-free medium (K-SFM; Invitrogen, Carlsbad, CA, USA) supplemented with $0.4 \mathrm{mM}$ calcium chloride, $25 \mu \mathrm{g} / \mathrm{mL}$ bovine pituitary extract and $0.2 \mathrm{ng} / \mathrm{mL}$ epidermal growth factor. Cells were transduced with amphotropic BABE bmi1.puro retroviral supernatants with $2 \mu \mathrm{g} / \mathrm{mL}$ polybrene (Sigma-Aldrich, St Louis, MO, USA) for $6 \mathrm{~h}$. Cells were subcultured in K-SFM and 
subjected to drug selection $(0.5 \mathrm{lg} / \mathrm{mL}$ puromycin) for $7 \mathrm{~d}$. GECs previously bmi 1 transduced were then transduced in a similar manner with amphotropic Wzl-TERT.Bsd retroviral supernatants with polybrene followed by subculture and drug selection $(5 \mu \mathrm{g} / \mathrm{mL}$ blasticidin $)$ in K-SFM [102].

\subsection{Study Rationale, Hypothesis, and Aims}

To further advance our knowledge of the role of $P$. gingivalis in the up-regulation of EMT markers, we proposed the following hypothesis and aims:

In this study, we hypothesized that $P$. gingivalis infection up-regulates the expression of ZEB1 and vimentin in human oral epithelial cells, hence an increased invasiveness of such infected cells.

Specific Aim \#1: To evaluate the regulation of Zeb1 expression in P. gingivalis ATCC 33277 strain infected TIGK cells at the transcriptional levels.

Specific Aim \#2: To determine the mechanism through which $P$. gingivalis up-regulates Zeb1 mRNA expression.

Specific Aim \#3: To examine the changes in vimentin, and Zeb1 mRNA expression levels in TIGK cells challenged by $P$. gingivalis.

Specific Aim \#4: To demonstrate that the up-regulation of Zeb1 in $P$. gingivalis infected TIGK cells would enhance their invasiveness and to determine whether knockdown of 
ZEB1 would have any effect on vimentin expression as well as invasiveness of $P$. gingivalis infected TIGK cells.

The overall goal is to evaluate how $P$. gingivalis in OSCC patients with chronic periodontitis may play a role in the enhanced invasion of OSCC, as well as identify the virulence factors or signaling pathways that might be helpful therapeutic targets in hindering the progression of EMT, which is the initiating step in the invasion of OSCC. 
CHAPTER II

MATERIALS AND METHODS

\subsection{Bacterial Stains and Growth Condition}

$P$. gingivalis strains WT ATCC 33277 and mutants $\Delta$ fimA, $\Delta m f a$ and $\Delta n d k$ were cultured anaerobically $(80 \% \mathrm{~N} 2,10 \% \mathrm{H} 2,10 \% \mathrm{CO} 2)$ at $37^{\circ} \mathrm{C}$ in Trypticase soy broth(TSB) (BDBBL) supplemented with $1 \mathrm{mg} / \mathrm{ml}$ yeast extract, $5 \mu \mathrm{g} / \mathrm{ml}$ hemin and $1 \mu \mathrm{g} / \mathrm{ml}$ menadione. Plate-cultured laboratory strains were grown on Trypticase soy broth (BBL-BD) supplemented with $1 \mathrm{mg} / \mathrm{ml}$ yeast extract, $5 \mu \mathrm{g} / \mathrm{ml}$ hemin and $1 \mu \mathrm{g} / \mathrm{ml}$ menadione, supplemented with 10\% defibrinated sheep blood (BD-BBL). Antibiotics were used, when appropriate, at the following concentrations: $5 \mu \mathrm{g} / \mathrm{ml}$ erythromycin ( $\Delta m f a$ and $\Delta n d k)$ and $1 \mu \mathrm{g} / \mathrm{ml}$ tetracycline $(\Delta$ fimA $) . P$. gingivalis strains were stored at $-80^{\circ} \mathrm{C}$ as frozen glycerol stocks and streaked onto TSB-blood agar plate. For use in experiments, $P$. gingivalis was sub-cultured from a TSB-blood agar plate into broth. Overnight broth cultures were used in experiments. An overnight subculture of OD 0.5-0.8 was used for infection.

\subsection{Cell Culture}

Telomerase immortalized gingival keratinocytes (TIGKs) were cultured in Dermalife-K serum free keratinocyte culture medium (Lifeline cell technology) containing the supplements, Transferrin, rh TGF- $\alpha$, rh Insulin, Epinephrine, L- Glutamine, Hydrocortisone and Extract-P. Cells were cultured in a humidified chamber at $37^{\circ} \mathrm{C}, 5 \%$ 
CO2. Medium was changed every 2-3 days and cells were passaged when $80-90 \%$ confluent.

Cells were passaged by washing twice with phosphate buffered saline (PBS) and incubating with $0.05 \%$ Trypsin $/ 0.53 \mathrm{mM}$ EDTA (warmed in water bath prior to usage) at $37^{\circ} \mathrm{C}$ for 5-10 minutes (dependent on the cell type), until cells lifted from the surface of the flask. Dermalife-K serum free keratinocyte culture medium was added to the cell suspension to inhibit the enzymatic activity of the Trypsin/EDTA, and cells were centrifuged at $1000 \mathrm{rpm}$ for 5 minutes. The supernatant was removed, the cell pellet resuspended in medium and re-seeded at $1.0 \times 10^{6}$ cells/T75 flask. The cells were seeded into 6-well plates at $30 \%$ confluence and infected when $80 \%$ confluence was attained (approx. $1.0 \times 10^{6}$ cells/well). Cells were maintained as frozen stocks.

\subsection{Infection Conditions}

After TIGK cells attained $80 \%$ confluence on 6-well plates, culture media was replaced by fresh media one day prior to when infection was carried out. TIGK cells were infected with $P$. gingivalis strains WT ATCC 33277, $\Delta f i m A, \Delta m f a, \Delta n d k$ already described mutants at multiplicity of infection (MOI) 50 and 100 for 6 hours, after which the culture media was replaced by fresh media and incubated overnight. Non-infected TIGKs served as a control for all conditions. 


\subsection{Quantitative RT-PCR (qRT-PCR) analysis of mRNA expression}

\subsection{1 mRNA Isolation}

Total RNA was purified from TIGK cells using the PerfectPure RNA Cell Kit (5 Prime).

Cultured TIGK cells were lysed using TCEP (0.5M) and lysis solution (5 Prime). Lysed cells were then homogenized using 18 gauge needle and $3 \mathrm{ml}$ syringe, thus releasing RNA into the lysis solution. All the samples were run through a 5 PRIME PRECLEAR column to remove any leftover debris following homogenization. The column binds RNA, while proteins, DNA and other impurities were washed away with wash buffer. Residual DNA was removed by on-column Dnase digestion. The DNA fragments and DNase were then removed by subsequent washing. RNA was eluted from the column using $50 \mu \mathrm{l}$ of RNase-free water. A small volume of the purified RNA was used for quantitative and qualitative analysis. The remaining RNA was stored at $-80^{\circ} \mathrm{C}$.

\subsubsection{RNA analysis with NanoDrop}

Quantification and purity of total RNA was assessed by using a NanoDrop 2000® spectrophotometer (Thermo Scientific). RNA absorbs at $260 \mathrm{~nm}$ and the ratio of the absorbance at 260 and $280 \mathrm{~nm}$ is used to assess the RNA purity. Pure RNA has an A260/A280 value of 1.8-2.0, depending on how the measurement is performed and the source of presumed contaminants. 


\subsection{3 cDNA Synthesis for mRNAs}

Complementary DNA was synthesized with the High Capacity cDNA Reverse

Transcription Kit (Applied Biosystems) following the manufacturer's protocol. Reverse transcription reactions were carried out for each RNA sample, subsequently followed by first strand cDNA synthesis from $2 \mu \mathrm{g}$ of the total RNA samples. The samples were cooled to $4{ }^{\circ} \mathrm{C}$, and stored at $-20{ }^{\circ} \mathrm{C}$ until quantitative (q)RT - PCR. 


\section{Table 1}

The components used to synthesize cDNA

\begin{tabular}{|l|c|}
\hline Reagent & Volume $(\boldsymbol{\mu l}) / \mathbf{2 0} \boldsymbol{\mu l}$ Reaction \\
\hline 10x RT buffer & 2.0 \\
25x dNTP Mix $(100 \mathrm{mM})$ & 0.8 \\
10x RT Random Primers & 2.0 \\
MultiScribe Reverse Transcriptase & 1.0 \\
Nuclease-free H20 & 4.2 \\
\hline Total & $\mathbf{1 0 . 0}$ \\
\hline
\end{tabular}

Reverse transcription was performed using the High-Capacity cDNA Reverse Transcription Kit (Applied Biosystems). Each $20 \mu \mathrm{l}$ consists of $10 \mu \mathrm{l}$ of $2 \mathrm{x}$ RT master mix, and $10 \mu \mathrm{l}$ of RNA sample.

\subsubsection{SYBR Green real-time qRT-PCR assays}

Power SYBR $®$ Green PCR Master Mix (Applied Biosystems) was used in the real time PCR reaction according to the manufacturer's suggested protocols. Specific mRNA targets (Zeb1, and vimentin) were analyzed, using GAPDH as the house keeping gene/endogenous control. Signals for mRNA transcripts were determined by qRT-PCR on 1:10 diluted cDNA. To prevent amplification of genomic DNA, forward and reverse primers for each transcript were designed to target separate exons, spanning at least one intron with a size of $200 \mathrm{bp}$ or more. The primer sequences used for qRT-PCR can be found in Table 3. Each sample was run in triplicate for three different set of experiments. The relative gene expression was calculated using the comparative $\mathrm{CT}(\Delta \Delta \mathrm{CT}) / 2^{-\Delta \mathrm{Ct}}$ method, where $\Delta \mathrm{Ct}=\mathrm{Ct}$ (target RNA) $-\mathrm{Ct}(\mathrm{GAPDH})$ [103]. 


\section{Table 2}

The reagents used in SYBR Green real-time qRT-PCR

\begin{tabular}{|l|c|}
\hline Reagent & Volume $(\boldsymbol{\mu l}) / \mathbf{2 0} \boldsymbol{\mu l}$ reaction \\
\hline Forward Primer & 0.50 \\
Reverse Primer & 0.50 \\
Power SYBR Green PCR Master Mix & 10.0 \\
Nuclease-free H20 & 7.00 \\
\hline Total & $\mathbf{1 8 . 0 0}$ \\
\hline
\end{tabular}

Each $20 \mu \mathrm{l}$ reaction consists of $18 \mu \mathrm{l}$ master mix, and $2 \mu \mathrm{l}$ cDNA sample.

\section{Table 3}

List of primers used for SYBR Green real-time qRT-PCR

\begin{tabular}{|l|l|l|}
\hline Name & Forward & Reverse \\
\hline ZEB1 & 5'-GCACCTGAAGAGGACCAGAG-3' & 5'-TGCATCTGGTGTTCCATTTT-3' \\
Vimentin & 5'-GGAACAATGACGCCCTGCGCCA-3' & 5'-AGTTAGCAGCTTCAACGGCAAA-3' \\
GAPDH & 5'-ACCACAGTCCATGCCATCAC-3' & 5'-GGCCATGCCAGTGAGCTTCC-3' \\
\hline
\end{tabular}




\subsection{Quantitative RT-PCR (qRT-PCR) analysis of miRNA expression.}

\subsection{1 microRNA Isolation by the 70\% Ethanol method.}

Small RNAs, including miRNA and short interfering RNAs (siRNA) were isolated from TIGK cells using the PureLink® miRNA Isolation Kit. The kit is based on the selective binding of small RNA molecules to silica-based membrane in the presence of $70 \%$

ethanol. TIGK cells were harvested by the addition of $300 \mu \mathrm{l}$ binding buffer and homogenization using 18 gauge needle and $3 \mathrm{ml}$ syringe. This was followed by addition of $70 \%$ ethanol and vortexing to optimize the binding conditions of all small RNA molecules. All the samples were run through a spin cartridge column where small RNA binds to the column membrane while ethanol and other impurities are washed away with wash buffer. Contaminating DNA was removed by on-column Dnase digestion. RNA was eluted from the column using $50 \mu \mathrm{l}$ of RNase-free water. A small volume of the purified small RNA was used for quantitative and qualitative analysis as described above. The remaining small RNA was stored at $-70^{\circ}$ to $-80^{\circ} \mathrm{C}$.

\subsection{2 cDNA Synthesis for miRNAs}

Complementary DNA was synthesized with the TaqMan MicroRNA Reverse Transcription Kit (Applied Biosystems) following the manufacturer's protocol. Reverse transcription reactions were carried out for each small 5 ng RNA sample per $15 \mu 1$ reaction, subsequently followed by first strand cDNA synthesis from $2 \mu \mathrm{g}$ of the total RNA samples. The samples were then cooled down to $4{ }^{\circ} \mathrm{C}$, and then stored at $-20{ }^{\circ} \mathrm{C}$ until qRT - PCR. 


\section{Table 4}

The components used to synthesize cDNA using specific microRNA Primers

\begin{tabular}{|l|c|}
\hline Reagent & Volume $(\boldsymbol{\mu l}) / \mathbf{1 5} \boldsymbol{\mu l}$ Reaction \\
\hline 10x RT buffer & 1.50 \\
dNTP Mix $(100 \mathrm{mM})$ & 0.15 \\
RNase Inhibitor & 0.19 \\
MultiScribe Reverse Transcriptase & 1.00 \\
Nuclease-free H20 & 4.16 \\
\hline Total & $\mathbf{7 . 0 0}$ \\
\hline
\end{tabular}

Reverse transcription was performed using the TaqMan ${ }^{\circledR}$ MicroRNA Reverse Transcription Kit (Applied Biosystems). Each $15 \mu 1$ reaction consists of $7 \mu$ master mix, $3 \mu l$ primer, and $5 \mu 1$ RNA sample.

\subsubsection{TaqMan real-time qRT-PCR MicroRNA Assays.}

Quantitative RT-PCR was carried out using an Applied Biosystems Step One Plus ${ }^{\text {TM }}$

Real-Time PCR System as described above. Specific microRNA targets (miR-200b, miR200c) expression were analyzed, using RNU48 as the house keeping gene/endogenous control. The PCR primers for miR-200b, miR-200c, and RNU48 were purchased from TaqMan (Applied Biosystems). The relative gene expression was calculated using the comparative $\mathrm{CT}(\Delta \Delta \mathrm{CT}) / 2^{-\Delta \mathrm{Ct}}$ method, where $\Delta \mathrm{Ct}=\mathrm{Ct}$ (target miRNA) $-\mathrm{Ct}(\mathrm{RNU} 48)$ [103]. 


\section{Table 5}

The reagents used in TaqMan MicroRNA Assays

\begin{tabular}{|l|c|}
\hline Reagent & Volume $(\boldsymbol{\mu l}) / \mathbf{2 0} \boldsymbol{\mu l}$ reaction \\
\hline Primer (forward and reverse) & 10.00 \\
TaqMan MicroRNA Assay Mix & 1.00 \\
cDNA & 1.33 \\
Nuclease-free H20 & 7.67 \\
\hline Total & $\mathbf{2 0 . 0 0}$ \\
\hline
\end{tabular}

Each $20 \mu \mathrm{l}$ reaction consists of $18.67 \mu \mathrm{l}$ master mix, and $1.33 \mu \mathrm{l}$ cDNA sample.

\subsection{Dual-Glo Luciferase Reporter Assay.}

The ZEB1 gene promoters used for the Dual Glo Luciferase reporter assay were prepared by PCR amplification of human genomic DNA. The plasmids Z1p.1000-Luc contains $912 \mathrm{bp}$ to $+43 \mathrm{bp}$ of the human ZEB1 gene (965 base pairs), Z1p-400-Luc contains $-367 \mathrm{bp}$ to +43 bp (417 base pairs), Z1p.196-Luc contains $-212 b p$ to $+43 b p$ (265 base pairs including Exon 1, 212 base pairs excluding Exon 1), all representing specific regions just upstream of ZEB1 gene that acts as a binding site for transcription factors were inserted into a promoterless Luciferase reporter vector (pGL3-Basic, Promega, Madison, WI).

TIGK cells suspension in $100 \mu$ of growth medium were seeded in 96-well plates $(1.0 \mathrm{x}$ 104/well) $24 \mathrm{~h}$ before transfection. A 3:1 FuGENE® 6 Transfection Reagent (Promega):Plasmid ratio was used. $2 \mu$ g of plasmids (Z1p.1000-Luc, Z1p.400-Luc, 
Z1p.196-Luc) were co-transfected with control Renilla luciferase plasmid (pGL4.73Rluc). The ratio of experimental plasmid to control plasmid was 10:2.

Luciferase assays were performed using the Dual-Glo Luciferase Assay (Promega). $48 \mathrm{~h}$ after transfection, TIGK cells were infected for $24 \mathrm{~h}$. After $24 \mathrm{~h}$ of infection, the 96 -well plate containing TIGK cells were removed from the incubator, $75 \mu 1$ of Dual-Glo Luciferase reagent was added into each well and then incubated for $15 \mathrm{mins}$ at room temperature. Firefly luciferase activity was measured using the Victor X3 2030 Multilabel Reader (PerkinElmer).The activity of the Dual-Glo Luciferase reagent was stopped by the addition of $75 \mu 1$ Dual-Glo Stop \& Glo reagent. The plate was again incubated for another $15 \mathrm{mins}$ at room temperature, and Renilla luminescence was measured. Background measurements for Firefly Luciferase was taken from nontransfected samples and Dual-Glo Luciferase reagent, while the background measurements for Renilla Luciferase was taken from non-transfected samples containing both Dual-Glo Luciferase reagent and Dual-GloStop \& Glo reagent. Each firefly luciferase activity was normalized to Renilla luciferase activity. All transfection experiments were conducted in triplicate for three different set of experiments. Cell lysates were transferred in triplicate to 96 -well plates.

\subsection{Transwell assay.}

A transwell assay was carried using a Permeable Transwell Pore Polyester Membrane Insert (0.4- $\mu \mathrm{m}$ pore size polycarbonate membrane, $24-\mathrm{mm}$ diameter, Corning, Inc., Corning, NY) to evaluate the effect of $P$. gingivalis secreted soluble factors mediating 
changes in TIGK cells behavior in the absence of cell-cell contact. $80 \%$ confluent TIGK cells were grown in 6-well plates at $37^{\circ} \mathrm{C}$ for $48 \mathrm{~h}$. Transwell inserts containing $P$. gingivalis at MOI of 50 \& 100 in Dermalife-K serum free keratinocyte culture medium (Lifeline cell technology) were inserted over each experimental well and further incubated for another $24 \mathrm{~h}$. After $24 \mathrm{~h}$ of incubation at $37^{\circ} \mathrm{C}$, the transwell inserts were discarded and total RNA was then isolated for qRT-PCR analyses of ZEB1, as described above.

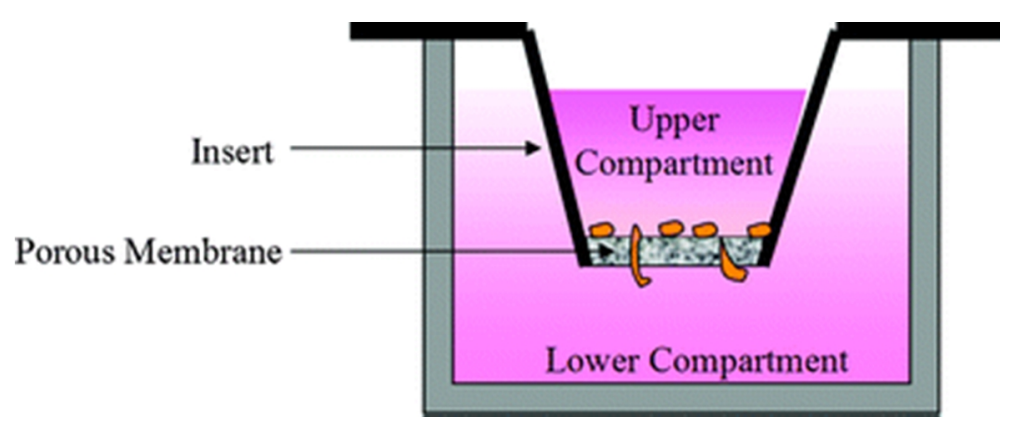

Figure 8. Schematic of a Transwell Permeable Support.

Corning Osteo Assay Surface Co-Culture System. The upper compartment contains P. gingivalis in cell culture media, the lower compartment contains TIGK cells. Adapted from: The evolution of chemotaxis assays from static models to physiologically relevant platforms.

\subsection{Matrigel Invasion Assay.}

In vitro cell invasion assays were analyzed as described previously [33] in a BD BioCoat $^{\mathrm{TM}}$ Matrigel ${ }^{\mathrm{TM}}$ Invasion Chamber (Two Oak Park, Bedford, MA, USA) according to the protocol provided by the manufacturer. Cells were allowed to grow to 
subconfluency (75-80\%) for $48 \mathrm{~h}$. After detachment with trypsin, cells were washed with PBS, resuspended in serum free medium and $2 \mathrm{ml}$ of cell suspension $\left(1.25 \times 10^{5}\right.$ cells $\left./ \mathrm{ml}\right)$ was seeded unto the Matrigel-coated Transwell Membrane (upper chamber 8- $\mu \mathrm{m}$ pore size). Chemoattractant (a 5\% fetal bovine serum in cell culture medium) was added to the bottom wells of the chamber. The BD BioCoat Matrigel Invasion Chambers were incubated in a humidified tissue culture incubator, at $37^{\circ} \mathrm{C}$ for $24 \mathrm{~h}$. Cells were infected with $P$. gingivalis at an MOI of $50 \& 100$ for $24 \mathrm{~h}$.

After incubation, non-invading cells were removed from the upper face of the membrane by scrubbing using cotton swabs, and the cells that had migrated to the lower face of the filters were fixed with $100 \%$ methanol solution for 2 minutes, air-dried, and stained with $1 \%$ solution of toluidine blue for 2 minutes. Images of three random x 20 magnification fields were captured from each membrane and the number of migratory cells was counted. The mean of triplicate assays for each experimental condition was used.

\subsection{Transfection of TIGKs with short interfering RNA.}

Approximately $0.8-1.0 \times 10^{6}$ of TIGK cells were plated in 6-well plates. After $24 \mathrm{~h}$ of incubation, cells were transfected with $30 \mathrm{nM}$ predesigned short interfering RNA (siRNA) (siGENOME SMARTpool siRNA) targeting ZEB1 or control siRNA purchased from GE Healthcare Dharmacon using LipoJet transfection reagent (SignaGen ${ }^{\circledR}$ Laboratories) according to the manufacturer's protocol. The cells were subsequently incubated for $48 \mathrm{~h}$ to achieve knockdown of expression of the target gene. Following 48 $\mathrm{h}$ in transfection medium, the medium was replaced with fresh culture medium for 
another $24 \mathrm{~h}$ of incubation. Transfected cells were thereafter infected with $P$. gingivalis at an MOI of $50 \& 100$ for $24 \mathrm{~h}$. To determine the knockdown efficiency, total RNA was isolated for qRT-PCR analyses of ZEB1 and vimentin expression, as described above. Transfected cells were used in the Matrigel invasion assay as described above.

\subsection{Statistical analysis}

Significance of correlations was done using GraphPad Prism 6 (GraphPad Software, San Diego, CA). All quantified data represents an average of at least triplicate samples from three biological replicates or as indicated. Data are presented as mean, error bars represent standard errors (SEs) of the mean. Differences were analyzed with one-way ANOVA and Student $t$ test where applicable. All tests were performed two tailed, and statistical significance was set at $P$ less than $0.05(P<0.05)$. 


\section{CHAPTER III}

\section{RESULTS}

\subsection{Vimentin and its transcriptional inducer, ZEB1 were up-regulated following $P$.}

gingivalis infection of TIGK cells.

A relationship between periodontal disease and the invasion of OSCC have been suggested, and $P$. gingivalis have been shown to occur frequently in the mouth of oral cancer patients $[13,14]$. In order to ascertain whether $P$. gingivalis could be involved in the up-regulation of EMT markers in epithelial cells, we focused on ZEB1 which is a crucial EMT inducer, as well as vimentin which is transcriptionally induced by ZEB1. Increased ZEB1 mRNA levels was confirmed with qRT-PCR, expression was upregulated $>1.7$-fold at MOI $50(P<0.0008)$ and $>3$-fold at MOI $100(P<0.0001)$ in infected groups compared with uninfected controls (Fig. 9). Increased vimentin levels was also shown by qRT-PCR, vimentin mRNA was up-regulated $>1.8$-fold at MOI 50 ( $P$ $<0.0011)$ and $>3$-fold at MOI $100(P<0.0012)$ in infected cells compared with uninfected control groups (Fig. 10). 


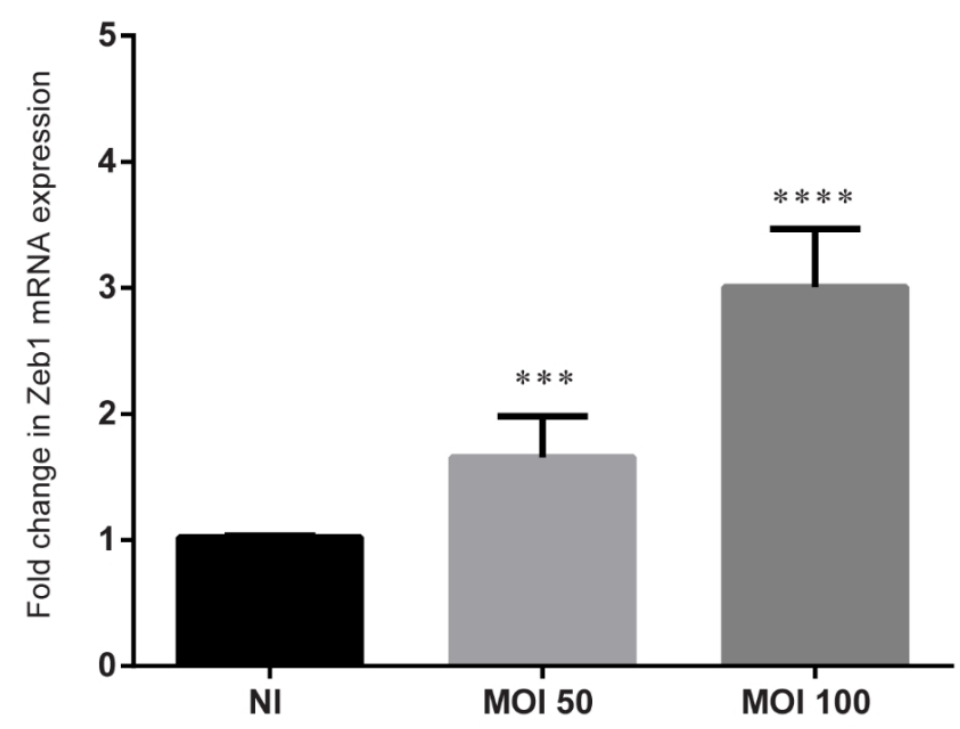

Figure 9. P. gingivalis infection up-regulated ZEB1 mRNA expression.

Results from qRT-PCR analysis showed a significant higher expression of ZEB1 mRNA at MOI $50(* * * P$ $<0.0008)$, and MOI $100(* * * * P<0.0001)$

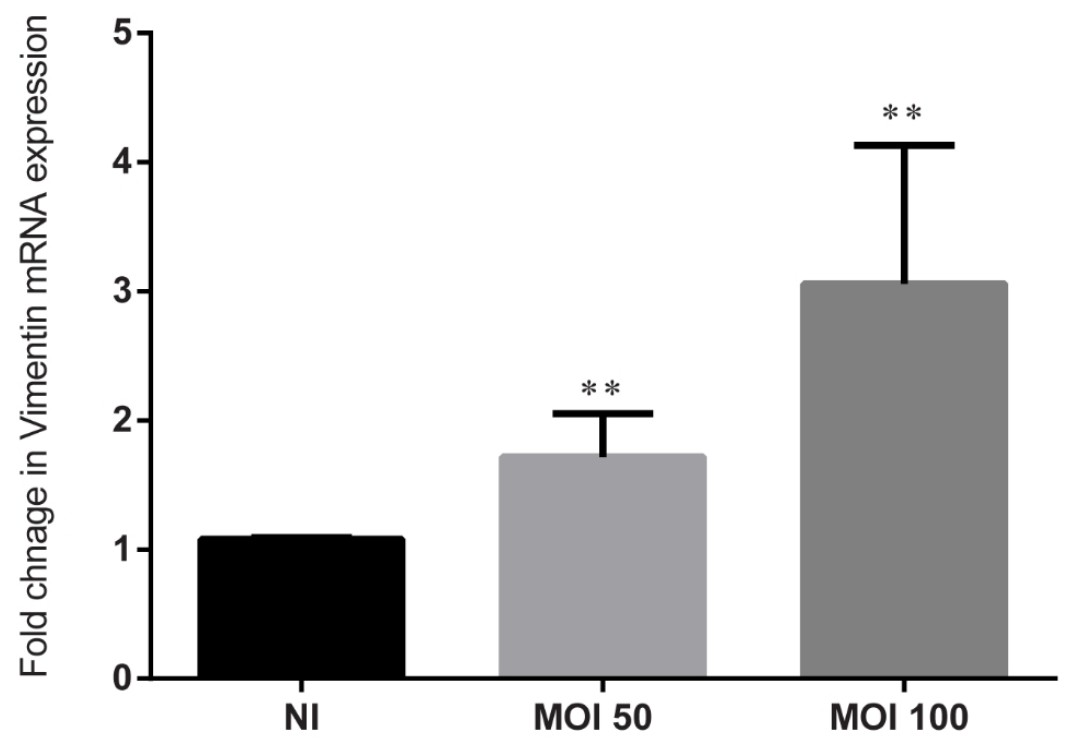

Figure 10. $P$. gingivalis infection up-regulated vimentin mRNA expression.

Results from qRT-PCR analysis showed a significant higher expression of ZEB1 mRNA at MOI $50(* * P<$ $0.0011)$, and MOI $100(* * P<0.0012)$. 


\section{2. $P$. gingivalis infection of TIGK cells enhances activity at the ZEB1 promoter region}

In order to investigate whether $P$. gingivalis infection has any effect on the human ZEB1 promoter, plasmid constructs Z1p.1000-Luc, Z1p-400-Luc, and Z1p.196-Luc (all representing specific regions upstream of ZEB1 gene that acts as a binding site for transcription factors) in Firefly luciferase reporter were transfected into TIGK cells. Data were analyzed relative to pGL4.73Rluc in Renilla luciferase (control). Increased promoter activity was confirmed in infected cells compared with uninfected cells. The highest activity was detected at the Z1p.196-Luc promoter region, which was higher than Z1p-400-Luc and Z1p, while the least activity was obtained at the Z1p.1000-Luc region (Fig. 11). This result suggests that activities at these promoter sites are enhanced in the presence of $P$. gingivalis infection, suggesting a significant role of $P$. gingivalis at transcriptional level of ZEB1 expression. 


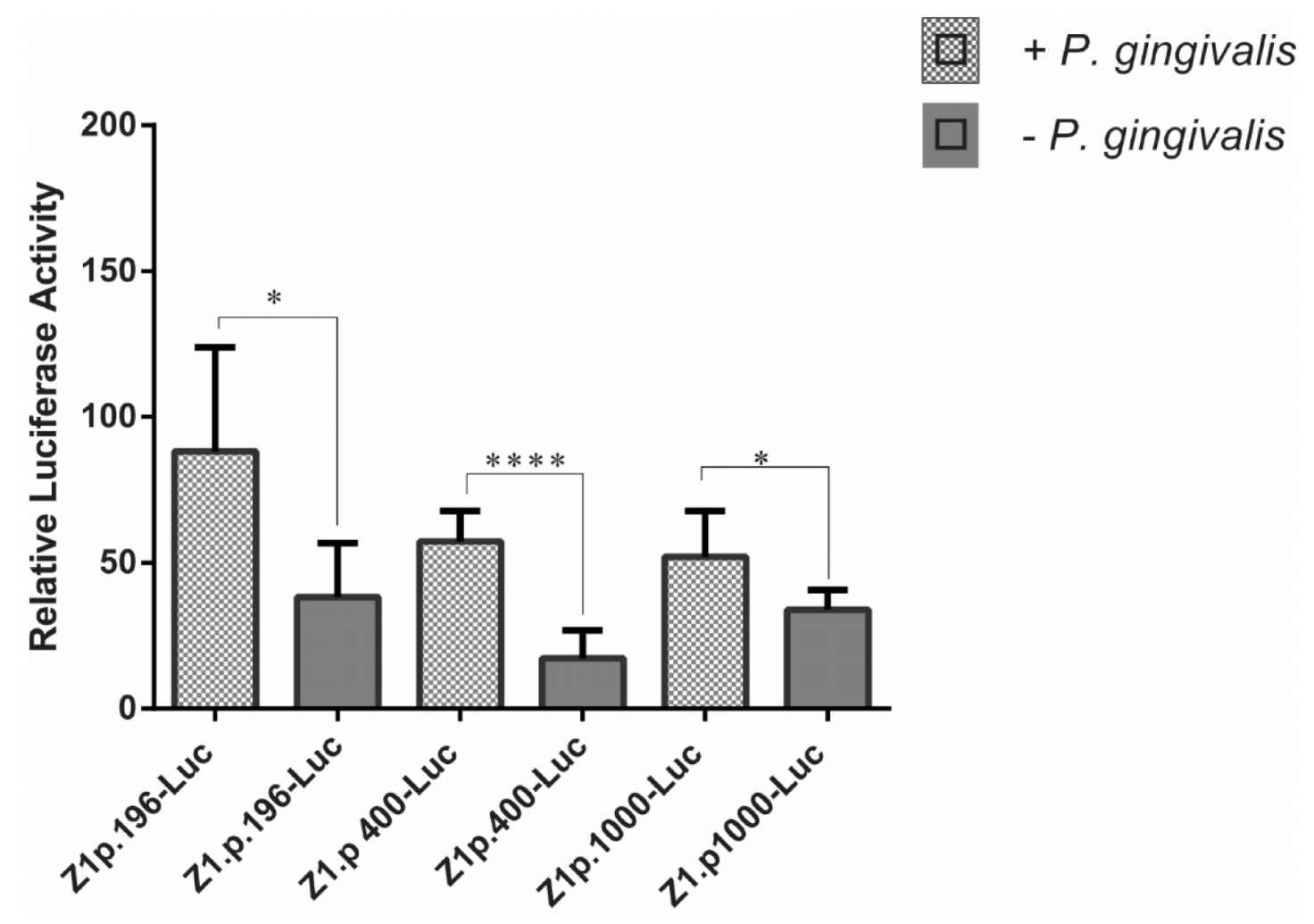

Figure 11. $P$. gingivalis infection enhances ZEB1 promoter activity in TIGK cells.

ZEB1 promoter activity was determined by co-transfection of TIGK cells with either Z1p.1000-Luc, Z1p400-Luc or Z1p.196-Luc, together with pGL4.73Rluc for 48 h, thereafter test samples were infected with $P$. gingivalis for $24 \mathrm{~h}$. Firefly Luciferase activity was measured by normalizing it to Renilla activity, results shows effect of $P$. gingivalis infection at the different promoter region with a pronounced activity at the Z1p.196-Luc region. A significant enhanced activity was noted between infected cells and non-infected control samples Z1p.196-Luc (***P<0.0127), Z1p.400-Luc $(* * P<0.0001)$ and Z1p.1000-Luc $(* * * P<$ $0.0272)$. 


\subsection{Up-regulation of ZEB1 mRNA represses miR-200 family in $P$. gingivalis infected}

\section{TIGK cells.}

It has been reported that Zeb1 expression is controlled by miRNAs of the miR-200 family in a negative feedback loop fashion [54]. Therefore, we investigated if $P$. gingivalis infection has a role to play in down-regulation of members of the miR-200 family (miR$200 \mathrm{~b}$ and miR-200c) which will lead to reduction in the repression of ZEB1 by miR-200 family. Our data showed that at early time points Zeb1 goes up without a decrease in mir200 and at later time points Zeb1 remained up-regulated, while both miR-200b and miR-200c were down-regulated (Fig 12), this shows that P. gingivalis infection having an effect on ZEB1 at the transcriptional level, and soon as ZEB1 mRNA gets significantly high, we get to see a drop in miR-200 levels which is consistent with ZEB1 negatively regulating miR-200. As shown in Fig. 13, down-regulation of miR-200b and miR-200c was confirmed using qRT-PCR. Expression was of miR-200b was down-regulated $>0.8$ fold at MOI 50 and $>0.5$-fold at MOI $100(P<0.0001)$, while miR-200c was downregulated $>0.6$-fold at MOI $50(P<0.0001)$ and $>0.4$-fold at MOI $100(P<0.0002)$ in infected groups compared with uninfected controls (Fig. 12). This result further stresses the role of $P$. gingivalis in ZEB1 control. 
(A) MOI 100

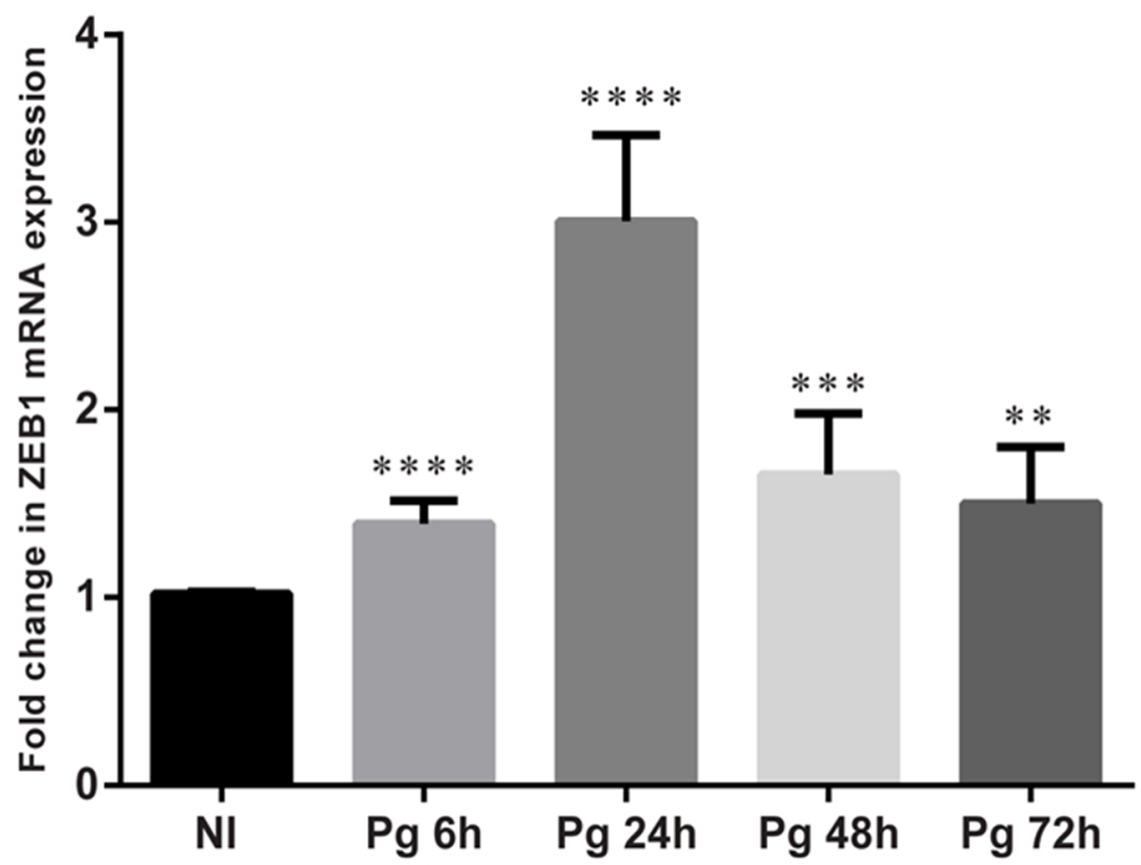

(B) MOI 100

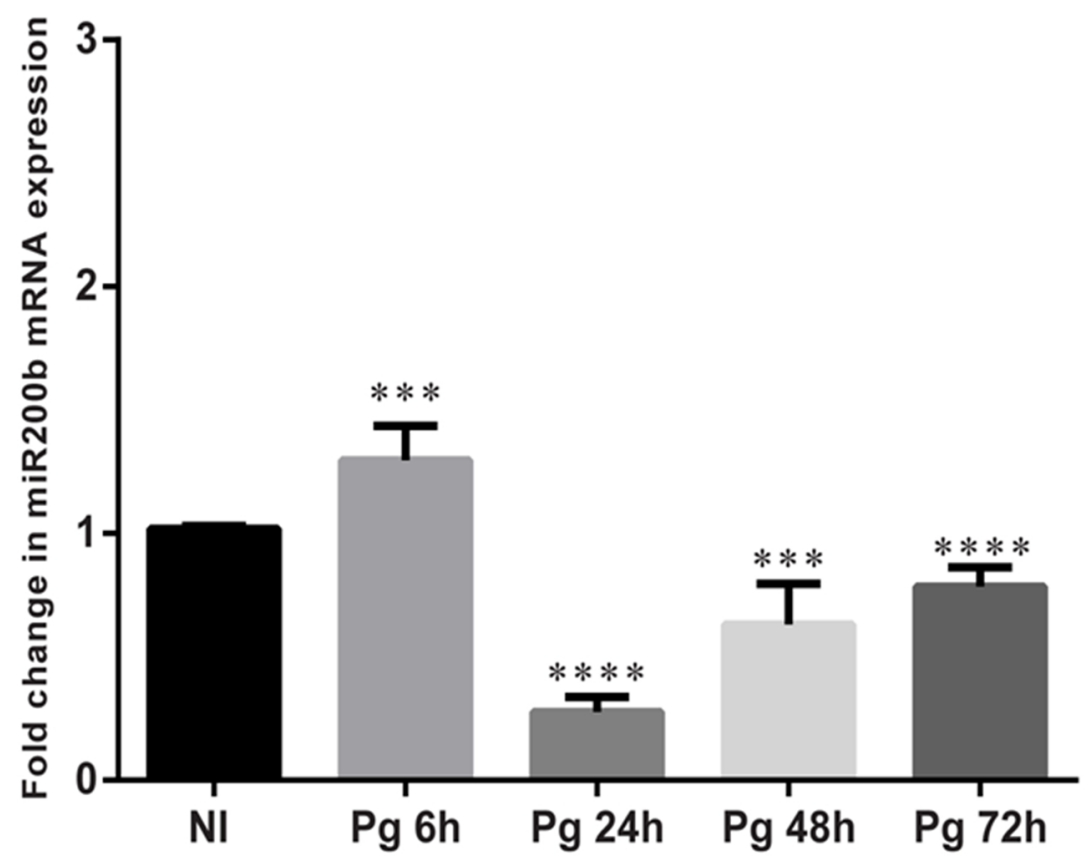


(C)

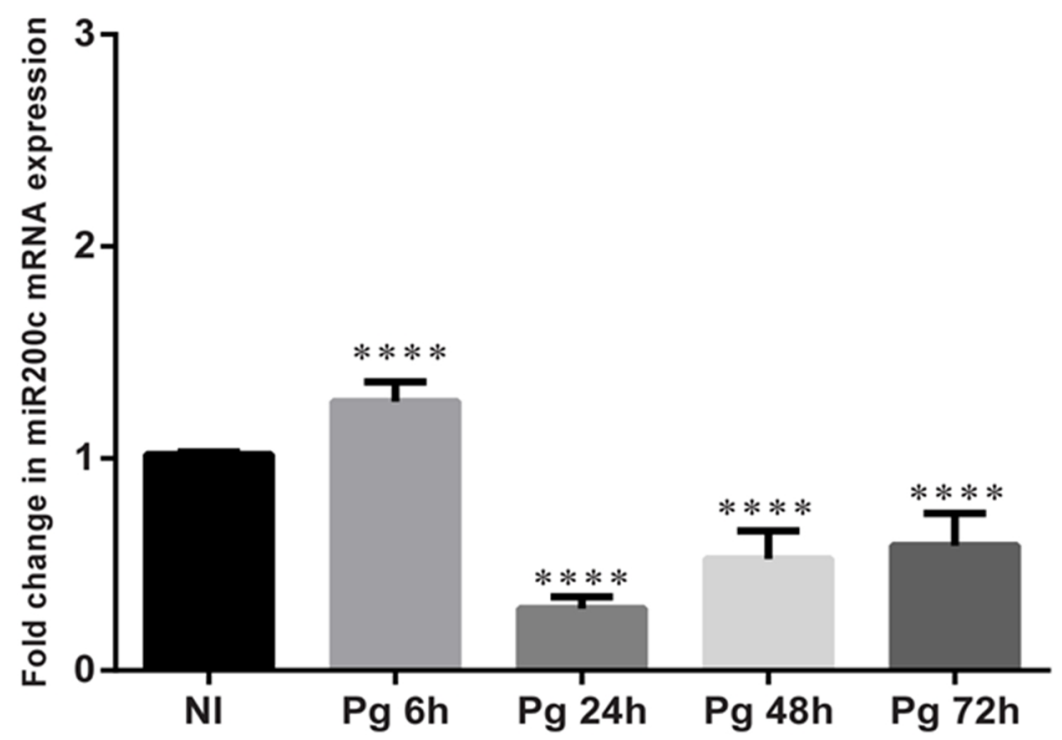

Figure 12. Effect of $P$. gingivalis infection on the expression of Zeb1 and miR-200 family.

Results from qRT-PCR analysis shows relative mRNA expression of ZEB1, miR-200b and miR-200c after $6 \mathrm{~h}, 24 \mathrm{~h}, 48 \mathrm{~h} \& 72 \mathrm{~h}$ of infection with P. gingivalis at an MOI of 100. (A) qRT-PCR shows a significant higher expression of ZEB1 at $6 \mathrm{~h}(* * * * P<0.0001)$, highest expression at $24 \mathrm{~h}(* * * * P<0.0001)$, and decrease but significant high level at $48 \mathrm{~h}(* * * P<0.0008)$ and $72 \mathrm{~h}(* * P<0.0029)$. (B) qRT-PCR shows levels of miR-200b remaining high at $6 \mathrm{~h}(* * * P<0.0007)$, and significant lower at $24 \mathrm{~h}(* * * * P<0.0001)$, at $48 \mathrm{~h}(* * * P<.0002) \& 72 \mathrm{~h}(* * * * \mathrm{P}<0.0001)$ miR-200b remained significantly low but a gradual increase was noted between both time points. (C) qRT-PCR shows levels of miR-200c remaining high at 6 $\mathrm{h}(* * * P<0.0001)$, and significant lower at $24 \mathrm{~h}(* * * * P<0.0001)$, at $48 \mathrm{~h} \& 72 \mathrm{~h}(* * * * P<0.0001) \mathrm{miR}-$ 200c remain significantly low but a gradual increase in mRNA level was noted between both time points. 
(A)

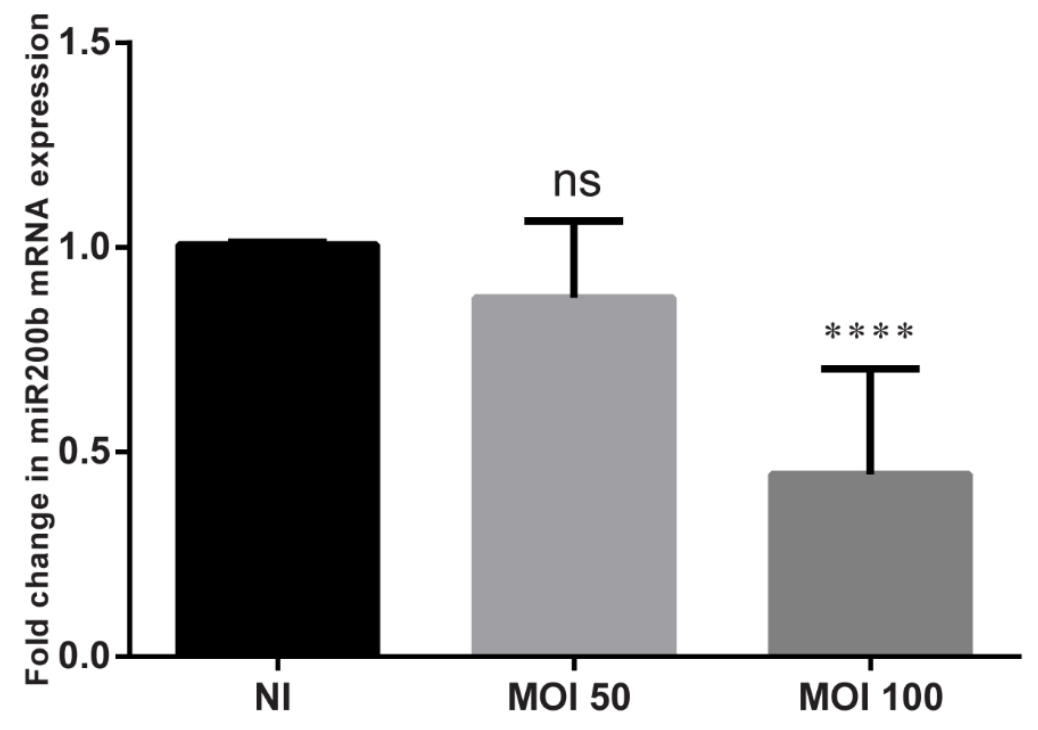

(B)

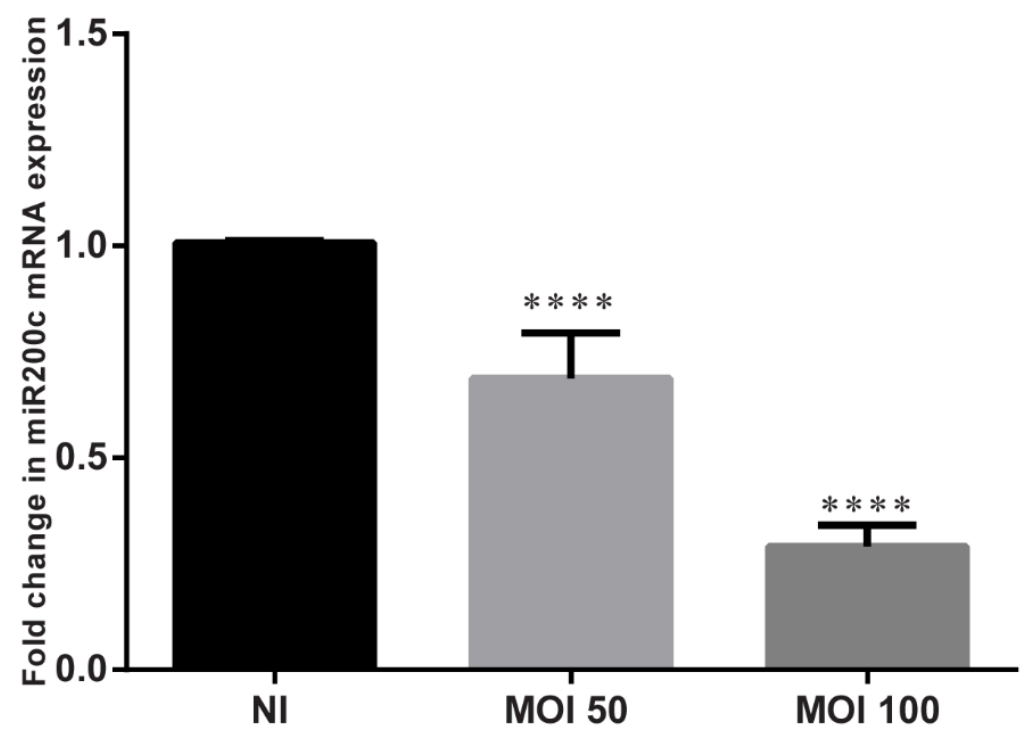

Figure 13. P. gingivalis infection down-regulated miR-200 family.

Results from qRT-PCR analysis shows relative mRNA expression of miR-200b and miR-200c after $24 \mathrm{~h}$ of infection with $P$. gingivalis at an MOI of 50 and 100. (A) qRT-PCR shows a significant lower expression of miR-200b at MOI $100(* * * * P<0.0001)$. (B) qRT-PCR shows a significant lower expression of miR200c at MOI $50(* * * * P<0.0001)$ and MOI $100(* * * * P<0.0002)$. 


\subsection{P. gingivalis-oral epithelial cell-cell interaction is required for the up-regulation}

of ZEB1.

Studies have shown that initial adherence and cellular internalization is required for the survival and virulence of $P$. gingivalis $[66,104]$. In order to determine whether internalization of $P$. gingivalis is important for the up-regulation of ZEB1, we co-cultured TIGK cells and $P$. gingivalis in the absence of cell-cell contact using a Transwell assay. After $24 \mathrm{~h}$ of inserting Transwell inserts containing P. gingivalis at MOI of 50 \& 100 in Dermalife-K serum free keratinocyte culture medium over each experimental well, a significant reduction in the ZEB1 mRNA expression $>0.4$-fold was noted at MOI $50(P$ $<0.0001)$ and $>0.6$-fold at MOI $100(P<0.0003)$ in infected cells compared with uninfected control groups (Fig. 14). This results suggest that contact between epithelial cells and $P$. gingivalis is needed for the up-regulation of ZEB1. 


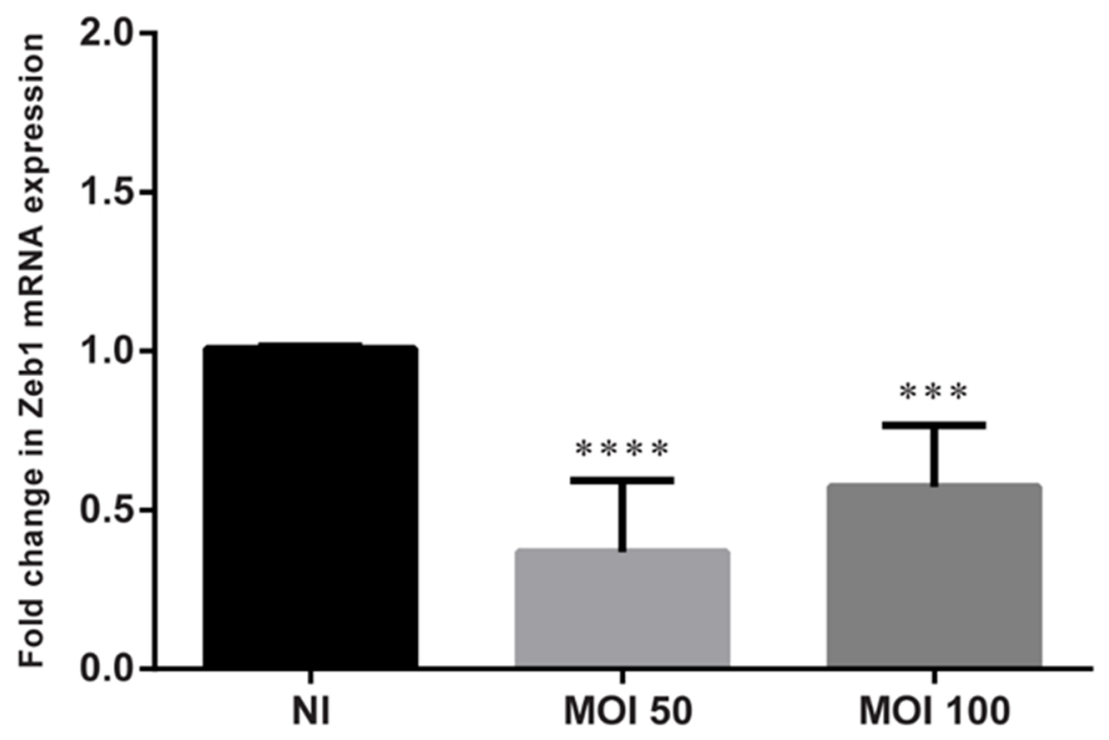

Figure 14. P. gingivalis-Epithelial cell-cell contact is required for the up-regulation of ZEB1.

Using a Transwell assay to co-culture TIGK cells and $P$. gingivalis at an MOI of 50 and 100 for 24 h. qRTPCR analysis showed a significant reduction in the expression of ZEB1 at MOI $50(* * * * P<0.0001)$, and MOI $100(* * * P<0.0003)$.

\subsection{P. gingivalis molecules have varying effect on the up-regulation of ZEB1.}

The presence of $\mathrm{P}$. gingivalis $m f a$ gene have been shown to deter the epithelial invasion potential of P. gingivalis, while the fimA gene does the reverse [84]. We examined the role of the $m f a$ gene fimA in the regulation of Zeb1 by testing mutants of $P$. gingivalis with deletions in the $m f a$ and $f i m A$ genes. The result showed that in the absence of $m f a$, ZEB1 expression was significantly enhanced compared to the absence of fimA $(P<$ 0.0014; Fig. 15 A). This effect was reversed in the $m f a$ complemented strain $(P<0.006$; Fig. $15 \mathrm{C} \& \mathrm{D})$. This suggests that enhanced invasion of TIGK cells by $P$. gingivalis would translate into up-regulation of the ZEB1 gene. 
Lack of the $n d k$ gene in $P$. gingivalis mutant strains have been linked with apoptosis of gingival epithelial cells [91] and activation of P2X7 receptors and intracellular ROS, therefore we investigated whether the lack of this $n d k$ gene would have effect on the expression of ZEB1. Quantitative RT-PCR analysis showed a reduction in ZEB1 mRNA levels ( $\mathrm{P}<0.0001$; Fig. $15 \mathrm{~A}$ ), however this effect was reversed in the completed strain $(\mathrm{P}<0.0001 ;$ Fig 15 E \& F $)$.

(A) $\quad$ MOI 50

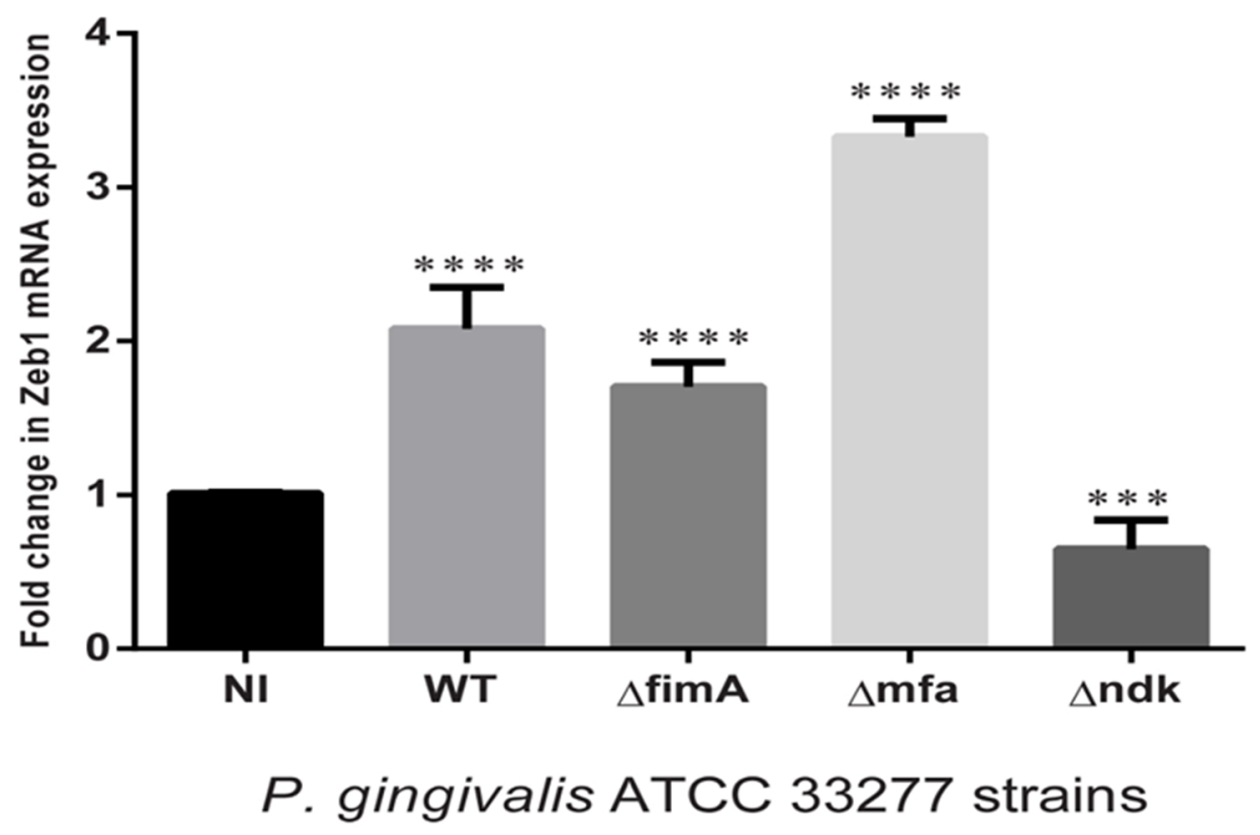


(B) MOI 100

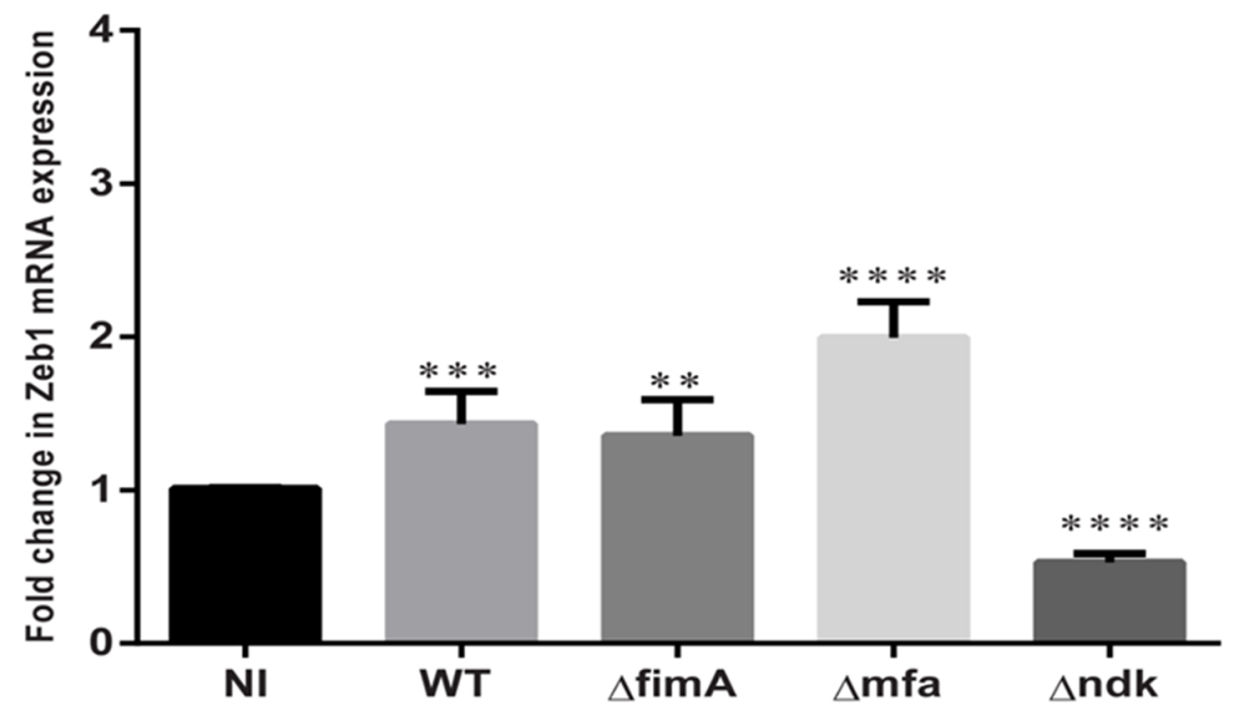

P. gingivalis ATCC 33277 strains

(C) $\quad$ MOI 50

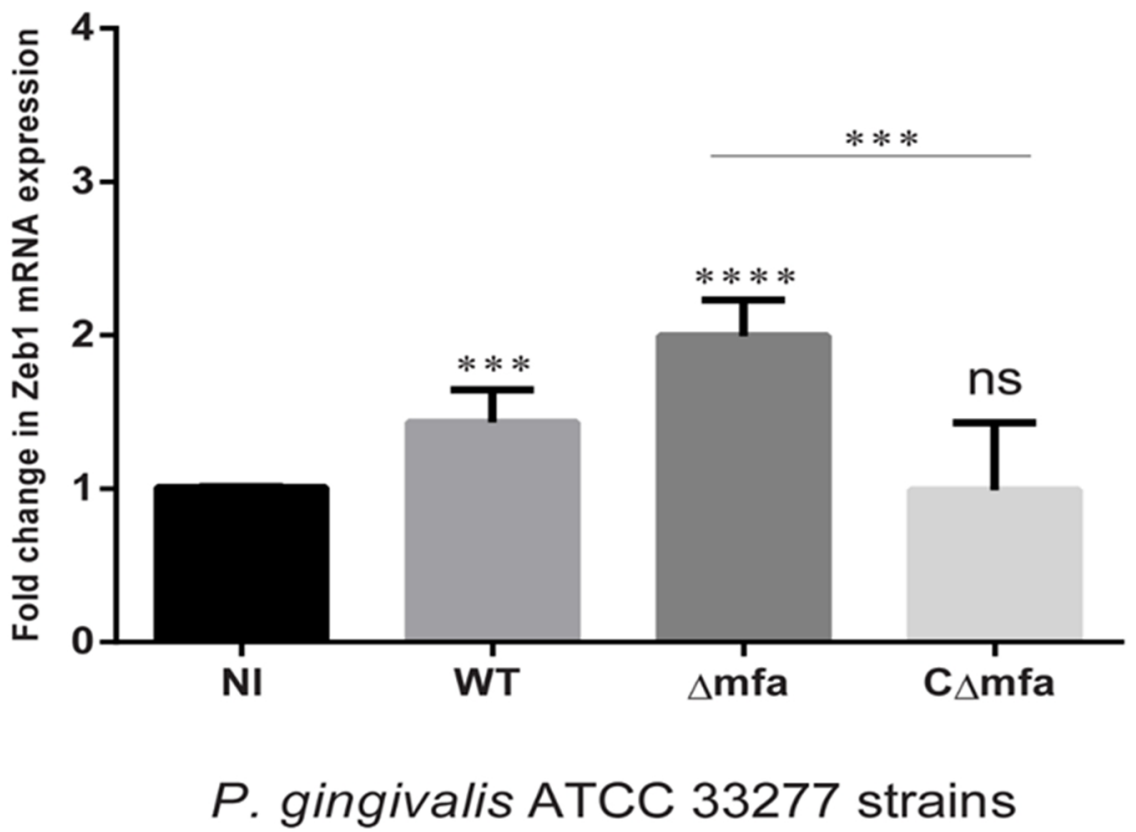


(D) MOI 100

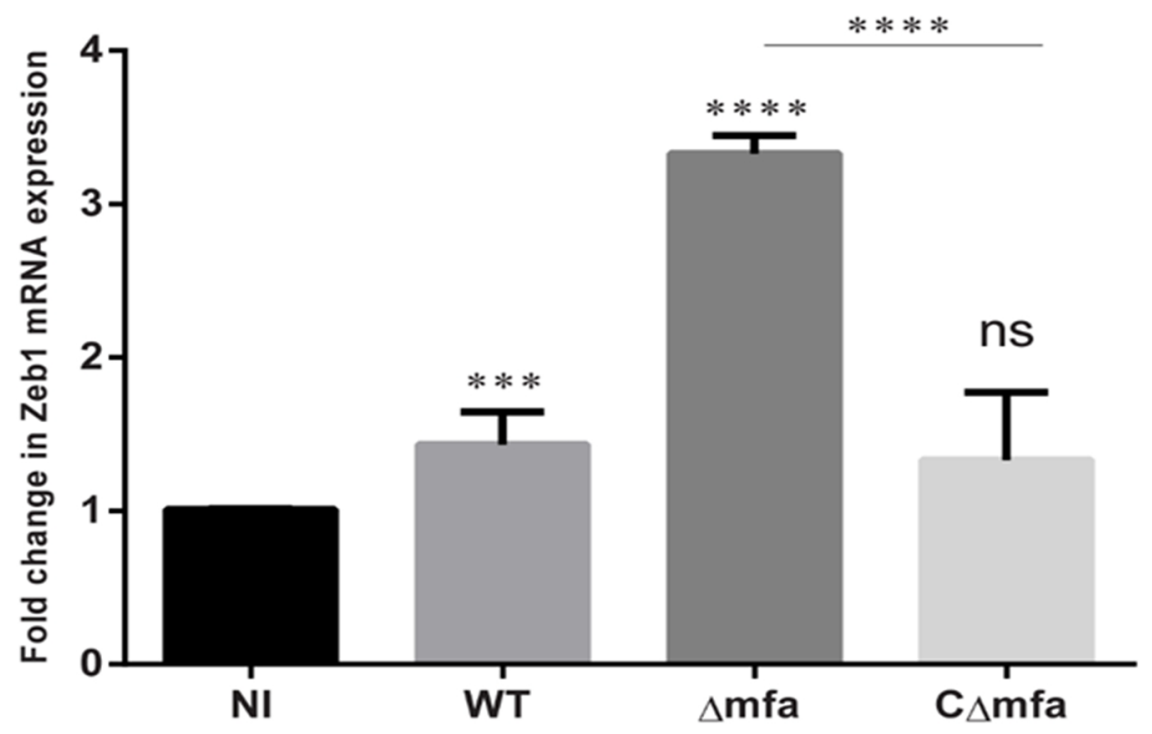

P. gingivalis ATCC 33277 strains

(E) MOI 50

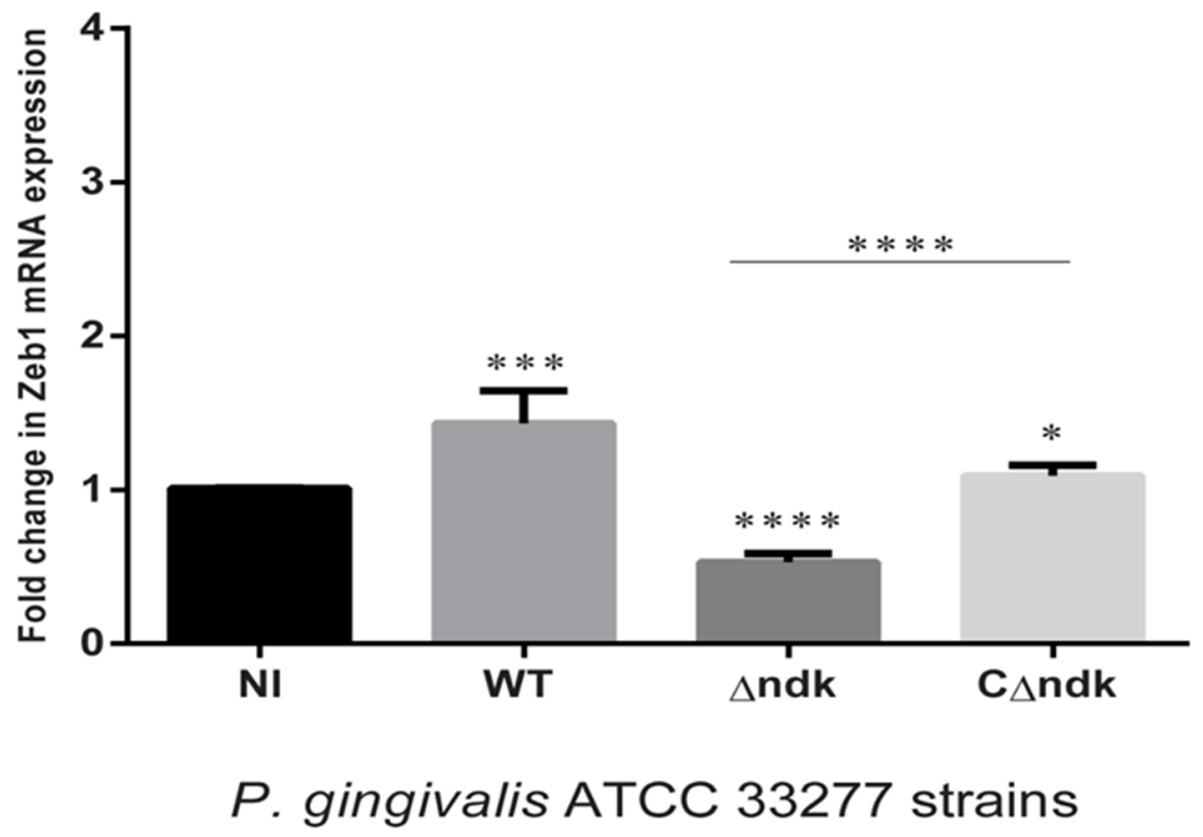


(F) MOI 100

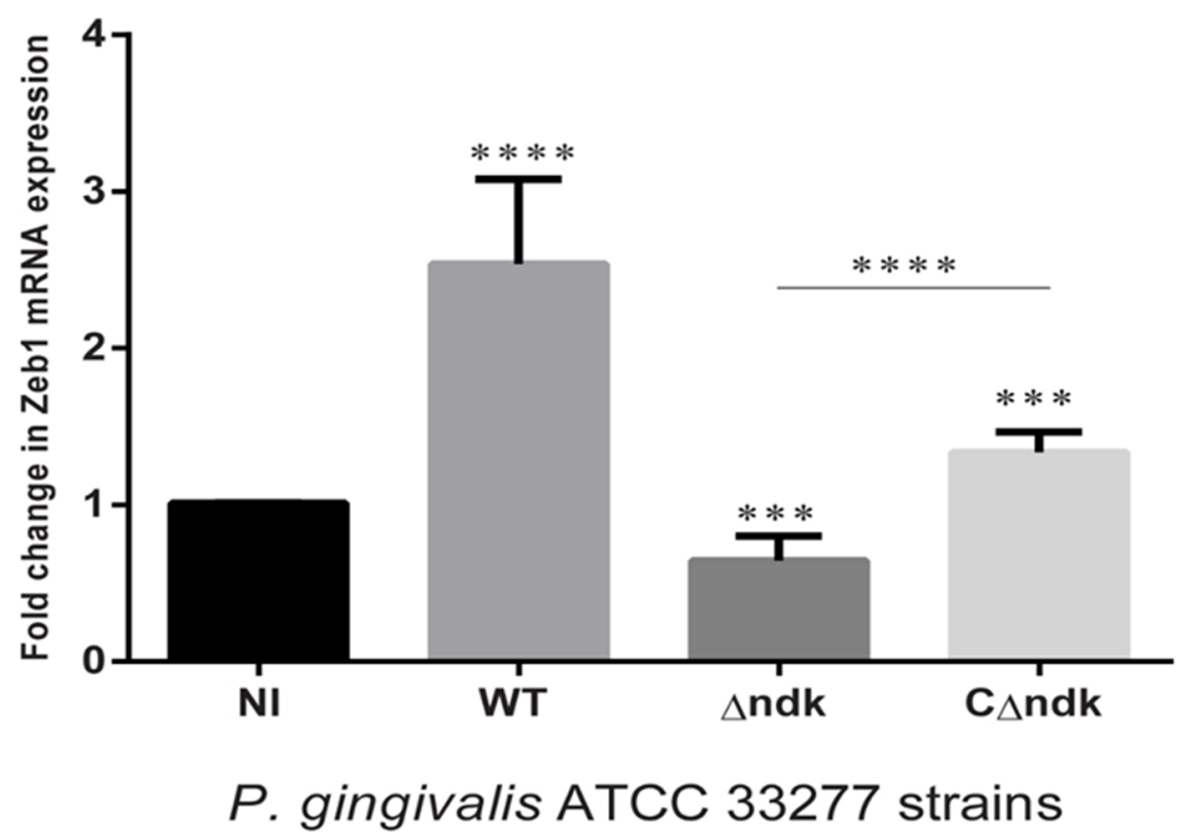

Figure 15. P. gingivalis molecules have varying effect on the up-regulation of ZEB1. Results from qRT-PCR analysis shows relative mRNA expression of ZEB1 after $24 \mathrm{~h}$ of infection TIGK cells with P. gingivalis WT 33277 and its mutant strains at an MOI of 50 and 100. (A) qRT-PCR shows a significant higher expression of ZEB1 with fimA mutant $(* * P=0.0044), m f a$ mutant $(* * * * P<0.0001)$ and a lower expression of ZEB1 with $n d k$ mutant $(* * * * P<0.0001)$ at MOI 50. (B) qRT-PCR shows a significant higher expression of ZEB1 with fimA mutant $(* * * * P<0.0001), m f a$ mutant $(* * P<0.0001)$ and a lower expression of ZEB1 with $n d k$ mutant $(* * * * P<0.0001)$ at MOI 100. (C) The effect of higher ZEB1 expression was reversed in the $m f a$ complemented strain at MOI 50. (D) The effect of higher ZEB1 expression was reversed in the $m f a$ complemented strain at MOI 100. (E) The effect of lower ZEB1 expression was reversed in the $n d k$ complemented strain $(* P=0.0149)$ at MOI 50. (F) The effect of higher ZEB1 expression was reversed in the $m f a$ complemented strain $(* * * P<0.0002)$ at MOI 100. 


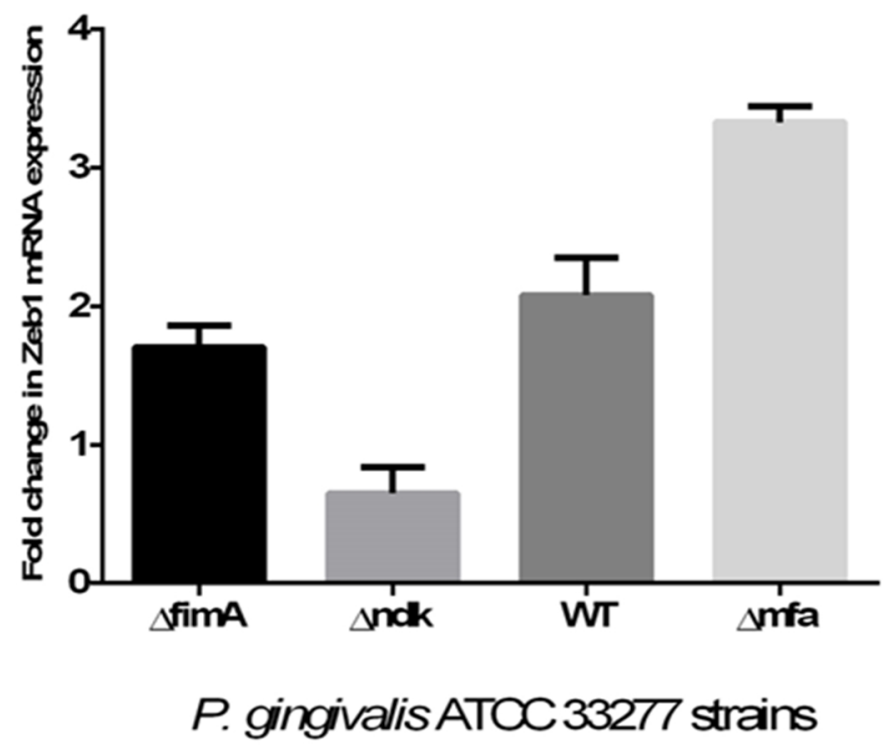

Figure 16. ZEB1 expression with $P$. gingivalis mutant strains infection in terms of their relative invasiveness.

Results from qRT-PCR analysis shows relative mRNA expression of ZEB1 after $24 \mathrm{~h}$ of infection of TIGK cells with $P$. gingivalis WT 33277 and its mutant strains at an MOI of 100.

\section{6. $P$. ginivalis infection promotes invasive potential of TIGK cells.}

To determine the effect of $P$. gingivalis infection on the invasive potential of epithelial cells, we analyzed the invasion of $P$. gingivalis infected TIGK cells using the Matrigel invasion assay. Compared with untreated controls, TIGK infected cells showed a significant increase in the number of invading cells, hence a higher ability to invade the Matrigel layer after $24 \mathrm{~h}$ of infection $(P<0.0001$; Fig. 16). 
(A)

NI

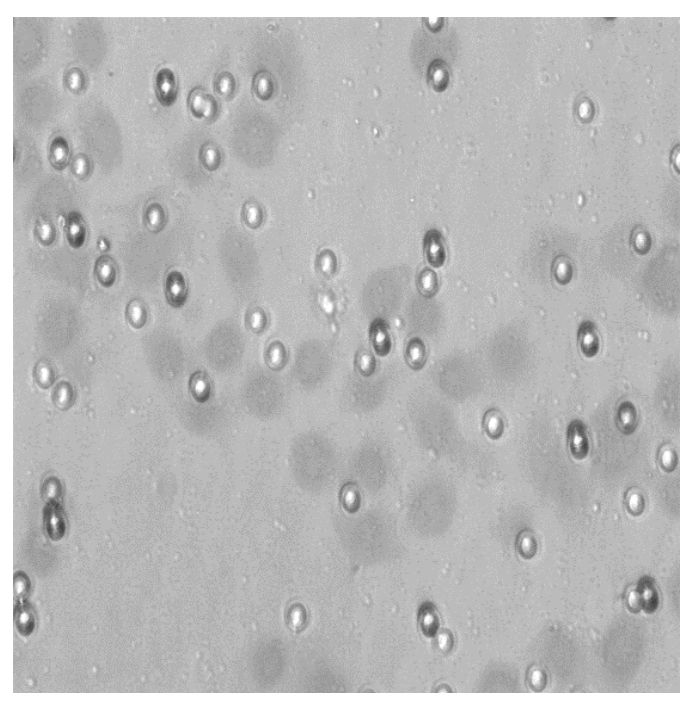

MOI 50

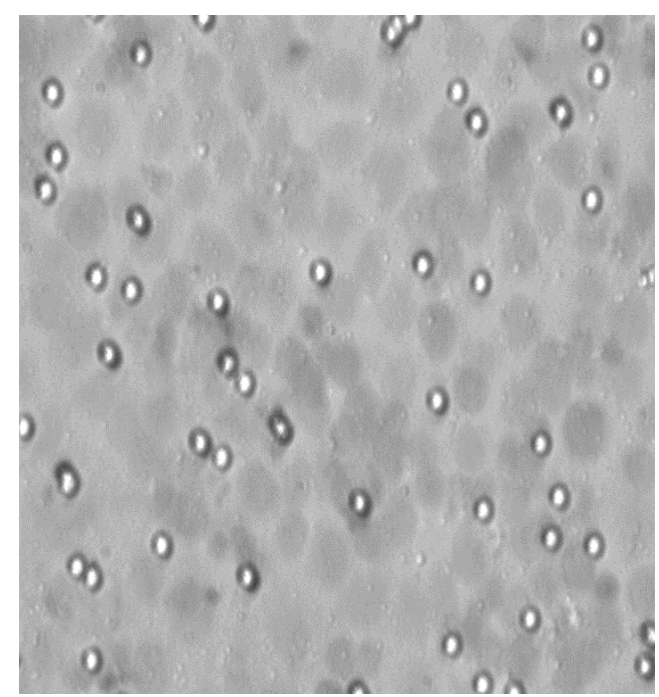

MOI 100

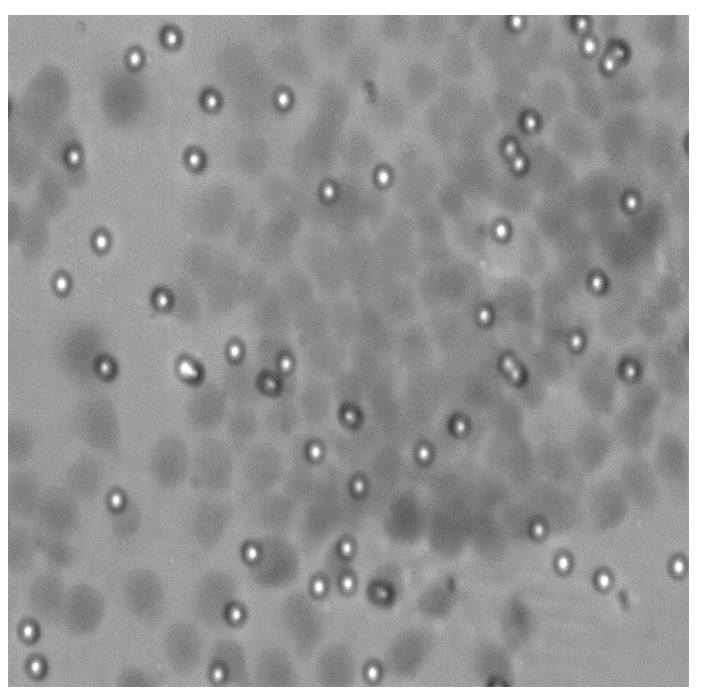


(B)

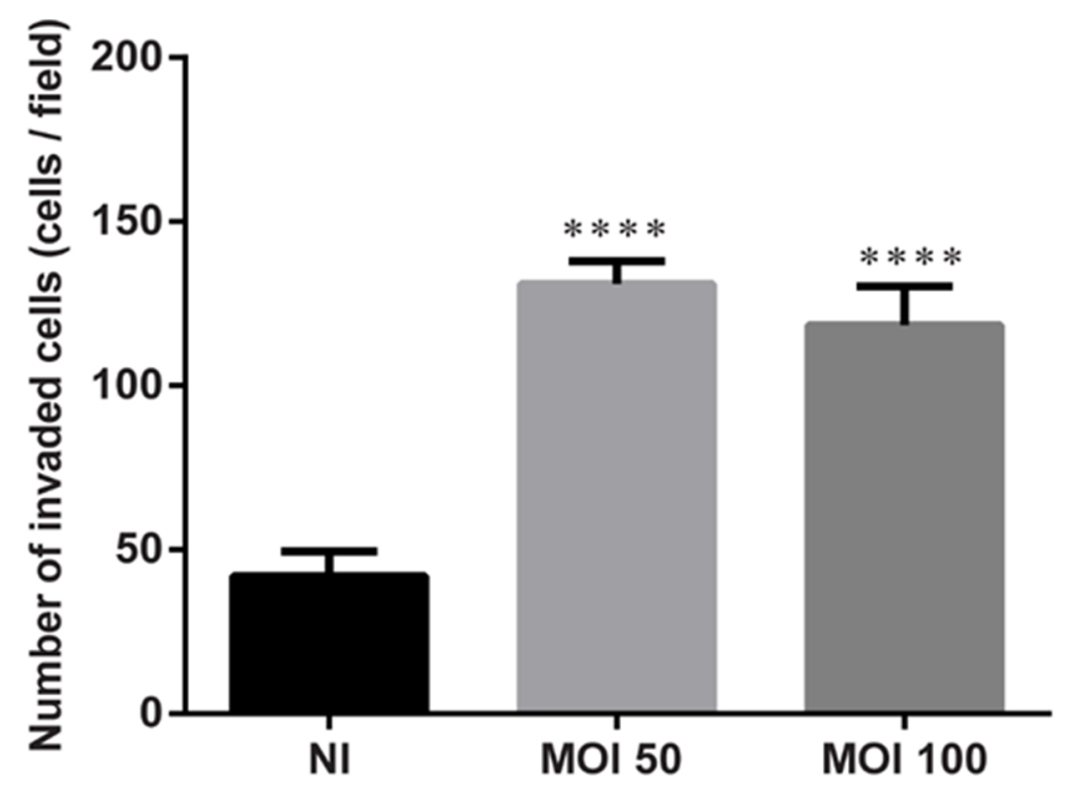

Figure 17. P. gingivalis infection promotes the invasiveness of TIGK cells.

(A) Representative images of non-infected (control) and $P$. gingivalis infected TIGK cells invading through a Matrigel-coated transwell membrane with an $8-\mu \mathrm{m}$ pore size (x20 magnification). (B) Cell invasion was evaluated by counting cells invading through a Matrigel-coated transwell membrane with an 8 - $\mu \mathrm{m}$ pore size. Cells embedded within the Matrigel were counted under light microscope (x20 magnification). Results showed significant increase in the number of invading cells after infection with $P$. gingivalis at MOI 50 and $100(* * * * P<0.0001)$. 


\subsection{Knockdown of ZEB1 by ZEB1-specific siRNA reduces the invasiveness of $P$. gingivalis infected TIGK cells.}

To verify whether ZEB1 up-regulation by $P$. gingivalis infection is responsible for Vimentin expression and Matrigel invasion, we knockdown ZEB1 by transfection of TIGK cells with ZEB1-specific siRNA. Following transfection and infection of TIGK cells with $P$. gingivalis, ZEB1 mRNA levels was quantified using qRT-PCR to confirm the action of the siRNA. Our results showed that ZEB1 was down-regulated $>1.5$ fold (P $<0.001$; Fig. 17). We found that the knockdown of ZEB1 decreased the mRNA expression of vimentin, which was significantly down-regulated after $24 \mathrm{~h}>2$ fold $(\mathrm{P}<$ 0.001; Fig. 18). This result is consistent with previously shown results.

In order to demonstrate that down-regulation of ZEB1 in transfected cells could affect P.gingivalis modulated behaviors of TIGK cells, the ability of ZEB1 knockdown cells to invade Matrigel was analyzed. There was a statistically significant reduction of invasion by $P$. gingivalis infected cells when ZEB1 was knocked down (Fig. 19). 
(A)

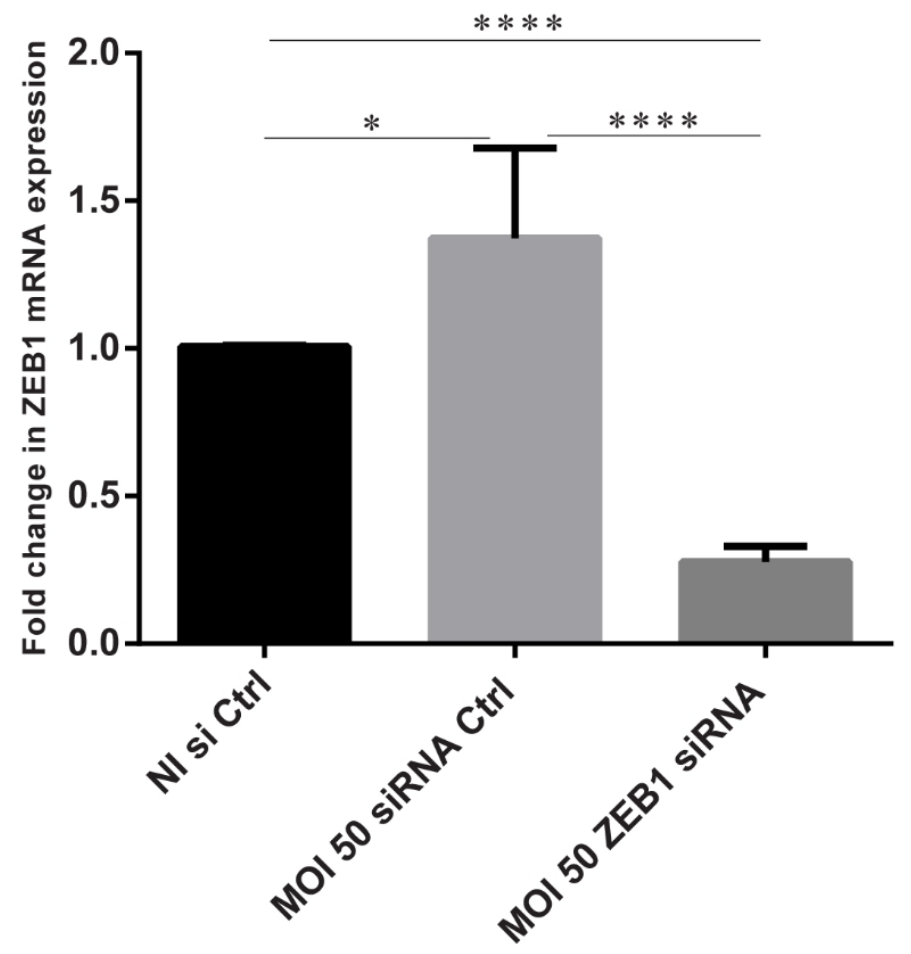


(B)

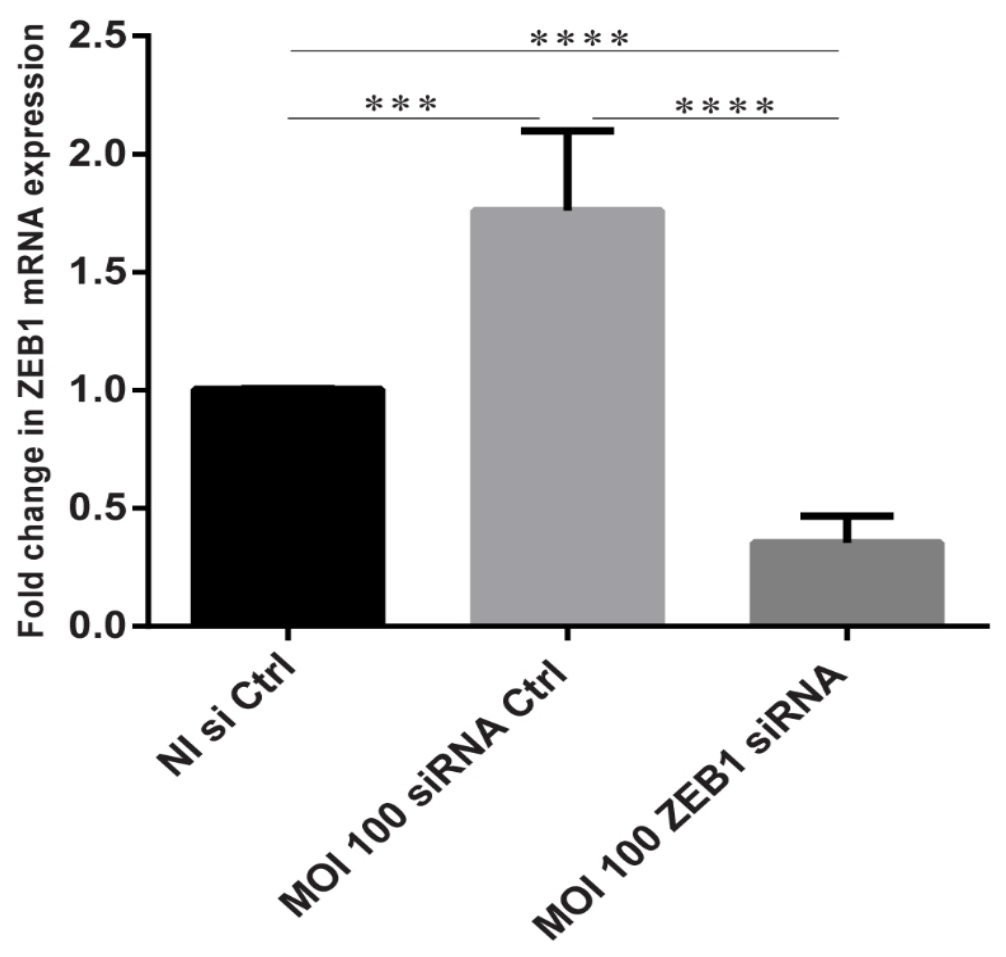

Figure 18. Effect of knockdown of ZEB1 on the relative expression of ZEB1 mRNA following $P$. gingivalis infection.

TIGK cells were transfected with control ( infected with $P$. gingivalis for $24 \mathrm{~h}$. Knockdown of ZEB1 resulted in down-regulation of ZEB1 mRNA expression at an MOI of $50(* * * P<0.0001 ;(\mathrm{A}))$ and MOI $100(* * * * P<0.0001 ;(\mathrm{B}))$. 
(A)

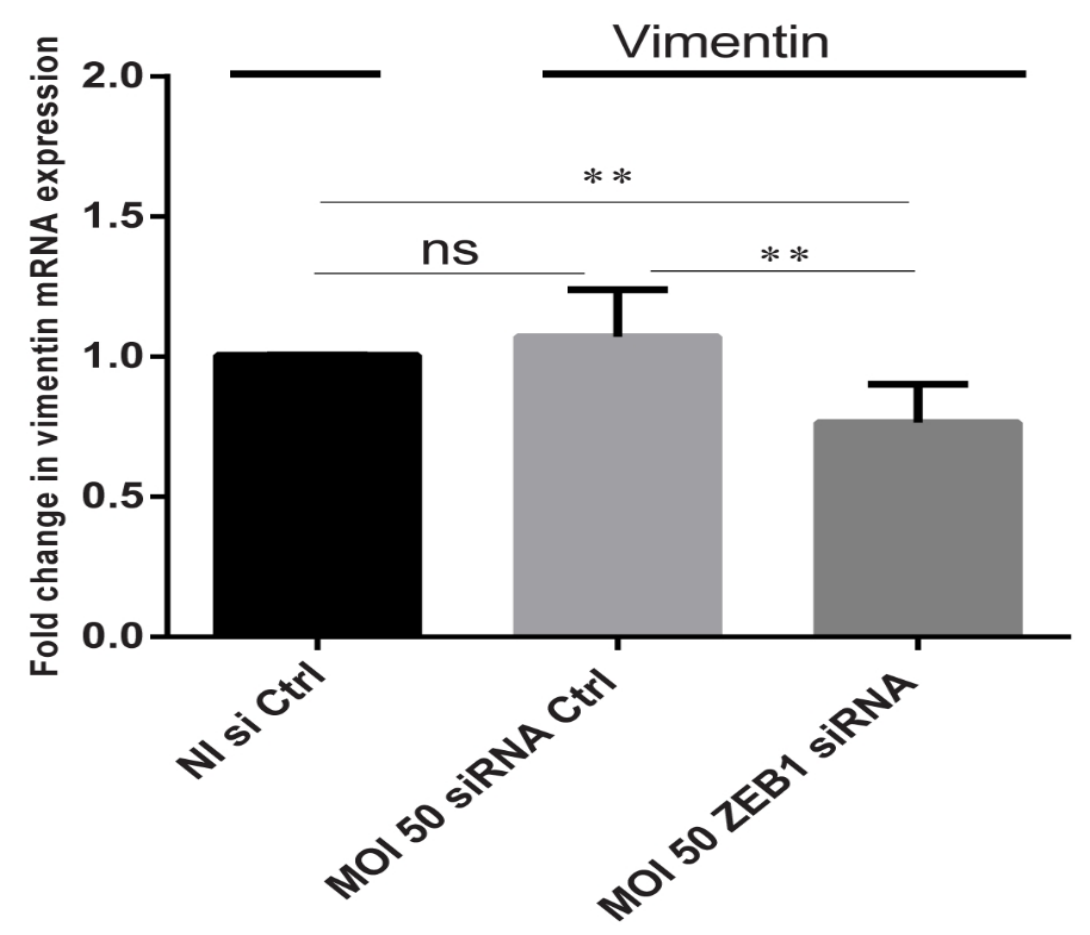


(B)

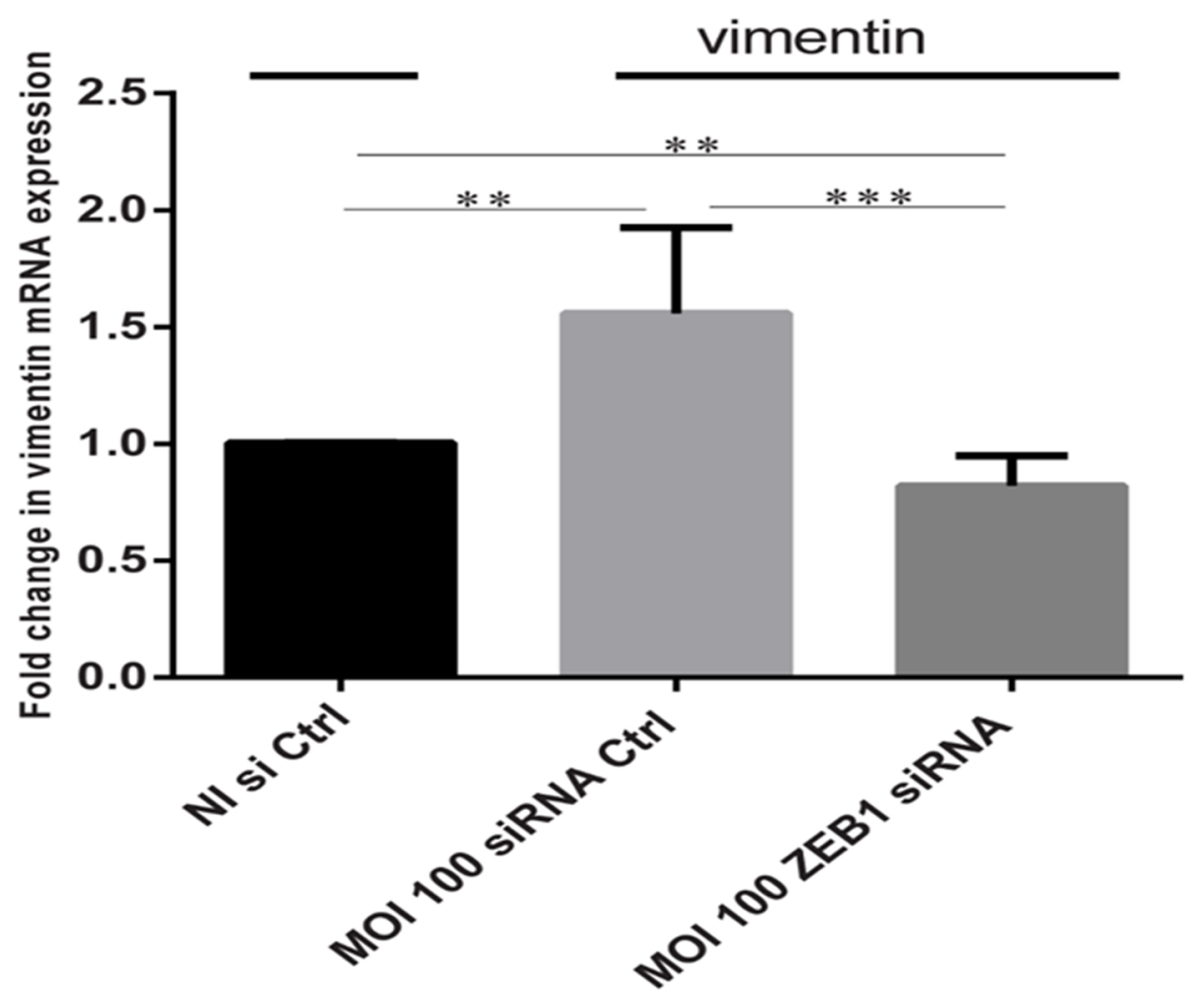

Figure 19. Effect of knockdown of ZEB1 on the relative expression of vimentin following $P$. gingivalis infection.

TIGK cells were transfected with control (siRNA control) or ZEB1 siRNA for $72 \mathrm{~h}$, after which cells were infected with $P$. gingivalis for $24 \mathrm{~h}$. Knockdown of ZEB1 resulted in down-regulation of vimentin mRNA expression at an MOI of $50(* * * P<0.0001$; (A)) and MOI $100(* * * * P<0.0001$; (B)). 
(A)
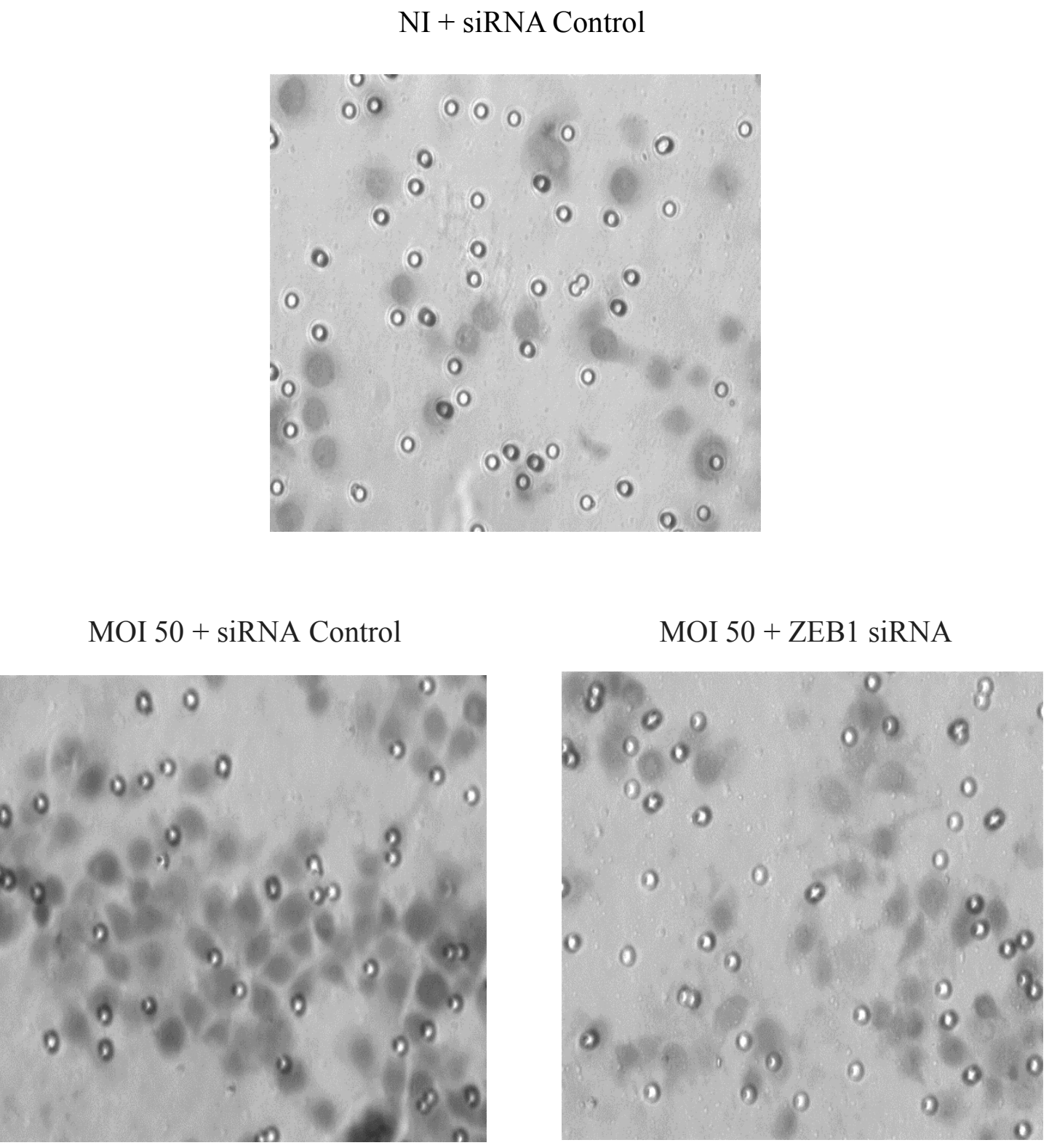
MOI $100+$ siRNA Control

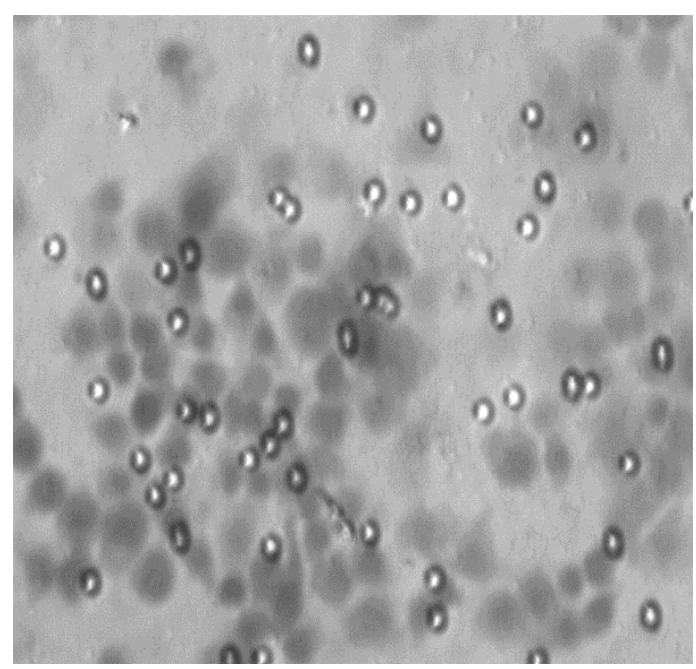

MOI $100+$ ZEB1 siRNA

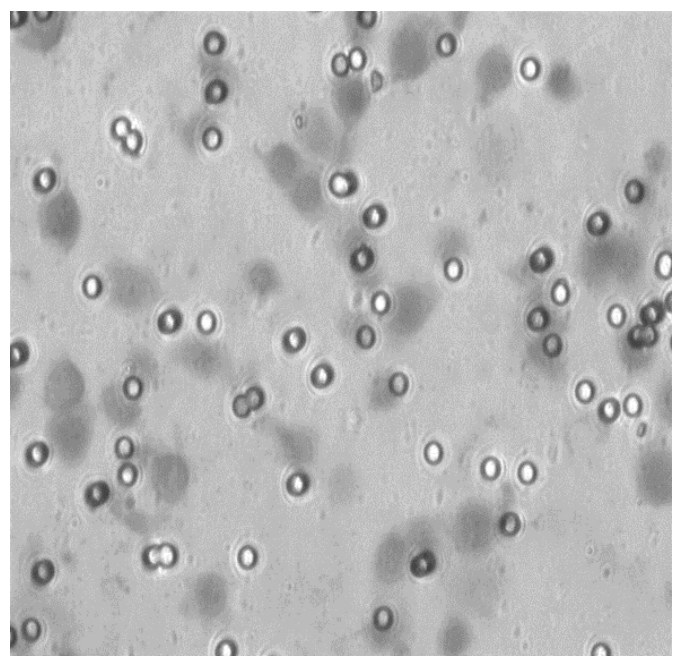


(B)

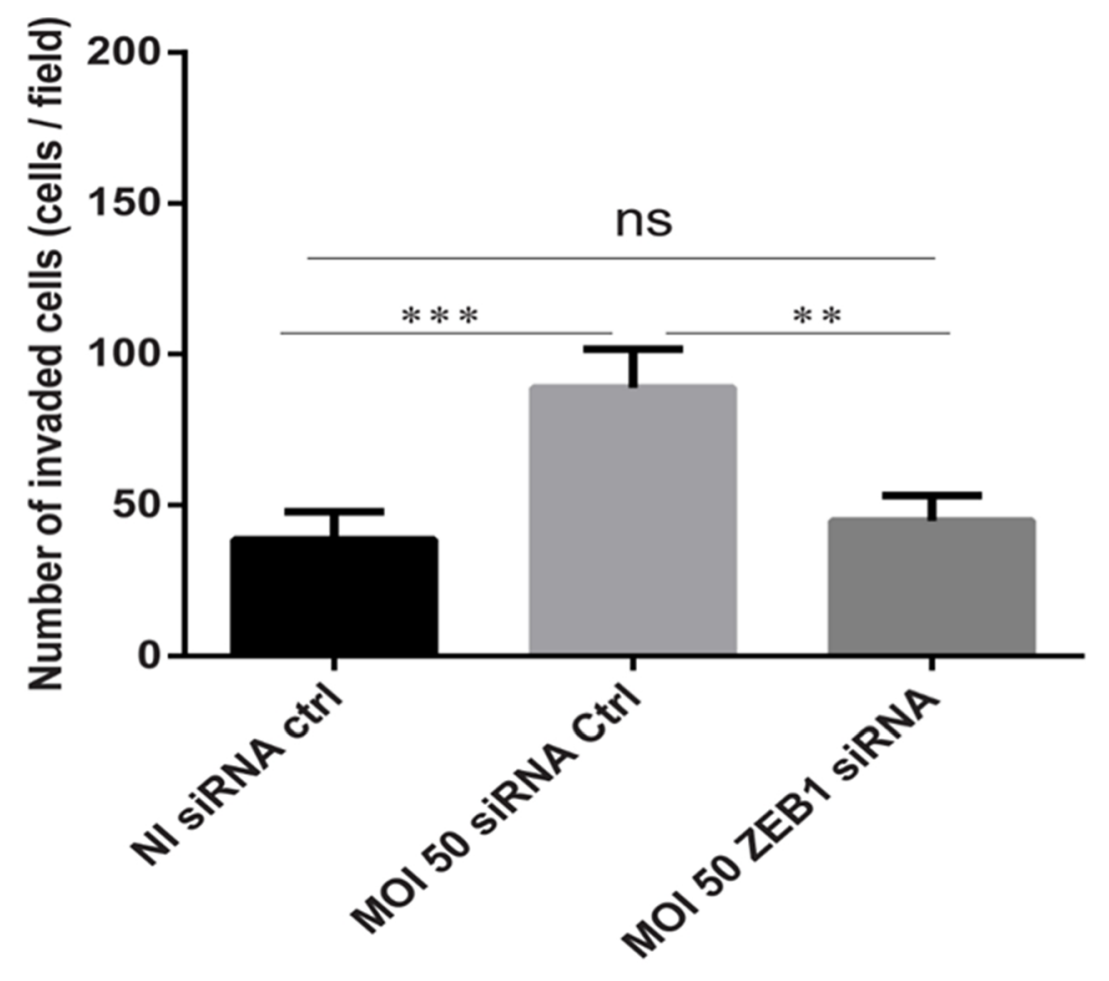




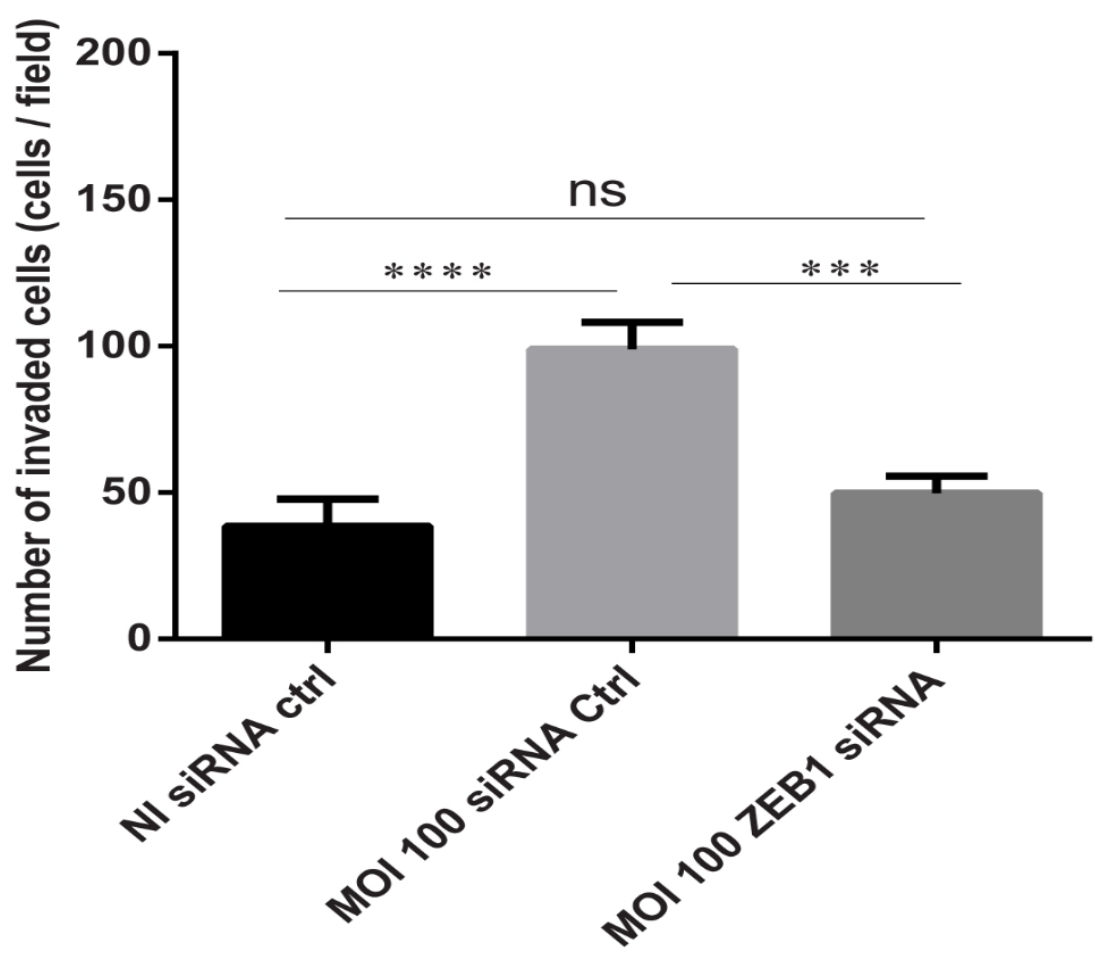

Figure 20. Effect of ZEB1 knockdown on the invasiveness of $P$. gingivalis infected TIGK cells.

(A) Representative images of non-infected (siRNA control transfected cells) and $P$. gingivalis infected TIGK cells siRNA control and ZEB1 siRNA transfected cells) invading through a Matrigel-coated transwell membrane with an 8 - $\mu$ m pore size (x20 magnification). (B) Cell invasion was evaluated by counting cells invading through a Matrigel-coated Transwell membrane with an 8 - $\mu \mathrm{m}$ pore size. Cells embedded within the Matrigel were counted under light microscope (x20 magnification). Results showed a significant increase in the number of siRNA control transfected cells and a decrease in number of ZEB1 siRNA transfected cells invading the Matrigel-coated membrane after infection with $P$. gingivalis at MOI $50 \& 100$. 


\section{CHAPTER IV}

\section{DISCUSSION}

A relationship between periodontitis and OSCC have been demonstrated by various studies. $P$. gingivalis, a successful colonizer of the oral epithelium and periodontal pathogen, has also been identified as an independent microbial factor that increases the risk of orodigestive cancer death [13]. Within gingival squamous carcinoma tumors, detection of $P$. gingivalis has been described [14]. This demonstrates the possibility of an interaction between $P$. gingivalis and OSCC cells in cancer and metastasis and progression. ZEB1, a crucial inducer of cancer metastasis has been described to be expressed in many tumor cell lines like OSCC.

In this study, we identified a correlation between an increased expression of ZEB1 in oral epithelial cells and $P$. gingivalis infection. Our results from ZEB1 reporter experiments showed that $P$. gingivalis infection plays a part in the elevation of the transcriptional activity of the ZEB1 promoter. Although the mechanism by which it does this is not yet understood, we were able to show a significant effect of $P$. ginigivalis on ZEB1 at the promoter level. These results buttresses the fact that periodontal infection plays a role in the transcriptional regulation of ZEB1 as an EMT inducer.

miRNAs have varying effects on the regulation of genes in terms of embryonic development and carcinogenesis. Due to this interest, several studies have shown the reverse interrelation between the inhibitory effect of miR-200 family on ZEB1 and the 
ability of ZEB1 directly to directly inhibit the transcription of members of the miR-200 family. An increased expression of ZEB1 in epithelial cells has been correlated with a down-regulation of the miR-200 family in-vivo [54]. In this study, we report that miR$200 \mathrm{~b}$ and miR-200c which are members of the miR-200 family are down-regulated in $P$. gingivalis infected TIGK cells compared to un-infected cells. Our results showed that there is an inverse relationship between the expression of miR-200 family (miR-200b and miR-200c) and ZEB1 mRNA in TIGK cells. These data are in agreement with other reports showing an inverse correlation between miR-200 family and ZEB1 expression in epithelial cells [54]. This indicates that the post-transcriptional regulation of ZEB1 by the miR-200 family via targeting its 3'UTR in the presence of $P$. gingivalis was attenuated, thereby stressing a possible mechanism through which it affects OSCC migration and invasion.

Vimentin have been reported to be transcriptionally activated by ZEB1, and a direct relationship has been shown between the transcriptional regulation of ZEB1 and vimentin [38]. We were able to demonstrate with our results that this relationship exists in the presence of $P$. gingivalis infection with a significant up-regulation of ZEB1 and vimentin mRNA levels. Knock down of ZEB1 prevented $P$. ginigivalis induced up-regulation of vimentin, suggesting that the transcriptional factor ZEB1 is very crucial for the progression of cancer metastasis even in the presence of $P$. gingivalis. There is also a high likelihood that transcriptional regulators other than ZEB1 can play some role in the transcriptional activation of endogenous vimentin as shown in this study, for example ZEB2 is also a known transcriptional regulator of EMT genes [39]. 
Previous studies have shown that initial adherence and cellular internalization is required for the survival and virulence of $P$. gingivalis $[63,66]$. Using a Transwell assay, were able to show that a close interaction between of oral epithelial cells and $P$. gingivalis is indeed required for the up-regulation of ZEB1. Not surprisingly, our results showed a significant reduction in the mRNA levels of ZEB1 because contact between $P$. gingivalis and epithelial cells is needed to be established for there to be inflammatory response or release of inflammatory cytokines that would probably initiate signaling pathways for ZEB1 expression.

Various virulence factors of $P$. gingivalis have been implicated in the initiation and progression of periodontal disease. Presence of the short fimbriae been shown to deter the epithelial invasion potential while the long fimbriae promotes invasion of $P$. gingivalis [63]. The $n d k$ gene have been shown to be crucial for the survival of epithelial cells once invaded by $P$. gingivalis. We examined the role of these genes in the up-regulation of ZEB1 by infecting TIGK cells with the relevant mutant strains. Our result showed that in the absence of $m f a, Z E B 1$ expression was significantly enhanced compared to noninfected cells. This effect was reversed with the $m f a$ complemented strain. This suggests that enhanced invasion of TIGK cells by $P$. gingivalis would lead to up-regulation of the ZEB1 gene. The lack of $n d k$ gene caused a significant lower expression level of ZEB1 mRNA, and this effect was reversed in the completed strain. These results may support the idea that TIGK cells could get apoptosed in the absence of the $n d k$ gene.

To gain further insight into whether $P$. gingivalis infection of oral epithelial cells could enhance the up-regulation of EMT related genes as well as the invasiveness of infected 
cells, we used the Matrigel invasion assay to analyze the number of invading cells following infection with $P$. ginigivalis. Interestingly, we found increased invasiveness of TIGK cells in the presence of infection as compared to non-infected cells. Furthermore, knockdown of Zeb1 reduced that invasion of $P$. gingivalis-infected cells. These results suggest that the transcriptional factor ZEB1 could increase cancer metastasis in the presence of $P$. gingivalis.

Overall, we found that the over-expression of ZEB1 and vimentin, and the downregulation of miR-200 family, as well as enhanced invasiveness of oral epithelial cells was associated with $P$. gingivalis infection. This demonstrates that $P$. gingivalis could potentially play a significant role in OSCC metastasis, although of course additional factors are also involved. These results could be a starting point for improving the understanding of the role of periodontal pathogens in tumor progression, as a diagnostic/prognostic tool, and as a new tool for designing innovative therapeutic strategies in OSCC patients with periodontitis. 


\section{CHAPTER V}

\section{DIRECTIONS FOR FUTURE RESEARCH}

The above study has demonstrated that $P$. gingivalis infection is an important factor to consider in terms of expression EMT related genes. Our results has shown that the periodontal pathogen, $P$. gingivalis plays a significant role in the up-regulation of ZEB1 which is an important inducer of EMT. It would be interesting to study other oral pathogens to know whether they behave similarly to $P$. gingivalis, and whether they have diagnostic/prognostic significance in the management of OSCC. The down-regulation of specific transcription factors may prove a potential target for therapeutic intervention.

Running same sets of experiments using OSCC cells as model for epithelial cells ould be a great idea, especially well differentiated and moderately differentiated cells to see how they behave in the presence of $P$. gingivalis.

As fundamental science research further proceed to clarify the role of $P$. gingivalis in EMT and progression of OSCC, it would be of great interest to look into signaling pathways impacted by this periodontal pathogen in ZEB1 expression. Several studies have suggested signaling pathways such as TGF $\beta-$ SMAD3, WNT- $\beta$-catenin, Notch, PI3K-AKT pathways to be involved in the up-regulation of EMT-related markers. NF$\kappa \mathrm{B}$-dependent expression of ZEB1 have also been shown to repress E-cadherin expression and to promote EMT, through up-regulation of transcription repressor 
function of ZEB1, which in turn represses the expression of miR-200 family. $P$. gingivalis triggers cell innate immunity by activating the nuclear factor $\mathrm{\kappa B}(\mathrm{NF}-\mathrm{\kappa B})$, a process which leads to the NF-kB-dependent transcription of pro-inflammatory cytokines such as interleukin (IL)-1 $\beta$, IL-6, IL-8 and tumor necrosis factor $\alpha$. The study of the involved signaling pathways could provide significant perception into understanding of pathways that link $P$. gingivalis infection with the EMT transition. 


\section{REFERENCES}

1. Shah, J.P. and Z. Gil, Current concepts in management of oral cancer--surgery. Oral Oncol, 2009. 45(4-5): p. 394-401.

2. Rapidis, A.D., et al., Major advances in the knowledge and understanding of the epidemiology, aetiopathogenesis, diagnosis, management and prognosis of oral cancer. Oral Oncol, 2009. 45(4-5): p. 299-300.

3. Bagan, J., G. Sarrion, and Y. Jimenez, Oral cancer: clinical features. Oral Oncol, 2010. 46(6): p. 414-417.

4. Kurita, H., et al., Impact of different surgical margin conditions on local recurrence of oral squamous cell carcinoma. Oral Oncol, 2010. 46(11): p. 814-817.

5. Feller, L. and J. Lemmer, Oral Squamous Cell Carcinoma: Epidemiology, Clinical Presentation and Treatment. J Cancer Therapy, 2012. 3: p. 263-268.

6. Warnakulasuriya, S., Global epidemiology of oral and oropharyngeal cancer. Oral Oncol, 2009. 45(4-5): p. 309-16.

7. Bello, I.O., Y. Soini, and T. Salo, Prognostic evaluation of oral tongue cancer: means, markers and perspectives (I). Oral Oncol, 2010. 46(9): p. 630-5.

8. Neville, B.W. and T.A. Day, Oral cancer and precancerous lesions. CA Cancer J Clin, 2002. 52(4): p. 195-215.

9. Mannarini, L., et al., Human Papilloma Virus (HPV) in head and neck region: review of literature. Acta Otorhinolaryngol Ital, 2009. 29(3): p. 119-126. 
10. Attar, E., et al., Head and neck cancer in a developing country: a population-based perspective across 8 years. Oral Oncol, 2010. 46(8): p. 591-6.

11. Ryerson, A.B., et al., Burden of potentially human papillomavirus-associated cancers of the oropharynx and oral cavity in the US, 1998-2003. Cancer, 2008. 113(10 Suppl): p. 2901-9.

12. Chaturvedi, A.K., et al., Human papillomavirus and rising oropharyngeal cancer incidence in the United States. J Clin Oncol, 2011. 29(32): p. 4294-4301.

13. Ahn, J., S. Segers, and R.B. Hayes, Periodontal disease, Porphyromonas gingivalis serum antibody levels and orodigestive cancer mortality. Carcinogenesis, 2012. 33(5): p. 10551058.

14. Katz, J., et al., Presence of Porphyromonas gingivalis in gingival squamous cell carcinoma. Int J Oral Sci, 2011. 3(4): p. 209-215.

15. Kalluri, R. and R.A. Weinberg, The basics of epithelial-mesenchymal transition. J Clin Invest, 2009. 119(6): p. 1420-1428.

16. Samatov, T.R., A.G. Tonevitsky, and U. Schumacher, Epithelial-mesenchymal transition: focus on metastatic cascade, alternative splicing, non-coding RNAs and modulating compounds. Mol Cancer, 2013. 12(1): p. 107.

17. Onder, T.T., et al., Loss of E-cadherin promotes metastasis via multiple downstream transcriptional pathways. Cancer Res, 2008. 68(10): p. 3645-3654.

18. De Craene, B. and G. Berx, Regulatory networks defining EMT during cancer initiation and progression. Nat Rev Cancer, 2013. 13(2): p. 97-9110.

19. Thiery, J.P., et al., Epithelial-mesenchymal transitions in development and disease. Cell, 2009. 139(5): p. 871-890. 
20. Dave, N., et al., Functional cooperation between Snail1 and twist in the regulation of ZEB1 expression during epithelial to mesenchymal transition. J Biol Chem, 2011. 286(14): p. $12024-12032$.

21. Baum, B., J. Settleman, and M.P. Quinlan, Transitions between epithelial and mesenchymal states in development and disease. Semin Cell Dev Biol, 2008. 19(3): p. 294-308.

22. Shook, D. and R. Keller, Mechanisms, mechanics and function of epithelial-mesenchymal transitions in early development. Mech Dev, 2003. 120(11): p. 1351-1383.

23. Tucker, R.P., Antisense knockdown of the beta1 integrin subunit in the chicken embryo results in abnormal neural crest cell development. Int J Biochem Cell Biol, 2004. 36(6): p. 1135-1139.

24. Hanahan, D. and R.A. Weinberg, The hallmarks of cancer. Cell, 2000. 100(1): p. 57-70.

25. Huber, M.A., N. Kraut, and H. Beug, Molecular requirements for epithelial-mesenchymal transition during tumor progression. Curr Opin Cell Biol, 2005. 17(5): p. 548-558.

26. Korsching, E., et al., The origin of vimentin expression in invasive breast cancer: epithelial-mesenchymal transition, myoepithelial histogenesis or histogenesis from progenitor cells with bilinear differentiation potential? J Pathol, 2005. 206(4): p. 451-7.

27. Comijn, J., et al., The two-handed E box binding zinc finger protein SIP1 downregulates Ecadherin and induces invasion. Mol Cell, 2001. 7(6): p. 1267-78.

28. Gheldof, A., et al., Evolutionary functional analysis and molecular regulation of the ZEB transcription factors. Cell Mol Life Sci, 2012. 69(15): p. 2527-2541.

29. Wellner, U., et al., The EMT-activator ZEB1 promotes tumorigenicity by repressing stemness-inhibiting microRNAs. Nat Cell Biol, 2009. 11(12): p. 1487-1495. 
30. Spaderna, S., et al., The transcriptional repressor ZEB1 promotes metastasis and loss of cell polarity in cancer. Cancer Res, 2008. 68(2): p. 537-544.

31. Schmalhofer, O., S. Brabletz, and T. Brabletz, E-cadherin, beta-catenin, and ZEB1 in malignant progression of cancer. Cancer Metastasis Rev, 2009. 28(1-2): p. 151-166.

32. Hill, L., G. Browne, and E. Tulchinsky, ZEB/miR-200 feedback loop: at the crossroads of signal transduction in cancer. Int J Cancer, 2013. 132(4): p. 745-754.

33. Wang, F., S. Reierstad, and D.A. Fishman, Matrilysin over-expression in MCF-7 cells enhances cellular invasiveness and pro-gelatinase activation. Cancer Lett, 2006. 236(2): p. 292-301.

34. Hay, E.D., The mesenchymal cell, its role in the embryo, and the remarkable signaling mechanisms that create it. Dev Dyn, 2005. 233(3): p. 706-720.

35. Lang, S.H., et al., Enhanced expression of vimentin in motile prostate cell lines and in poorly differentiated and metastatic prostate carcinoma. Prostate, 2002. 52(4): p. 253263.

36. Zhang, C., et al., PF-00477736 mediates checkpoint kinase 1 signaling pathway and potentiates docetaxel-induced efficacy in xenografts. Clin Cancer Res, 2009. 15(14): p. 4630-4640.

37. Gilles, C., et al., Vimentin contributes to human mammary epithelial cell migration. J Cell Sci, 1999. 112 ( Pt 24): p. 4615-4625.

38. Furuta, M., Kozaki, K.I., Tanaka, S., Arii, S., Imoto, I., Inazawa, J., miR-124 and miR-203 are epigenetically silenced tumor-suppressive microRNAs in hepatocellular carcinoma . 2010. 31: p. 766-776. 
39. Yamasaki, T.e.a., Tumor suppressive microRNA138 contributes to cell migration and invasion through its targeting of vimentin in renal cell carcinoma. Int J Oncol, 2012. 41: p. $805-817$.

40. Davies, P.F., T. Mundel, and K.A. Barbee, A mechanism for heterogeneous endothelial responses to flow in vivo and in vitro. J Biomech, 1995. 28(12): p. 1553-1560.

41. Flitney, E.W., et al., Insights into the mechanical properties of epithelial cells: the effects of shear stress on the assembly and remodeling of keratin intermediate filaments. FASEB J, 2009. 23(7): p. 2110-2119.

42. Suresh, S., Biomechanics and biophysics of cancer cells. Acta Biomater, 2007. 3(4): p. 413-438.

43. Eckes, B., et al., Impaired wound healing in embryonic and adult mice lacking vimentin. J Cell Sci, 2000. 113 ( Pt 13): p. 2455-2462.

44. Lee, R.C., R.L. Feinbaum, and V. Ambros, The C. elegans heterochronic gene lin-4 encodes small RNAs with antisense complementarity to lin-14. Cell, 1993. 75(5): p. 843854.

45. Reinhart, B.J., et al., The 21-nucleotide let-7 RNA regulates developmental timing in Caenorhabditis elegans. Nature, 2000. 403(6772): p. 901-906.

46. Lewis, B.P., C.B. Burge, and D.P. Bartel, Conserved seed pairing, often flanked by adenosines, indicates that thousands of human genes are microRNA targets. Cell, 2005. 120(1): p. 15-20.

47. Saini, H.K., A.J. Enright, and S. Griffiths-Jones, Annotation of mammalian primary microRNAs. BMC Genomics, 2008. 9: p. 564-564.

48. Lu, J., et al., MicroRNA expression profiles classify human cancers. Nature, 2005. 435(7043): p. 834-838. 
49. Forman, J.J., A. Legesse-Miller, and H.A. Coller, A search for conserved sequences in coding regions reveals that the let-7 microRNA targets Dicer within its coding sequence. Proc Natl Acad Sci U S A, 2008. 105(39): p. 14879-14884.

50. Lytle, J.R., T.A. Yario, and J.A. Steitz, Target mRNAs are repressed as efficiently by microRNA-binding sites in the 5' UTR as in the 3' UTR. Proc Natl Acad Sci U S A, 2007. 104(23): p. 9667-9672.

51. Dennis, C., The brave new world of RNA. Nature, 2002. 418(6894): p. 122-124.

52. Wiklund, E.D., et al., Coordinated epigenetic repression of the miR-200 family and miR205 in invasive bladder cancer. Int J Cancer, 2011. 128(6): p. 1327-1334.

53. Vrba, L., et al., Role for DNA methylation in the regulation of miR-200c and miR-141 expression in normal and cancer cells. PLoS One, 2010. 5(1).

54. Bracken, C.P., et al., A double-negative feedback loop between ZEB1-SIP1 and the microRNA-200 family regulates epithelial-mesenchymal transition. Cancer Res, 2008. 68(19): p. 7846-7854.

55. Gregory, P.A., et al., The miR-200 family and miR-205 regulate epithelial to mesenchymal transition by targeting ZEB1 and SIP1. Nat Cell Biol, 2008. 10(5): p. 593601.

56. Lamont, R.J. and H.F. Jenkinson, Life below the gum line: pathogenic mechanisms of Porphyromonas gingivalis. Microbiol Mol Biol Rev, 1998. 62(4): p. 1244-1263.

57. Hajishengallis, G. and R.J. Lamont, Breaking bad: manipulation of the host response by Porphyromonas gingivalis. Eur J Immunol, 2014. 44(2): p. 328-338.

58. Yilmaz, O., The chronicles of Porphyromonas gingivalis: the microbium, the human oral epithelium and their interplay. Microbiology, 2008. 154(Pt 10): p. 2897-903. 
59. Tribble, G.D. and R.J. Lamont, Bacterial invasion of epithelial cells and spreading in periodontal tissue. Periodontol 2000, 2010. 52(1): p. 68-83.

60. Kinane, D.F., et al., P. gingivalis interactions with epithelial cells. Front Biosci, 2008. 13: p. $966-84$.

61. Bostanci, N. and G.N. Belibasakis, Porphyromonas gingivalis: an invasive and evasive opportunistic oral pathogen. FEMS Microbiol Lett, 2012. 333(1): p. 1-9.

62. Lamont, R.J. and O. Yilmaz, In or out: the invasiveness of oral bacteria. Periodontol 2000, 2002. 30: p. 61-9.

63. Lamont, R.J., et al., Porphyromonas gingivalis invasion of gingival epithelial cells. Infect Immun, 1995. 63(10): p. 3878-3885.

64. Okada, H., Murakami, S. , Cytokine Expression in Periodontal Health and Disease. Crit Rev Oral Biol Med, 1998. 9: p. 248-266.

65. Belanger, M., et al., Autophagy: a highway for Porphyromonas gingivalis in endothelial cells. Autophagy, 2006. 2(3): p. 165-70.

66. Capestany, C.A., et al., Role of the Clp system in stress tolerance, biofilm formation, and intracellular invasion in Porphyromonas gingivalis. J Bacteriol, 2008. 190(4): p. 14361446.

67. Yoshimura, M., et al., Formation of methyl mercaptan from L-methionine by Porphyromonas gingivalis. Infect Immun, 2000. 68(12): p. 6912-6916.

68. Coats, S.R., et al., The lipid A phosphate position determines differential host Toll-like receptor 4 responses to phylogenetically related symbiotic and pathogenic bacteria. Infect Immun, 2011. 79(1): p. 203-210.

69. Kadowaki, T., et al., Porphyromonas gingivalis proteinases as virulence determinants in progression of periodontal diseases. J Biochem, 2000. 128(2): p. 153-9. 
70. Travis, J., et al., Porphyromonas gingivalis proteinases as virulence factors in the development of periodontitis. J Periodontal Res, 1997. 32(1 Pt 2): p. 120-5.

71. Amano, A., Molecular interaction of Porphyromonas gingivalis with host cells: implication for the microbial pathogenesis of periodontal disease. J Periodontol, 2003. 74(1): p. 90-6.

72. Lin, X., J. Wu, and H. Xie, Porphyromonas gingivalis minor fimbriae are required for cellcell interactions. Infect Immun, 2006. 74(10): p. 6011-6015.

73. Hamada, N., et al., Isolation and characterization of a minor fimbria from Porphyromonas gingivalis. Infect Immun, 1996. 64(11): p. 4788-4794.

74. Arai, M., N. Hamada, and T. Umemoto, Purification and characterization of a novel secondary fimbrial protein from Porphyromonas gingivalis strain 381. FEMS Microbiol Lett, 2000. 193(1): p. 75-81.

75. Lamont, R.J., et al., Role of the Streptococcus gordonii SspB protein in the development of Porphyromonas gingivalis biofilms on streptococcal substrates. Microbiology, 2002. 148(Pt 6): p. 1627-1636.

76. Amano, A., et al., Prevalence of specific genotypes of Porphyromonas gingivalis fimA and periodontal health status. J Dent Res, 2000. 79(9): p. 1664-8.

77. Brunner, J., et al., The core genome of the anaerobic oral pathogenic bacterium Porphyromonas gingivalis. BMC Microbiol, 2010. 10: p. 252-252.

78. Darveau, R.P., G. Hajishengallis, and M.A. Curtis, Porphyromonas gingivalis as a potential community activist for disease. J Dent Res, 2012. 91(9): p. 816-820.

79. Curtis, M.A., J. Aduse-Opoku, and M. Rangarajan, Cysteine proteases of Porphyromonas gingivalis. Crit Rev Oral Biol Med, 2001. 12(3): p. 192-216. 
80. Polanowska, J. and A. Polanowski, [The role of Porphyromonas gingivalis proteinases in periodontitis]. Postepy Hig Med Dosw, 1997. 51(2): p. 149-69.

81. Kharlamova, N., et al., A6.8 Elevated antibody levels to porphyromonas gingivalis detected in rheumatoid arthritis patients with a specific anti-citrullinated protein/peptide antibody profile. Annals of the Rheumatic Diseases, 2014. 73(Suppl 1):

p. A73-A74.

82. Koziel, J., P. Mydel, and J. Potempa, The link between periodontal disease and rheumatoid arthritis: an updated review. Curr Rheumatol Rep, 2014. 16(3): p. 408.

83. Tsuda, K., et al., Functional analysis of alpha5beta1 integrin and lipid rafts in invasion of epithelial cells by Porphyromonas gingivalis using fluorescent beads coated with bacterial membrane vesicles. Cell Struct Funct, 2008. 33(1): p. 123-32.

84. Weinberg, A., et al., Role of fimbriae in Porphyromonas gingivalis invasion of gingival epithelial cells. Infect Immun, 1997. 65(1): p. 313-316.

85. Malek, R., et al., Inactivation of the Porphyromonas gingivalis fimA gene blocks periodontal damage in gnotobiotic rats. J Bacteriol, 1994. 176(4): p. 1052-9.

86. Rosan, B. and R.J. Lamont, Dental plaque formation. Microbes Infect, 2000. 2(13): p. 1599-1607.

87. Miller, C.M., et al., The role of the $P 2 X_{7}$ receptor in infectious diseases. PLoS Pathog, 2011. 7(11).

88. Chaves, S.P., et al., Modulation of P2X(7) purinergic receptor in macrophages by Leishmania amazonensis and its role in parasite elimination. Microbes Infect, 2009. 11(10-11): p. 842-849.

89. Wiley, J.S., et al., The human $P 2 X 7$ receptor and its role in innate immunity. Tissue Antigens, 2011. 78(5): p. 321-332. 
90. Avila, M., D.M. Ojcius, and O. Yilmaz, The oral microbiota: living with a permanent guest. DNA Cell Biol, 2009. 28(8): p. 405-411.

91. Yilmaz, O., et al., ATP scavenging by the intracellular pathogen Porphyromonas gingivalis inhibits P2X7-mediated host-cell apoptosis. Cell Microbiol, 2008. 10(4): p. 863-875.

92. Spooner, R. and Ö. Yilmaz, Nucleoside-diphosphate-kinase: a pleiotropic effector in microbial colonization under interdisciplinary characterization. Microbes Infect, 2012. 14(3): p. 228-237.

93. Windoffer, R., et al., Cytoskeleton in motion: the dynamics of keratin intermediate filaments in epithelia. J Cell Biol, 2011. 194(5): p. 669-678.

94. Kedjarune, U., et al., Culturing primary human gingival epithelial cells: comparison of two isolation techniques. J Craniomaxillofac Surg, 2001. 29(4): p. 224-231.

95. Oda, D. and E. Watson, Human oral epithelial cell culture I. Improved conditions for reproducible culture in serum-free medium. In Vitro Cell Dev Biol, 1990. 26(6): p. 589-95.

96. Sharpless, N.E., Ink4a/Arf links senescence and aging. Exp Gerontol, 2004. 39(11-12): p. 1751-1759.

97. Harley, C.B., A.B. Futcher, and C.W. Greider, Telomeres shorten during ageing of human fibroblasts. Nature, 1990. 345(6274): p. 458-460.

98. Nakamura, T.M., et al., Telomerase catalytic subunit homologs from fission yeast and human. Science, 1997. 277(5328): p. 955-959.

99. Dabelsteen, S., et al., Epithelial cells derived from human embryonic stem cells display p16INK4A senescence, hypermotility, and differentiation properties shared by many P63+ somatic cell types. Stem Cells, 2009. 27(6): p. 1388-1399. 
100. Rheinwald, J.G., et al., A two-stage, p16(INK4A)- and p53-dependent keratinocyte senescence mechanism that limits replicative potential independent of telomere status. Mol Cell Biol, 2002. 22(14): p. 5157-5172.

101. Dickson, M.A., et al., Human keratinocytes that express $h T E R T$ and also bypass a p16(INK4a)-enforced mechanism that limits life span become immortal yet retain normal growth and differentiation characteristics. Mol Cell Biol, 2000. 20(4): p. 1436-1447.

102. Moffatt-Jauregui, C.E.e.a., Establishment and characterization of a telomerase immortalized human gingival epithelial cell line. J Periodont Res 2013. 48: p. 713-721.

103. Livak, K.J. and T.D. Schmittgen, Analysis of relative gene expression data using real-time quantitative PCR and the 2(-Delta Delta C(T)) Method. Methods, 2001. 25(4): p. 402-8.

104. Smalley, J.W., et al., HmuY haemophore and gingipain proteases constitute a unique syntrophic system of haem acquisition by Porphyromonas gingivalis. PLoS One, 2011. $6(2)$. 


\section{CURRICULUM VITA}

NAME: Akintunde Olaniyi Ojo

ADDRESS: Dept. of Oral Health and Systemic Diseases

University of Louisville

501 South Preston

Louisville, KY 40202

DOB: Ikare-Akoko, Ondo State, Nigeria. - June 3, 1981

\section{EDUCATION}

\& TRAINING: B. Sc. Chemistry.

University of Ado-Ekiti, Ekiti State, Nigeria

$1999-2003$

BDS

University of Benin, Edo State, Nigeria

$2005-2010$

AWARDS: Dr. Douglas Darling/Melissa Atkinson School of Interdisciplinary and Graduate Studies) Scholarship Award

University of Louisville School of Dentistry

2014 
Ondo State Government Scholarship Award

Akure, Ondo State Nigeria

$2008-2010$

PROFESSIONAL SOCIETIES: American Association for the Advancement of Science (AAAS)

May 2014 - present

American Association for Dental Research (AADR)

Student Research Group, University of Louisville

Chapter

April 2014 - present

Nigeria Dental Association (NDA)

April 2011 - present

Medical and Dental Council of Nigeria (MDCN)

April 2011 - present

International Association for Dental Research (IADR)

Oct. 2010 - present

PUBLICATIONS: Ehigiator O., Ojo A.O., Asodo C.C., Ejike E.B. Knowledge of Ethical Obligations Amongst Dental House Officers and Final Year Dental Students

Published in Nigeria Dental Journal Vol 19, No 2 (2011) 


\section{NATIONAL MEETING}

PRESENTATIONS: The 89th General Session \& Exhibition of the IADR/AADR/CADR San Diego Convention Center, San Diego, California

March 16, 2011 - March 19, 2011

Presented an abstract on Ethical Obligations of Dental Professionals in Patients care. 